\title{
Exchange Rate Dynamics and Monetary Spillovers with Imperfect Financial Markets
}

Akinci, Ozge and Albert Queralto

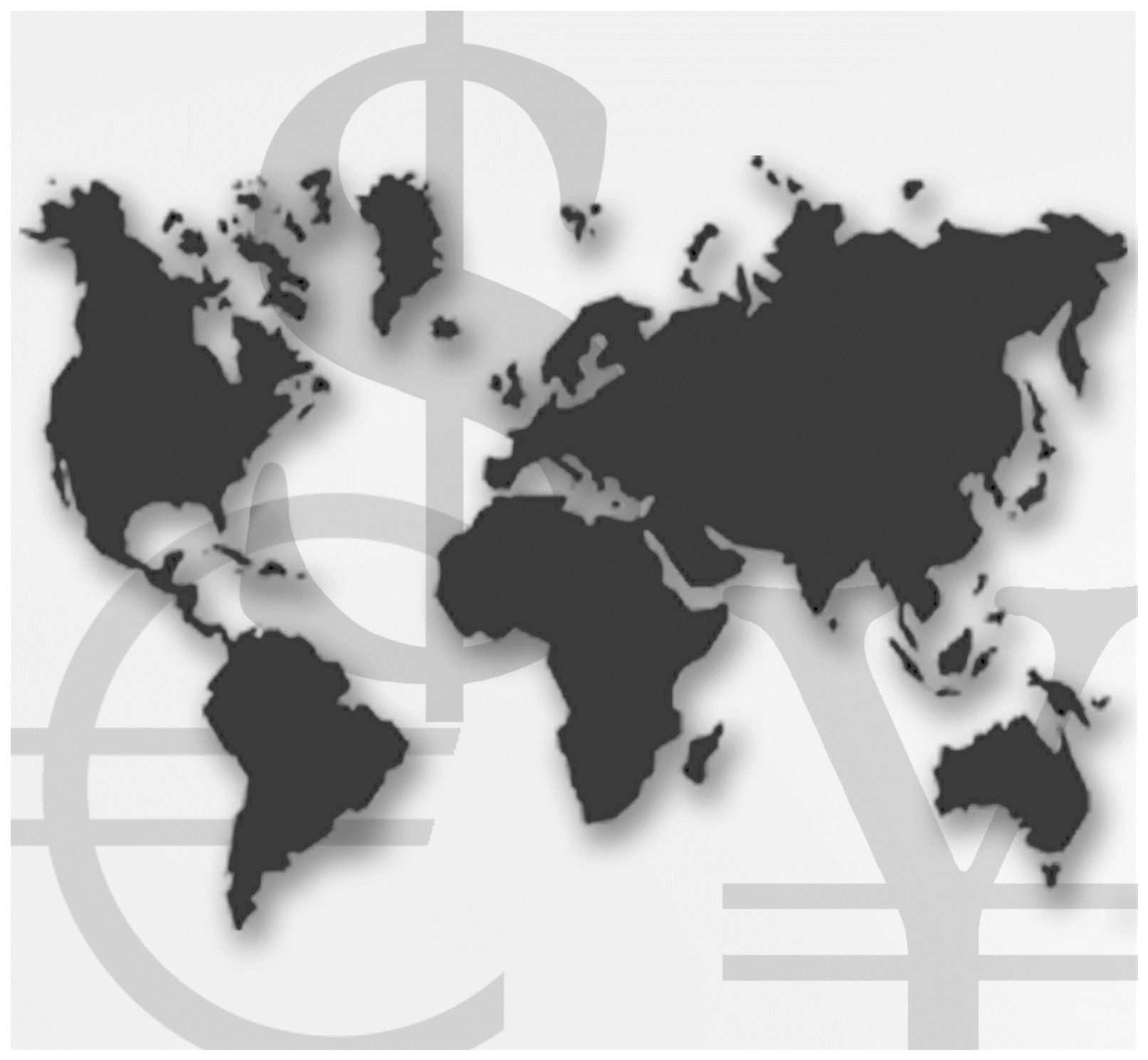

\section{International Finance Discussion Papers}

Board of Governors of the Federal Reserve System

Number 1254

July 2019 
Board of Governors of the Federal Reserve System

International Finance Discussion Papers

Number 1254

July 2019

\title{
Exchange Rate Dynamics and Monetary Spillovers with Imperfect Financial Markets
}

\author{
Ozge Akinci and Albert Queralto
}

NOTE: International Finance Discussion Papers are preliminary materials circulated to stimulate discussion and critical comment. References to International Finance Discussion Papers (other than an acknowledgment that the writer has had access to unpublished material) should be cleared with the author or authors. Recent IFDPs are available on the Web at www.federalreserve.gov/pubs/ifdp/. This paper can be downloaded without charge from the Social Science Research Network electronic library at www.ssrn.com. 


\title{
Exchange Rate Dynamics and Monetary Spillovers with Imperfect Financial Markets*
}

\author{
Ozge Akinci ${ }^{\dagger}$ \\ Albert Queralto ${ }^{\ddagger}$ \\ Federal Reserve Bank of New York \\ Federal Reserve Board
}

May 24, 2019

\begin{abstract}
We use a two-country New Keynesian model with financial frictions and dollar debt in balance sheets to investigate the foreign effects of U.S. monetary policy. Financial amplification works through an endogenous deviation from uncovered interest parity (UIP) arising from limits to arbitrage in private intermediation. Combined with dollar trade invoicing, this mechanism leads to large spillovers from U.S. policy, consistent with the evidence. Foreign monetary policies that attempt to stabilize the exchange rate reduce welfare, and may exacerbate exchange rate volatility. We document empirically a link between UIP deviations and measures of credit market frictions, as predicted by the model.
\end{abstract}

Keywords: Financial Frictions; U.S. Monetary Policy Spillovers; Currency Premium; Uncovered Interest Rate Parity Condition.

JEL classification: E32; E44; F41.

\footnotetext{
${ }^{*}$ We would like to thank Chris Erceg for many fruitful discussions that inspired much of this work, as well as Gianluca Benigno, Jordi Galí, Sebnem Kalemli-Ozcan, and Paolo Pesenti for very useful comments. Special thanks to our discussants Giancarlo Corsetti, Tommaso Monacelli, Jenny Tang, Luca Fornaro, Emine Boz, and Ambrogio Cesa-Bianchi for very helpful suggestions. We also thank seminar participants at various institutions for their comments. Camilla Schneier and Dawson Miller provided excellent research assistance. The views expressed in this paper are those of the authors and do not necessarily reflect the position of the Federal Reserve Bank of New York, the Board of Governors of the Federal Reserve, or the Federal Reserve System.

${ }^{\dagger}$ Federal Reserve Bank of New York, 33 Liberty Street, New York, NY 10045, U.S.A. Email: ozge.akinci@ny.frb.org.

${ }^{\ddagger}$ Federal Reserve Board, 20th St\&Cons. Ave,NW, Washington, DC, 20551, USA. Email: albert.queralto@frb.gov.
} 


\section{Introduction}

The aftermath of the recent monetary tightening cycle in the United States, in which several emerging markets (EMs) experienced heightened volatility - with particularly severe stresses in Turkey and Argentina - has renewed interest in the foreign effects of U.S. monetary policy actions. An empirical literature is rapidly developing that aims to quantify these cross-border monetary spillovers, with the common finding that changes in the stance of U.S. policy have sizable effects on economic activity in EMs. ${ }^{1}$ One prominent theme within this literature is an emphasis on the financial channel of spillovers, whereby a rise in U.S. rates transmits to foreign economies via tighter credit market conditions abroad. Recent work by Giovanni, Kalemli-Ozcan, Ulu and Baskaya (2017) finds that the financial channel involves deviations from uncovered interest parity (UIP) that fluctuate countercyclically, with the premium on domestic relative to foreign borrowing costs rising as global financial conditions tighten.

At the same time, an ongoing debate both in policy circles and in the academic literature focuses on the appropriate monetary policy response of EMs to shifts in U.S. policy. ${ }^{2}$ Textbook open-economy New Keynesian (NK) models like Gali and Monacelli (2005) prescribe that policy should focus on domestic objectives and allow the exchange rate to fluctuate. This prescription stands in contrast with actual practice by EM central banks, which are often seen as attaching a substantial weight to exchange rate stabilization. A common argument in favor of this practice is the presence of dollar-denominated liabilities in domestic borrowers' balance sheets, which render the latter undesirably vulnerable to exchange rate fluctuations. ${ }^{3}$

Our goal in this paper is to develop a quantitative model that can capture the key channels of transmission of U.S. monetary policy abroad - including the financial channeland that can be used to investigate the appropriate policy response. We augment a twocountry asymmetric NK framework with financial market imperfections, as described in Section 3, in which the home country represents an EM and the foreign economy is the United States. The two-country dimension is critical to allow for expenditure-switching and expenditure-reducing effects operating through trade linkages, at the heart of conventional accounts of monetary transmission across borders. ${ }^{4}$ In turn, the friction in credit markets

\footnotetext{
${ }^{1}$ Examples include Rey (2015), Bruno and Shin (2015), Dedola et al. (2017), Iacoviello and Navarro (2018), Bräuning and Ivashina (2019), and Miranda-Agrippino and Rey (2019).

${ }^{2}$ See, for example, Obstfeld (2015), Blanchard (2017), Bernanke (2017), or Obstfeld and Taylor (2017).

${ }^{3}$ Calvo and Reinhart (2002) is the classic reference on "fear of floating" among EM policymakers.

${ }^{4}$ See Ammer, De Pooter, Erceg and Kamin (2016) for a clear exposition of the channels through which
} 
permits capturing the financial channel of spillovers. Our model also features balance sheet mismatches: EM borrowers issue both domestic currency debt and dollar-denominated debt, consistent with the evidence.

A key mechanism in our setting involves an endogenous deviation from UIP that arises due to imperfect arbitrage (resulting from the credit market friction). This UIP deviation, defined as the premium of the local safe rate over the expected dollar rate, is inversely related to the aggregate state of EM borrowers' balance sheets, and therefore moves countercyclically, consistent with the evidence in Giovanni et al. (2017). Thus, fluctuations in the state of balance sheets become themselves a driver of exchange rate dynamics, with weakening balance sheets exerting downward pressure on the value of the local currency. In general equilibrium, and given the presence of dollar debt, this mechanism induces a feedback effect between currency depreciation and borrowers' financial position, and leads to excess currency volatility relative to a setting in which UIP holds at all times. Because it plays an important role in driving both the magnitude of spillovers and the appropriate policy response, in Section 2 we illustrate the mechanism it within a very simple and transparent model, and in Section 6 we provide novel empirical evidence in its support. As Section 2 makes clear, the UIP deviation arises because credit market frictions are assumed to apply more severely to funds of foreign origin - making foreigners demand a larger external finance premium, and effectively creating a positive wedge between the local safe rate and the expected dollar rate.

The main findings that emerge from the analysis of our quantitative model are as follows. On the positive side, described in Section 4, we find that effects on the EM of a policy rate hike in the United States are substantially magnified by the financial channel. At the heart of this result is the two-way feedback between balance sheets and exchange rates described previously: the U.S. rate hike initiates declines in EM borrowers' net worth (due to general equilibrium declines in the price of capital and the exchange rate), triggering the adverse feedback effect. As balance sheets deteriorate, the cost of borrowing for nonfinancial firms in the EM rises sharply, depressing investment spending (by much more than would occur in a frictionless complete-markets benchmark) and thereby pushing down GDP.

The above effects play out more dramatically when we consider spillovers under the Dominant Currency Paradigm (DCP, Gopinath, Boz, Casas, Diez, Gourinchas and PlagborgMøller 2018) instead of under our baseline model with producer currency pricing. Under DCP, exporting firms in both the EM and the United States set prices in dollars, and therefore the (large) EM depreciation resulting from the U.S. rate hike no longer has the

monetary spillovers operate. 
side benefit of boosting the EM's exports. As a consequence, the drop in the EM's GDP following a U.S. rate hike becomes even larger, and in fact approaches the drop in the U.S. itself, consistent with the empirical evidence. This result underscores how the financial and trade invoicing dimensions of the dollar's dominant status work together to imply powerful effects of U.S. policy abroad. ${ }^{5}$

It bears emphasizing that the results above are obtained in a setting in which EM monetary policy targets domestic inflation only, with the consequence that the EM policy rate does not react much (in either direction) to a hike in the U.S. policy rate. Thus, these results echo Rey's (2016) argument that U.S. policy can exert a strong influence on EMs even when the latter's monetary policy focuses solely on domestic objectives (and allows the exchange rate to depreciate).

Turning to the normative analysis, in Section 5 we find, somewhat paradoxically, that the presence of partly dollarized balance sheets does not provide grounds for monetary policies that attempt to stabilize the exchange rate. In fact, the welfare losses from exchange-rate oriented monetary regimes are orders of magnitude larger in our baseline setting with dollar debt than in the canonical complete-markets paradigm. Thus, even if exchange rate flexibility contributes to amplification through feedback effects with borrowers' net worth, attempting to damp these effects using domestic monetary policy turns out to be counterproductive. Key to this finding is the observation that the UIP deviation is also endogenous to domestic monetary policy (due to the impact of the latter on credit market frictions), implying that a domestic rate hike of a given size has a smaller effect on the exchange rate (and a larger one on output) compared to the frictionless benchmark. Thus, our results call into question the view that "fear of floating" monetary strategies are desirable in the presence of dollardenominated debts. In fact, we show how such regimes can actually make the dollarization problem worse: the average share of dollar debt in balance sheets (an endogenous variable in our model, determined by the solution to borrowers' portfolio problem) is increasing in the degree to which the domestic authority targets the exchange rate. ${ }^{6}$

Section 7 provides concluding remarks. Appendices A-C include supplementary material.

Related Literature. Our paper builds on research aimed at developing open economy New Keynesian macroeconomic models - for example, Corsetti and Pesenti (2001), Gali and

\footnotetext{
${ }^{5}$ Gopinath and Stein (2018) develop a model in which these two forms of dominance complement each other, thus providing a unified explanation of the dollar's prominent international role.

${ }^{6}$ Diamond, Hu and Rajan (2018) argues informally that fear of floating can induce moral hazard if corporations are confident that the central bank will moderate currency volatility. Our analysis shows formally how such outcome can arise.
} 
Monacelli (2005), Erceg, Gust and Lopez-Salido (2007), Farhi and Werning (2014), and Corsetti et al. (2018). This literature is based on seminal work by Obstfeld and Rogoff (1995), studying the effects of monetary policy in open economies. The models in this literature generally feature frictionless domestic and international financial markets, ${ }^{7}$ while we depart by introducing financial market frictions as in Gertler and Kiyotaki (2010). ${ }^{8}$

This paper also relates to a lengthy literature that developed in response to the EM crises of the 1990s, which in several cases highlighted the balance-sheet channel of exchange rate changes. Well-known examples include Krugman (1999), Céspedes, Chang and Velasco (2004), and Gertler et al. (2007). ${ }^{9}$ Our model differs from this literature by embedding balance sheet currency mismatches within a quantitative model in which financial imperfections are microfounded via an explicit agency problem. More importantly, borrowers in our model hold both local currency and dollar debt, consistent with the evidence, which requires them to solve an optimal portfolio problem to decide on the share of dollar debt to hold.

The focus of our paper is closely related to recent work by Gourinchas (2018): both papers focus on quantifying the different channels of spillovers from U.S. monetary shocks, and on the desirability of flexible exchange rate regimes in the face of large adverse financial spillovers. There are, however, some important differences between the modeling frameworks. For example, our framework motivates borrowing constraints as arising from an explicit agency friction, and we show how this leads to endogenous UIP deviations. ${ }^{10}$ In addition, we allow for a portfolio choice determining how much dollar debt borrowers take on. The latter feature enables us to explore the consequences of exchange-rate targeting monetary policy regimes for borrowers' portfolio choice.

The present paper is also related to recent work by Aoki, Benigno and Kiyotaki (2016), who develop a small open economy model with financing frictions to study monetary and financial policies in EMs. While the frameworks share several similarities, our work differs both in terms of focus - we study spillovers from U.S. monetary policy in the context of an asymmetric medium scale two-country model - and in terms of modeling features - for example, we highlight the importance of allowing for dollar invoicing of international trade

\footnotetext{
${ }^{7}$ More specifically, in these models there are either no deviations or exogenous deviations from UIP.

${ }^{8}$ See also Bernanke, Gertler and Gilchrist (1999), Gertler and Karadi (2011), Gertler, Kiyotaki and Queralto (2012), Gourinchas et al. (2016), and Akinci and Queralto (2017) for related frameworks.

${ }^{9}$ Other prominent papers are Aghion et al. (2001), Aghion et al. (2004) and Braggion et al. (2009).

${ }^{10}$ The mechanism giving rise to UIP deviations is different from that in the well-known work by Gabaix and Maggiori (2015): in our case, agency frictions lead to limited arbitrage of the part of EM borrowers, resulting in the distinct prediction that the UIP premium is tied to the magnitude of a measure of the domestic premium on external finance. As we show, this prediction is strongly supported by EM data.
} 
in EMs. ${ }^{11}$ In addition, our paper emphasizes the critical role of endogenous deviations from UIP in shaping dynamics, and we provide empirical evidence supporting the model-implied UIP deviations. These considerations also differentiate our work from other related papers by Fornaro (2015) and Devereux, Young and Yu (2015), who focus on capital controls and exchange rate policy during sudden stops in the context of a small open economy framework with an occasionally binding collateral constraint.

\section{A Simple Model with Imperfect Financial Markets}

We begin with a very simple, stripped-down model which permits isolating the role of financial market imperfections in exchange rate dynamics. We deliberately abstract here from many features of the quantitative model presented below, with the goal of clearly illustrating the mechanism linking UIP deviations with borrower balance sheets. The main intuition on this mechanism will carry over to the more realistic setting we present later.

\section{$2.1 \quad$ Setup}

The model consists of a foreign economy (the United States) and a domestic country (an EM) which is populated by households, firms, and bankers. There are two distinct nondurable consumption goods, one produced at home and the other produced abroad, and a durable capital good. Home bankers borrow from domestic households and from U.S. households to fund the acquisition of the capital good. Financial markets are incomplete: bankers can only obtain funding via non-contingent deposits. Crucially, an agency friction in financial markets potentially limits bankers' ability to borrow.

Banks. -Each banker $i$ lives for only two periods, and operates on behalf of the representative household. ${ }^{12}$ At the beginning of the period, the banker receives an exogenous equity transfer $\xi_{i t}$ from the household. He or she then uses this equity endowment as well as borrowed funds from domestic households ( $D_{i t}$, in units of the domestic good) and from foreign households $\left(D_{i t}^{*}\right.$, in units of the foreign good) to finance purchases of claims on the

\footnotetext{
${ }^{11}$ Also different from Aoki et al. (2016), our framework includes numerous features that have been found to be critical for an empirically realistic response to monetary policy and other shocks (e.g. Christiano et al. 2005, Smets and Wouters 2007), such as Calvo wage and price stickiness, flow investment adjustment costs, habits in consumption, and costs of adjusting trade flows. These features are at the core of medium-scale open economy models used for policy analysis (see, for example, Erceg et al. 2006 or Blanchard et al. 2016).

${ }^{12}$ The assumption that banks live for only two periods is helpful to make the model simple and transparent, but it is not essential. In the quantitative model we allow bankers to have infinite horizons.
} 
capital good, denoted $S_{i t}$. The banker's budget constraint is thus

$$
q_{t} S_{i t}=D_{i t}+\mathcal{Q}_{t} D_{i t}^{*}+\xi_{i t}
$$

where $q_{t}$ is the price of capital and $\mathcal{Q}_{t}$ is the price of the foreign good (both in terms of the domestic good). We will refer to $\mathcal{Q}_{t}$ as the real exchange rate. ${ }^{13} S_{i t}$ denotes bank $i$ 's holdings of claims on domestic capital. As in much of the financial accelerator literature, we assume there are no frictions between banks and non-financial firms (the ultimate users of physical capital), and therefore the payoff that bankers obtain from each claim is given by the dividend obtained by non-financial firms. Thus, the banker can be thought of as a holder of equity of domestic firms. For this reason, banks are best interpreted as a "bank-firm" entities capturing the entire corporate sector.

Let $Z_{t}$ be the dividend payout from ownership of claims on domestic capital, $R_{t+1}$ the (non-contingent) gross real interest rate on domestic deposits, and $R_{t+1}^{*}$ the real interest rate on foreign deposits. In $t+1$, the bank earns profits $\pi_{i t+1}$, given by

$$
\pi_{i t+1}=R_{K t+1} q_{t} S_{i t}-R_{t+1} D_{i t}-R_{t+1}^{*} \mathcal{Q}_{t+1} D_{i t}^{*}
$$

where $R_{K t+1} \equiv \frac{Z_{t+1}+q_{t+1}}{q_{t}}$ is the gross return earned on domestic assets. The banker then transfers earnings $\pi_{i t}$ to the household and exits.

The credit market friction takes the form of a simple limited enforcement problem: after borrowing funds, the banker may decide to default and divert a fraction of resources for personal gain, rather than honoring obligations with creditors. If the banker defaults, its intermediary goes into bankruptcy, and the banker obtains the following payoff:

$$
\theta\left(D_{i t}+(1+\gamma) \mathcal{Q}_{t} D_{i t}^{*}+\xi_{i t}\right)
$$

where we assume $\theta, \gamma>0$ and $\theta(1+\gamma)<1$. Thus, the banker loses some resources in the event of default $(\theta<1)$, which are recovered by creditors in bankruptcy proceedings. In addition, everything else equal the banker obtains a greater payoff from defaulting when he or she has a larger foreign liabilities $D_{i t}^{*}$. The parameter $\gamma$ indexes the degree to which foreign funds are more prone to malfeasance by the banker than are funds borrowed from

\footnotetext{
${ }^{13}$ In the simple model we normalize the price of the domestic good in each country to unity, so $\mathcal{Q}_{t}$ is the only relevant relative price (aside from $q_{t}$ ). The distinction between the real exchange rate and the terms of trade will become relevant in the quantitative model, in which prices of domestically-produced goods will also fluctuate.
} 
domestic depositors. ${ }^{14}$

The assumption that $\gamma>0$ captures the idea that the features of the legal environment and institutional framework in EMs that make it harder for foreign creditors to recover assets from a defaulting borrower, compared with domestic depositors. We elaborate more on this assumption in Section 3.7.

To solve the banker's problem, let

$$
\begin{aligned}
\mu_{t} & \equiv \beta \mathbb{E}_{t}\left(R_{K t+1}-R_{t+1}\right) \\
\varrho_{t} & \equiv \beta \mathbb{E}_{t}\left(R_{K t+1}-R_{t+1}^{*} \mathcal{Q}_{t+1} / \mathcal{Q}_{t}\right)
\end{aligned}
$$

The variable $\mu_{t}$ denotes expected excess returns with respect to the domestic rate $R_{t+1}$, while $\varrho_{t}$ is expected excess returns relative to the foreign borrowing rate. Also, let $x_{i t}$ be the ratio of foreign liabilities to total assets: $x_{i t} \equiv \frac{\mathcal{Q}_{t} D_{i t}^{*}}{q_{t} S_{i t}}$, with $x_{i t} \in(0,1)$. Banker $i$ solves

$$
\max _{S_{i t}, x_{i t}}\left[x_{i t} \varrho_{t}+\left(1-x_{i t}\right) \mu_{t}\right] q_{t} S_{i t}+\xi_{i t}
$$

subject to

$$
\left[x_{i t} \varrho_{t}+\left(1-x_{i t}\right) \mu_{t}\right] q_{t} S_{i t}+\xi_{i t} \geq \theta\left(1+\gamma x_{i t}\right) q_{t} S_{i t} \quad(\mathrm{IC})
$$

The incentive constraint (IC) above requires that the banker's continuation value be higher than the value of defaulting - otherwise, no creditor would be willing to lend to the bank.

Throughout, we assume that the primitive parameters are such that the IC binds in a neighborhood of the steady state. Given a binding IC, the banker's first order conditions imply the optimal liability portfolio condition

$$
(1+\gamma) \mu_{t}=\varrho_{t}
$$

To understand (7), consider an operation whereby the bank marginally increases its foreign borrowing, financed by a decrease of the amount of borrowing from the domestic market. The benefit of this operation is $\varrho_{t}$, the excess return on foreign borrowing. The cost is

\footnotetext{
${ }^{14}$ To see this, let $\xi_{i t} \rightarrow 0$ and consider a bank that finances its assets solely with loans from domestic residents $\left(D_{i t}^{*}=0\right)$. The bank's payoff from defaulting is $\theta q_{t} S_{i t}$. If instead the bank finances its asset holdings with foreign funds only $\left(D_{i t}=0\right)$ the payoff from defaulting is $\theta(1+\gamma) q_{t} S_{i t}$, i.e. $100 \gamma$ percent higher than the previous case.
} 
$(1+\gamma) \mu_{t}$, the excess return on domestic borrowing, $\mu_{t}$, plus the loss due to a tighter IC, $\gamma \mu_{t}$ (since an extra unit of foreign borrowing tightens the incentive constraint by $\gamma$ marginally). If the bank's portfolio is optimal in the first place, the benefit of this operation must equal its cost. Intuitively, in equilibrium the "foreign" excess return $\varrho_{t}$ must be greater than $\mu_{t}$ for foreign lenders to be willing to supply funds, given the greater divertability of funds of foreign origin.

The violation of the UIP condition (or the premium on the domestic currency), denoted $\mu_{t}^{*}$, is then

$$
\begin{aligned}
\mu_{t}^{*} & \equiv \beta \mathbb{E}_{t}\left(R_{t+1}-R_{t+1}^{*} \mathcal{Q}_{t+1} / \mathcal{Q}_{t}\right) \\
& =\varrho_{t}-\mu_{t} \\
& =\gamma \mu_{t}
\end{aligned}
$$

where use has been made of (7). Thus, the currency premium is proportional to the domestic excess return $\mu_{t}$, with the constant of proportionality given by the parameter $\gamma$.

Throughout, we assume that the primitive parameters are such that the IC binds in a neighborhood of the steady state, so that

$$
\left(1+\gamma x_{i t}\right) q_{t} S_{i t}=\frac{\xi_{i t}}{\theta-\mu_{t}}
$$

for all $i$. Bank $i$ 's assets, "augmented" by factor $\left(1+\gamma x_{i t}\right)$, are constrained by the bank's net worth $\xi_{i t}$.

Households. - The representative consumer's optimization problem is

$$
\max _{\left\{C_{D t+j}, M_{C t+j}, D_{t+j}\right\}_{j=0}^{\infty}} \mathbb{E}_{t} \sum_{j=0}^{\infty} \beta^{j}\left[C_{D t+j}+\chi_{m} \log \left(M_{C t+j}\right)\right]
$$

subject to

$$
C_{D t}+\mathcal{Q}_{t} M_{C t}+D_{t} \leq W_{t} \bar{L}+R_{t} D_{t-1}+\pi_{t}
$$

for all $t . C_{D t}$ is consumption of the domestic good (the price of which price is normalized to 1 ), $M_{C t}$ is imports of the foreign good, $D_{t}$ is bank deposits, and $\pi_{t}$ is net transfers from 
bankers. The household's first-order conditions are:

$$
\begin{aligned}
R & =\beta^{-1} \\
M_{C t} & =\chi_{m} \mathcal{Q}_{t}^{-1}
\end{aligned}
$$

Given symmetric preferences in the foreign country, export demand from the foreign country is analogous to import demand: $M_{C t}^{*}=\chi_{x} \mathcal{Q}_{t}$ (we use asterisks to denote foreign variables). We assume inelastic labor supply and linear utility in $C_{D t}$ for simplicity, as these features are not essential (qualitatively) to the link between agency frictions and exchange rate dynamics. On the other hand, it is important to allow for a response of the economy's foreign debt position to the exchange rate (via net exports). That is the reason why we allow for curvature in the preferences for imported goods.

Equilibrium. - The aggregate supply of physical capital is fixed at $\bar{K}$. Capital market clearing then requires $\int S_{i t} d i=\bar{K}$. We assume the equity transfer to banks is a fraction of the value of capital: $\xi_{i t}=\xi_{t} q_{t} \bar{K}$, where $\xi_{t}$ follows an exogenous process with mean given by parameter $\xi \in(0,1)$. Aggregating banks' incentive constraint (9) and assuming symmetric balance sheets across banks, we obtain

$$
1+\gamma x_{t}=\frac{1}{\theta-\mu_{t}} \xi_{t}
$$

Aggregating domestic budget constraints, we find

$$
\begin{aligned}
R^{*} D_{t-1}^{*}-D_{t}^{*} & =N X_{t} \\
N X_{t} & =\chi_{x}-\chi_{m} \mathcal{Q}_{t}^{-1}
\end{aligned}
$$

where it is assumed that $R^{*}=1 / \beta^{*}<R$ : EM households are more impatient than households in the United States. Above, $N X_{t}$ is net exports expressed in terms of the foreign good $\left(N X_{t} \equiv \mathcal{Q}_{t}^{-1} M_{C t}^{*}-M_{C t}\right){ }^{15}$

We assume firms are perfectly competitive and operate a Cobb-Douglas technology $Y_{t}=$ $K_{t}^{\alpha} L_{t}^{1-\alpha}$. Given the aggregate supplies of labor and capital $\bar{K}$ and $\bar{L}$, the dividend payout is $Z_{t}=Z=\alpha(\bar{K} / \bar{L})^{\alpha-1} \forall t$.

The equilibrium conditions characterizing the home economy consist of 5 equations de-

\footnotetext{
${ }^{15}$ As shown in Appendix A.1, equations (15) and (16) follow from combining budget constraints of domestic households and banks.
} 
termining $x_{t}, \mu_{t}, \mathcal{Q}_{t}, q_{t}$ and $D_{t}^{*}$ :

$$
\begin{aligned}
\mu_{t} & =\theta-\frac{\xi_{t}}{1+\gamma x_{t}} \\
x_{t} & =\frac{\mathcal{Q}_{t} D_{t}^{*}}{q_{t} \bar{K}} \\
q_{t} & =\beta \frac{\mathbb{E}_{t}\left(Z+q_{t+1}\right)}{1+\mu_{t}} \\
\mathcal{Q}_{t} & =\frac{\frac{\beta}{\beta^{*}} \mathbb{E}_{t}\left(\mathcal{Q}_{t+1}\right)}{1-\gamma \mu_{t}} \\
D_{t}^{*} & =\frac{\chi_{m}}{\mathcal{Q}_{t}}-\chi_{x}+R^{*} D_{t-1}^{*}
\end{aligned}
$$

Equation (17) is the incentive constraint (9), determining the domestic excess return $\mu_{t}$ as a function of the equity transfer $\xi_{t}$ and the foreign funding ratio $x_{t}$. Equation (18) is the definition of $x_{t}$. Equations (19) and (20) follow from (3) and (8), and determine prices $q_{t}, \mathcal{Q}_{t}$ as a function of $\mu_{t}$ and expectations of $q_{t+1}$ and $\mathcal{Q}_{t+1}$. The balance of payments equation (21) follows from (15) and (16).

We next consider a first-order approximation to the system (17)-(21) around the nonstochastic steady state. Further, we also assume that $\beta$ is arbitrarily close to $\beta^{*}$, let $\chi_{m}=\chi_{x}$, and choose an appropriate normalization of $\bar{K}$ such that the elasticity of $N X_{t}$ to $\mathcal{Q}_{t}$ equals unity. Under these assumptions, letting $\widehat{y}_{t} \equiv \log \left(\frac{y_{t}}{y}\right)$ and $\widetilde{y}_{t} \equiv y_{t}-y$ for any variable $y_{t}$, the dynamic system (17)-(21) simplifies to ${ }^{16}$

$$
\begin{aligned}
\widetilde{\mu}_{t} & =-\frac{\theta}{\xi} \widetilde{\xi}_{t}+\frac{\theta}{\xi}(\xi-\theta) \widehat{x}_{t} \\
\widehat{x}_{t} & =\widehat{\mathcal{Q}}_{t}+\widehat{D}_{t}^{*}-\widehat{q}_{t} \\
\widehat{\mathcal{Q}}_{t} & =\gamma \widetilde{\mu}_{t}+\mathbb{E}_{t}\left\{\widehat{\mathcal{Q}}_{t+1}\right\} \\
\widehat{q}_{t} & =-\widetilde{\mu}_{t}+\beta \mathbb{E}_{t}\left\{\widehat{q}_{t+1}\right\} \\
\widehat{D}_{t}^{*} & =-r^{*} \widehat{\mathcal{Q}}_{t}+\left(1+r^{*}\right) \widehat{D}_{t-1}^{*}
\end{aligned}
$$

where $r^{*} \equiv \frac{1}{\beta^{*}}-1$ is the net foreign interest rate.

The system above makes the mechanics of the model reasonably transparent. A drop in $\widetilde{\xi}_{t}$ works to push excess returns $\widetilde{\mu}_{t}$ up from (22), given $\widehat{x}_{t}$. From (25), $\widehat{q}_{t}$ is determined by (the negative of) current and future expected values of $\widetilde{\mu}_{t}$, so rises in the latter work to depress the

\footnotetext{
${ }^{16}$ See Appendix A for details.
} 
price of capital. Similarly, from (24) rising excess returns depreciate the home currency, with the strength of the effect governed by parameter $\gamma$. The intuition follows from condition (8), in turn a consequence of the optimal portfolio condition (7): rising excess returns must be matched by a rise in the UIP wedge $\mu_{t}^{*}$, which occurs via a depreciation along with expected appreciation of the home currency. Rising $\widehat{\mathcal{Q}}_{t}$ and falling $\widehat{q}_{t}$ both affect $\widehat{x}_{t}$ positively, with a drop in $\widehat{D}_{t}^{*}$ working in the opposite direction. The latter effect, however, will tend to be relatively small, as the elasticity of $D_{t}^{*}$ to $\mathcal{Q}_{t}$ is the net interest $r^{*}$.

\subsection{Effects of a Drop in Net Worth}

We next illustrate the mechanics just described by means of an impulse response to a negative innovation to $\xi_{t}$. We calibrate the discount factors, $\beta$ and $\beta^{*}$, to 0.9925 and 0.9950 respectively, as in the calibration of the larger-scale model described below. We set the divertable fraction of assets, $\theta$, to 0.18 , and the steady-state equity transfer, $\xi$, to 20 percent of the value of capital. We assume that foreign funds are fifty percent more divertable than domestic credit $(\gamma=0.5)$. Finally, we let $\chi_{m}=\chi_{x}=1$ and continue to set $\bar{K}$ such that the elasticity of net exports to $\mathcal{Q}_{t}$ is unity. These parameter values yields similar values for the leverage ratio (assets to net worth) and for the foreign liability ratio as those we target in our quantitative model. We emphasize, however, that the basic qualitative patterns hold regardless of the specific calibration, so long as the parameterization ensure that the steady state is well-behaved (as described in Appendix A.2).

What are the consequences of a deterioration in banks' balance sheets? The blue solid line in Figure 1 shows the impulse responses to a negative innovation of two percentage points percent to $\xi_{t}$ (i.e. the equity endowment falls from 20 to 18 percent of the value of capital) which persists with autoregressive parameter 0.75, implying a half-life of one year. The spread $\mu_{t}$ rises by around the same amount of the drop in the transfer (as suggested by equation (22)), and through the optimal loan portfolio condition the currency premium also rises - by half as much as the spread $\mu_{t}$, given $\gamma=0.5$. The price of capital falls by six percent, and the domestic currency depreciates by three percent. Aggregate foreign borrowing $D_{t}^{*}$ falls persistently - a capital outflow. Once the effects of the lower $\xi_{t}$ begin to fade, the economy is left with lower net foreign liabilities $D_{t}^{*}$ (the only endogenous state variable), which everything else equal works to improve the agency friction. This accounts for the rise in $q_{t}$ above steady state after about two years. For the same reason, $\mathcal{Q}_{t}$ falls below steady state (i.e. home appreciates) starting after two years. The appreciation then 
slowly erodes the net foreign asset position by reducing net exports, thus bringing $D_{t}^{*}$ slowly back up toward steady state.

The dynamics described above stand in contrast to what would obtain if $\gamma$ were zero, i.e. if the credit market friction was equally severe for domestic and foreign credit. In that case we would simply have that $\mu_{t}=\theta-\xi_{t}$ and $\mu_{t}^{*}=0$. A drop in $\xi_{t}$ would lead to a commensurate rise in $\mu_{t}$ and a fall in $q_{t}$ (as in standard models of the financial accelerator), but would not have any effect on the currency premium, the exchange rate, or the net foreign debt position.

\section{A Medium-Scale Model}

This section describes our baseline quantitative model. The core framework is a twocountry open-economy New Keynesian model (for example, Gali and Monacelli 2005 and Erceg et al. 2007). The critical departure from this literature is that we allow for imperfect financial markets: as in the simple model described previously, the financial imperfection leads to endogenous fluctuations in the domestic borrowing spread and in the UIP deviation. Different from the simple model, banks have infinite horizons. This feature allows for endogenous persistence in banks' net worth and, crucially, makes the latter endogenous to movements in the exchange value of domestic currency (to the extent that part of banks' liabilities are in foreign currency) as well as to domestic asset prices.

We also include a standard set of nominal and real rigidities: nominal price and wage stickiness, habit persistence in consumption, and adjustment costs in investment and in the import share. These features help the model generate empirically realistic effects of monetary policy shocks (as shown by Christiano et al. 2005, for example).

\subsection{Bankers}

The representative household has two types of members: workers and bankers, with measures $1-f$ and $f$ respectively. There is random turnover between bankers and workers: bankers alive in period $t$ survive into $t+1$ with exogenous probability $\sigma_{b}>0$, and become workers with complementary probability. Workers become bankers with probability (1 $\left.\sigma_{b}\right) \frac{f}{1-f}$, so there is a measure $\left(1-\sigma_{b}\right) f$ of new bankers each period, exactly offsetting the number that exit. Entrant bankers receive a small endowment in the form of fraction $\frac{\xi_{b}}{f}$ of the value of the capital stock. 
Like before, bank $i$ 's balance sheet identity is

$$
q_{t} S_{i t}=D_{i t}+\mathcal{Q}_{t} D_{i t}^{*}+N_{i t}
$$

A continuing banker's budget constraint, expressed in (real) domestic currency, is

$$
q_{t} S_{i t}+R_{t} D_{i t-1}+R_{t}^{*} \mathcal{Q}_{t} D_{i t-1}^{*} \leq R_{K t} q_{t-1} S_{i t-1}+D_{i t}+\mathcal{Q}_{t} D_{i t}^{*}
$$

The left-hand side is bank $i$ 's uses of funds, including lending to non-financial firms $\left(q_{t} S_{i t}\right)$ plus deposit repayments (both domestic, $R_{t} D_{i t-1}$, and foreign, $R_{t}^{*} \mathcal{Q}_{t} D_{i t-1}^{*}$ ). The right-hand side is the source of funds, including returns from past loans (the first term) plus deposits issued (to domestic residents and to foreign households: second and third term, respectively). Given frictionless contracting between banks and domestic non-financial firms, the return $R_{K t}$ satisfies

$$
R_{K t}=\frac{Z_{t}+(1-\delta) q_{t}}{q_{t-1}}
$$

where $Z_{t}$ is the (real) capital rental rate and $\delta$ is capital's depreciation rate.

Combining (27) and (28) yields the evolution of net worth (conditional on surviving into $t+1)$ :

$$
N_{i t+1}=\left(R_{K t+1}-R_{t+1}\right) q_{t} S_{i t}+\left(R_{t+1}-R_{t+1}^{*} \mathcal{Q}_{t+1} / \mathcal{Q}_{t}\right) \mathcal{Q}_{t} D_{i t}^{*}+R_{t+1} N_{i t}
$$

Banker $i$ 's objective is

$$
V_{i t}=\max _{S_{i t}, D_{i t}^{*}}\left(1-\sigma_{b}\right) \mathbb{E}_{t}\left(\Lambda_{t, t+1} N_{i t+1}\right)+\sigma_{b} \mathbb{E}_{t}\left(\Lambda_{t, t+1} V_{i t+1}\right)
$$

subject to (30) and

$$
\left(1-\sigma_{b}\right) \mathbb{E}_{t}\left(\Lambda_{t, t+1} N_{i t+1}\right)+\sigma_{b} \mathbb{E}_{t}\left(\Lambda_{t, t+1} V_{i t+1}\right) \geq \Theta\left(x_{i t}\right) q_{t} S_{i t}
$$

where $x_{i t} \equiv \mathcal{Q}_{t} D_{i t}^{*} / q_{t} S_{i t}$ and $\Lambda_{t, t+1}$ is the domestic household's real stochastic discount factor between $t$ and $t+1$. Equation (32) is the incentive constraint, which now incorporates the fact that bankers are infinite-lived. Unlike in the simple model of Section 2, we assume $\Theta\left(x_{t}\right)$ 
is quadratic rather than linear:

$$
\Theta\left(x_{t}\right)=\theta\left(1+\frac{\gamma}{2} x_{i t}^{2}\right)
$$

This formulation has the feature of inducing an interior solution for banks' portfolio choice $x_{i t}$, without affecting the key qualitative insights obtained from the simpler linear case. This feature will prove useful later when we analyze banks' portfolio choice as a function of the monetary regime in place.

Appendix (B.1) contains a detailed derivation of the solution to the banker's problem. All bankers choose the same ratio of dollar debt to assets: $x_{i t}=x_{t} \forall i$. The associated first order condition is

$$
\mu_{t}^{*}=\left(\frac{\Theta\left(x_{t}\right)}{\Theta^{\prime}\left(x_{t}\right)}-x_{t}\right)^{-1} \mu_{t}
$$

where the coefficients $\mu_{t}^{*}, \mu_{t}$ are given by

$$
\begin{aligned}
\mu_{t}^{*} & =\mathbb{E}_{t}\left[\Lambda_{t, t+1} \Omega_{t+1}\left(R_{t+1}-R_{t+1}^{*} \mathcal{Q}_{t+1} / \mathcal{Q}_{t}\right)\right] \\
\mu_{t} & =\mathbb{E}_{t}\left[\Lambda_{t, t+1} \Omega_{t+1}\left(R_{K t+1}-R_{t+1}\right)\right]
\end{aligned}
$$

with

$$
\begin{aligned}
\Omega_{t} & =1-\sigma_{b}+\sigma_{b}\left[\nu_{t}+\left(\mu_{t}+\mu_{t}^{*} x_{t}\right) \phi_{t}\right] \\
\nu_{t} & =\mathbb{E}_{t}\left(\Lambda_{t, t+1} \Omega_{t+1}\right) R_{t+1}
\end{aligned}
$$

The leverage ratio, $\phi_{i t}=q_{t} S_{i t} / N_{i t}$, is also common across bankers, and satisfies

$$
\phi_{t}=\frac{\nu_{t}}{\Theta\left(x_{t}\right)-\left(\mu_{t}+\mu_{t}^{*} x_{t}\right)}
$$

Compared to the simple model described previously, bankers now discount future returns using an "augmented" discount factor $\Lambda_{t+1} \Omega_{t+1}$, which accounts for the marginal value of funds internal to the bank (given by the variable $\Omega_{t+1}$ ). Equation (34) is the counterpart of (8) in the simple model. Given curvature in $\Theta\left(x_{t}\right)$, now $\mu_{t}^{*}$ and $\mu_{t}$ are not linked simply by a constant, but rather their relationship also depends on $x_{t}$, as banks adjust the latter to equalize the marginal benefit of foreign funds with their marginal cost.

From equation (39), the leverage ratio $\phi_{t}$ is increasing in $\nu_{t}$, the saving to the bank in 
deposit costs from an extra unit of net worth, and in $\mu_{t}+\mu_{t}^{*} x_{t}$, the discounted total excess return on the bank's assets; and decreasing in the fraction of funds banks are able to divert, $\Theta\left(x_{t}\right)$.

If bank $i$ is a new entrant, its net worth is given by

$$
N_{i t}=\frac{\xi_{b}}{f} q_{t-1} S_{t-1}
$$

Given that banks' leverage ratio $\phi_{t}$ and foreign funding ratio $x_{t}$ do not depend on bankspecific factors, aggregating across banks yields the following relationships between aggregate

assets and foreign debt $\left(S_{t}=\int_{0}^{f} S_{i t} d i\right.$ and $D_{t}^{*}=\int_{0}^{f} D_{i t}^{*} d i$ respectively) and aggregate net worth $N_{t}=\int_{0}^{f} N_{i t} d i$ :

$$
\begin{array}{r}
q_{t} S_{t}=\phi_{t} N_{t} \\
\mathcal{Q}_{t} D_{t}^{*}=x_{t} \phi_{t} N_{t}
\end{array}
$$

Aggregating $N_{i t}$ across all banks (continuing ones and new entrants) and using (30) and (40) yields the evolution of aggregate net worth:

$$
N_{t}=\sigma_{b}\left[\left(R_{K t}-R_{t}\right) q_{t-1} S_{t-1}+\left(R_{t}-R_{t}^{*} \mathcal{Q}_{t} / \mathcal{Q}_{t-1}\right) \mathcal{Q}_{t-1} D_{t-1}^{*}+R_{t} N_{t-1}\right]+\left(1-\sigma_{b}\right) \xi_{b} q_{t-1} S_{t-1}
$$

\subsection{Households and Employment Agencies}

Following Erceg, Henderson and Levin (2000), there is a continuum of households indexed by $i \in[0,1]$, each of which is a monopolistic supplier of specialized labor $L_{i t}$. A large number of competitive "employment agencies" combine specialized labor into a homogeneous labor input used by intermediate goods producers, according to

$$
L_{t}=\left(\int_{0}^{1} L_{i t}^{\frac{1}{1+\theta_{w}}} d i\right)^{1+\theta_{w}}
$$

From employment agencies' cost minimization, demand for labor variety $i$ is

$$
L_{i t}=\left(\frac{W_{i t}}{W_{t}}\right)^{-\frac{1+\theta_{w}}{\theta_{w}}} L_{t}
$$

where $W_{i t}$ is the nominal wage received by supplier of labor of type $i$ and the wage paid by 
goods producers is $W_{t}=\left(\int_{0}^{1} W_{i t}^{-\frac{1}{\theta_{w}}} d j\right)^{-\theta_{w}}$.

Household $i$ seeks to solve

$$
\max _{\substack{\left\{C_{D t+j}, M_{C t+j}, C_{t+j}, D_{t+j}, W_{i t+j}, L_{i t+j}\right\}_{j=0}^{\infty}}} \mathbb{E}_{t}\left\{\sum_{j=0}^{\infty} \beta^{j}\left[\frac{\sigma}{\sigma-1}\left(C_{t+j}-h C_{t+j-1}\right)^{\frac{\sigma-1}{\sigma}}-\frac{\chi_{0}}{1+\chi} L_{i t+j}^{1+\chi}\right]\right\}
$$

subject to (45) and to a sequence of budget constraints

$$
P_{t} C_{t}+P_{t} D_{t}+B_{t} \leq W_{i t} L_{i t}+P_{t} R_{t} D_{t-1}+R_{t}^{n} B_{t-1}+\mathcal{W}_{i t}+\Pi_{t}
$$

for all $t$, where $C_{t}$ and $P_{t}$ satisfy

$$
\begin{aligned}
C_{t} & =\left((1-\omega)^{\frac{\rho}{1+\rho}} C_{D t}^{\frac{1}{1+\rho}}+\omega^{\frac{\rho}{1+\rho}}\left(\varphi_{C t} M_{C t}\right)^{\frac{1}{1+\rho}}\right)^{1+\rho} \\
P_{t} & =\left((1-\omega) P_{D t}^{-\frac{1}{\rho}}+\omega P_{M t}^{-\frac{1}{\rho}}\right)^{-\rho}
\end{aligned}
$$

Above, $C_{t}$ denotes the consumption basket, a CES aggregate of a domestically-produced composite good, $C_{D t}$, and an imported composite good, $M_{C t} ; D_{t}$ is deposits in domestic banks, which pay real (i.e. in terms of the domestic basket) gross interest rate $R_{t} ; B_{t}$ is holdings of nominal one-period riskless bonds, which pay interest $R_{t}^{n}$ between $t-1$ and $t ; \mathcal{W}_{i t}$ is the net cash flow from household $i$ 's portfolio of state-contingent securities (used to ensure that all workers in the household consume the same amount $C_{t}$, despite earning different wage income); and $\Pi_{t}$ is bank and firm profits distributed to the household.

The variables $P_{D t}$ and $P_{M t}$ denote, respectively, the price of the domestically-produced composite good and of the imported good, and $P_{t}$ denotes the price of the home basket (i.e. the $\mathrm{CPI}$ ). In our baseline case, we assume that exporters in each country practice producer currency pricing $(\mathrm{PCP})$ :

$$
P_{M t}=e_{t} P_{D t}^{*}
$$

and

$$
P_{M t}^{*}=e_{t}^{-1} P_{D t},
$$

where $e_{t}$ is the nominal exchange rate (i.e. the price of a dollar in terms of the home 
currency), $P_{D t}^{*}$ is the price of the foreign composite good (in dollars), and $P_{M t}^{*}$ is the price of the domestic composite good abroad. The real exchange rate then satisfies $\mathcal{Q}_{t}=e_{t} P_{t}^{*} / P_{t}$.

The household also faces costs of adjusting consumption imports, which take the following form:

$$
\varphi_{C t}=1-\frac{\varphi_{M}}{2}\left(\frac{M_{C t} / C_{D t}}{M_{C t-1} / C_{D t-1}}-1\right)^{2}
$$

The above follows Blanchard et al. (2016) and Erceg et al. (2006). It implies that it is costly to change the proportion of domestic and foreign goods in the aggregate consumption basket. As such, it dampens the short-run to response of the import share to movements in the relative price of imports, but allows the level of imports to respond quickly to changes in overall consumption $C_{t}{ }^{17}$

Finally, problem (46) is also subject to a constraint on wage adjustment, whereby the wage can only be set optimally with probability $1-\xi_{w}$, and otherwise must follow the indexation rule

$$
W_{i t}=W_{i t-1} \pi_{w t-1}^{\iota w}
$$

where wage inflation is given by

$$
\pi_{w t}=W_{t} / W_{t-1}
$$

\subsection{Firms and Price Setting}

A continuum of mass unity of retail firms produce domestic output using intermediate goods as inputs. Final output $Y_{t}$ is a CES composite of retailers' output:

$$
Y_{t}=\left(\int_{0}^{1} Y_{i t}^{\frac{1}{1+\theta_{p}}} d i\right)^{1+\theta_{p}}
$$

where $Y_{i t}$ is output by retailer $i \in[0,1]$. Let the price set by home retailer $i$ be $P_{D i t}$. The price level of domestic final output is $P_{D t}=\left(\int_{0}^{1} P_{D i t}^{-\frac{1}{\theta_{p}}} d i\right)^{-\theta_{p}}$. Cost minimization by users

\footnotetext{
${ }^{17}$ As emphasized by Erceg et al. (2005), adjustment costs modeled in this way permit the model to match the evidence described in Hooper et al. (2000) and in Mc Daniel and Balistreri (2003) that the short-run trade price elasticity is smaller than the long-run elasticity.
} 
of final output yields the following demand function for firm $i$ 's output:

$$
Y_{i t}=\left(\frac{P_{D i t}}{P_{D t}}\right)^{-\frac{1+\theta_{p}}{\theta_{p}}} Y_{t}
$$

Domestic intermediates producer $i$ employs the production function

$$
Y_{i t}=K_{i t}^{\alpha} L_{i t}^{1-\alpha}
$$

and pays real wage and capital rental rates $w_{t}$ and $Z_{t}$ respectively. Firm $i$ can reset its price with probability $1-\xi_{p}$, and otherwise must follow the indexation rule

$$
P_{D i t}=P_{D i t-1} \pi_{t-1}^{\iota p}
$$

\subsection{Capital Producers}

Capital producers produce new capital goods subject to costs of adjusting the level of investment $I_{t}$ given by

$$
\phi_{I t}=\frac{\psi_{I}}{2}\left(\frac{I_{t}}{I_{t-1}}-1\right)^{2} I_{t}
$$

(in units of the home good). The representative capital producer solves

$$
\max _{\left\{I_{t+j}\right\}_{j=0}^{\infty}} \mathbb{E}_{t}\left\{\sum_{j=0}^{\infty} \Lambda_{t, t+j}\left[q_{t+j} I_{t+j}-\frac{P_{D t+j}}{P_{t+j}} \phi_{I t+j}\right]\right\}
$$

where $q_{t}$ denotes the real price of capital goods (in terms of the home basket). Similar to consumption, investment goods are a composite of domestic $\left(I_{D t}\right)$ and imported $\left(M_{I t}\right)$ goods, also subject to costs of adjusting the imported-domestic good mix:

$$
I_{t}=\left[(1-\omega)^{\frac{\rho}{1+\rho}} I_{D t}^{\frac{1}{1+\rho}}+\omega^{\frac{\rho}{1+\rho}}\left(\varphi_{I t} M_{I t}\right)^{\frac{1}{1+\rho}}\right]^{1+\rho}
$$

with

$$
\varphi_{I t}=1-\frac{\varphi_{M}}{2}\left(\frac{M_{I t} / I_{D t}}{M_{I t-1} / I_{D t-1}}-1\right)^{2}
$$


Optimality with respect to the investment aggregate $I_{t}$ gives rise to an investment-Tobin's $q$ relation:

$q_{t}=1+\frac{P_{D t}}{P_{t}}\left[\psi_{I}\left(\frac{I_{t}}{I_{t-1}}-1\right) \frac{I_{t}}{I_{t-1}}+\frac{\psi_{I}}{2}\left(\frac{I_{t}}{I_{t-1}}-1\right)^{2}\right]-\mathbb{E}_{t}\left\{\Lambda_{t, t+1} \frac{P_{D t+1}}{P_{t+1}} \psi_{I}\left(\frac{I_{t+1}}{I_{t}}-1\right)\left(\frac{I_{t+1}}{I_{t}}\right)^{2}\right\}$

\subsection{The Foreign Economy}

U.S. household $i$ seeks to solve

$$
\max _{\substack{\left\{C_{D t+j}^{*}, M_{C t+j}^{*}, C_{t+j}^{*}, D_{t+j}^{*}, B_{t+j}^{*}, W_{i t+j}^{*}, L_{i t+j}^{*}\right\}_{j=0}^{\infty}}} \mathbb{E}_{t} \sum_{j=0}^{\infty} \beta^{* j}\left[\frac{\sigma}{\sigma-1}\left(C_{t+j}^{*}-h C_{t+j-1}^{*}\right)^{\frac{\sigma-1}{\sigma}}-\frac{\chi_{0}{ }^{*}}{1+\chi} L_{i t+j}^{* 1+\chi}\right]
$$

subject to a sequence of budget constraints

$$
P_{t}^{*} C_{t}^{*}+B_{t}^{*}+P_{t}^{*} D_{t}^{*} \leq W_{i t}^{*} L_{i t}^{*}+R_{t}^{n *} B_{t}^{*}+P_{t}^{*} \widetilde{R}_{t}^{*} D_{t-1}^{*}+\Pi_{t}^{*}+\mathcal{W}_{i t}^{*}
$$

where $D_{t}^{*}$ is short-term deposits in EM banks by U.S. households, $B_{t}^{*}$ is short-term (dollardenominated) nominal bonds, $\widetilde{R}_{t}^{*}$ is the real return received from deposits in EM banks (in real dollars), and $R_{t}^{n *}$ is the federal funds rate. We allow for the possibility of a tax $\tau$ on home banks' foreign borrowing: $R_{t}^{*}=(1+\tau) \widetilde{R}_{t}^{*}$. Our baseline calibration sets $\tau=0$; we only use $\tau>0$ as a device to drive EM banks' steady-state dollar debt to zero, with the goal of illustrating the role of the latter in driving dynamics.

Aside from the absence of financial frictions, the foreign economy mirrors the features of the home country - including nominal wage and price rigidity, investment adjustment costs, and costs of adjusting the import share in consumption and investment.

\subsection{Market Clearing, Balance of Payments, and Monetary Policy}

The market clearing condition for the home good is as follows:

$$
Y_{t}=C_{D t}+I_{D t}+\frac{\xi^{*}}{\xi}\left(M_{C t}^{*}+M_{I t}^{*}\right)+\phi_{I t}
$$

where $\frac{\xi^{*}}{\xi}$ is the relative population size of the foreign economy (note that all variables are expressed in per capita terms). The aggregate capital stock, $K_{t}=\int_{0}^{1} K_{i t} d i$, evolves according 
to

$$
K_{t+1}=(1-\delta) K_{t}+I_{t}
$$

In turn, market clearing for claims on EM physical capital (held by EM banks) implies $S_{t}=(1-\delta) K_{t}+I_{t}$.

The balance of payments, obtained by aggregating the budget constraints of agents in the home economy, is given by

$$
\mathcal{Q}_{t}\left(D_{t}^{*}-R_{t}^{*} D_{t-1}^{*}\right)=C_{t}+I_{t}+p_{D t} \phi_{I t}-p_{D t} Y_{t}
$$

As a baseline case, we assume that monetary policy in the home country follows an inertial Taylor rule:

$$
R_{t+1}^{n}=\left(R_{t}^{n}\right)^{\gamma_{r}}\left(\beta^{-1} \pi_{t}^{\gamma_{\pi}}\right)^{1-\gamma_{r}} \varepsilon_{t}^{r}
$$

where $\varepsilon_{t}^{r}$ is an exogenous shock. Later we consider an alternative policy rule which allows for an exchange rate stabilization motive. Finally, monetary policy in the United States is conducted according to an inertial Taylor rule which, in addition to inflation, includes the output gap as an argument and is buffeted by exogenous shocks $\varepsilon_{t}^{r *}$, in a manner analogous to (69). The U.S. monetary shock is assumed to follow the process $\varepsilon_{t}^{r *}=\rho_{r} \varepsilon_{t-1}^{r *}+u_{t}$, where $u_{t} \sim \mathcal{N}\left(0, \sigma_{u}^{2}\right)$.

Appendix B.2 contains a complete description of the model's equilibrium conditions.

\subsection{Discussion of Assumptions}

Two important assumptions underlying the model's implications for the failure of UIP are (i) financial contracts are less enforceable across than within borders; and (ii) there is market segmentation, whereby only domestic banks can borrow from foreign households (and must do so in foreign currency).

Assumption (i) is meant to capture features of the institutional environment in EMs that make it harder for foreign creditors to recover assets from a defaulting borrower, compared with domestic depositors. For example, domestic depositors may be able to benefit from deposit insurance protections unavailable to foreign lenders, and bankruptcy law may be biased toward domestic lenders (Hermalin and Rose 1999). More generally, differences in 
the legal systems between EMs and advanced countries may create additional difficulties in contract enforcement (Rajan and Zingales 1998). Foreign creditors may also face greater informational disadvantages. ${ }^{18}$ While our model captures these considerations by means of the simple assumption that $\gamma>0$, deeper microfoundations are possible inducing similar implications for the failure of UIP. ${ }^{19}$

In Appendix A.4 we illustrate that the key results survive under a weaker form of market segmentation than (ii). We extend the simple model of Section 2 by permitting households to participate in foreign exchange, subject to a convex transaction cost (capturing the notion that there is a limited supply of households sophisticated enough to borrow from the foreign country), and show that the key result linking the UIP failure to domestic net worth continues to hold.

Our analysis focuses on private debt. We next discuss whether the presence of government debt, together with "deep pocket" international investors, might undo the UIP deviation that we uncover. Suppose there is a one-period real risk-free government bond in each country that is traded internationally. This bond is a perfect substitute for bank deposits so yields interest $R_{t}$ and $R_{t}^{*}$ at home and abroad respectively. Assuming that an unconstrained international investor can trade both bonds, the standard UIP condition would follow (at least to a first order), as in the canonical open-economy NK model.

We view the combination of assumptions above as unrealistic and unlikely to hold in practice for EMs. First, international investors likely suffer from limited risk-bearing capacity themselves, as in the popular framework studied by Gabaix and Maggiori (2015). This channel is likely even more relevant for EM currencies than for advanced economy ones, as EMs are generally perceived to be riskier. Note that in our model, taking advantage of a positive currency premium would involve buying EM bonds precisely when financial conditions in the EM are deteriorating - possibly further constraining international investors' capacity to invest in the EM.

In addition, the assumption that EM government bonds are risk-free is unrealistic in the first place, given the possibility of default. It is plausible that the probability of a sovereign default would rise as domestic banks' balance sheets deteriorate - in response to an increased likelihood of an eventual bailout of domestic banks by the government - thus

\footnotetext{
${ }^{18}$ Caballero and Simsek (2016) make an assumption in this spirit to motivate "fickleness" of foreign investors during domestic distress episodes.

${ }^{19}$ In Gopinath and Stein (2018), for example, banks have more difficulty in creating dollar-denominated collateral than domestic-currency collateral, as the bank's underlying assets pay off in domestic currency.
} 
also prompting a rise in the currency risk premium. ${ }^{20}$ Finally, there may be imperfect arbitrage between deposits and government bonds if balance-sheet-constrained banks also play a role in intermediating government bonds, as in Gertler and Karadi's (2013) model.

While extending the model in the directions outlined above would certainly be interesting, we expect the basic link we emphasize between the currency premium and net worth to survive in these more general settings. The empirical evidence of Section 6 provides strong support for the link between UIP deviations and measures of the domestic external finance premium, consistent with the model's key prediction.

\subsection{Calibration}

We calibrate the foreign economy to the United States, and take the home economy to represent an EM, such as Mexico, with trade and financial linkages to the United States. An alternative possibility is to think of the home economy as a bloc of emerging economies, such as the Asian or the Latin American EMs. ${ }^{21}$ The calibration is asymmetric: the U.S. is much larger in size, and EM households are assumed to be relatively impatient, which introduces a motive for the latter to borrow from U.S. households. The relative impatience feature can be seen as capturing more-structural differences between EMs and advanced economies, such as faster prospective trend growth in EMs.

Table 1 reports parameter values. We calibrate the U.S. discount factor, $\beta^{*}$, to 0.9950 , implying a steady-state real interest rate of $2 \%$ per year. This choice follows several recent studies (e.g. Reifschneider 2016) and is motivated by estimates indicating a decline in the U.S. natural rate (see, for example, Holston, Laubach and Williams 2017). To calibrate the home discount factor, we rely on estimates of Mexico's long-run natural rate from Carrillo et al. (2017) of about 3 percent, and accordingly calibrate $\beta$ to $0.9925 .^{22}$ The size of the home economy relative to the United States is $\xi / \xi^{*}=1 / 3$.

The intertemporal elasticity of substitution $(\sigma)$, capital share $(\alpha)$ and capital depreciation rate $(\delta)$ are calibrated to the conventional values of $1,0.33$, and 0.025 , respectively. We calibrate the steady-state wage and price markups, $\theta_{p}$ and $\theta_{w}$, to 20 percent in each case, a conventional value. For the remaining parameters governing household and firm behavior,

\footnotetext{
${ }^{20}$ Burnside et al. (2001) make a similar argument in the context of the 1997 East Asian crisis.

${ }^{21}$ The approach of grouping countries into blocs is often used in larger-scale models for policy analysis, e.g. Erceg et al. (2006).

${ }^{22}$ Magud and Tsounta (2012) also estimate the natural rate for several Latin American countries using various methodologies. Averaging across methodologies yields a range of values between 2 and 5 percent across countries, with a cross-country average of about 3 percent.
} 
we rely on estimates from Justiniano et al. (2010). These parameters include the degree of consumption habits $(h)$, the inverse Frisch elasticity of labor supply $(\chi)$, the parameters governing price and wage rigidities $\left(\xi_{p}, \iota_{p}, \xi_{w}\right.$, and $\left.\iota_{w}\right)$, and the investment adjustment cost parameter $\left(\Psi_{I}\right)$. These parameters are set symmetrically across the two economies, and their values are fairly conventional. They are listed in the top part of Table 1.

The Taylor rule both at home and in the U.S. features inertia with a coefficient of 0.82 (an estimate also taken from Justiniano et al. 2010). In our baseline experiments we set the home Taylor rule coefficient $\gamma_{\pi}$ to the standard value of 1.5 , capturing a rule focused on stabilizing domestic inflation. We use the domestic monetary shock $\varepsilon_{t}^{r}$ in Section 5 to illustrate the effects of domestic monetary policy, and otherwise set its volatility to zero. Turning to the U.S. Taylor rule, we set the coefficients $\gamma_{\pi}^{*}$ and $\gamma_{x}^{*}$ to 1.5 and 0.125 respectively, conventional values used in the literature (e.g. Taylor 1993). To calibrate the standard deviation and persistence of U.S. monetary shocks, we use the calibrated U.S. Taylor rule, together with observations on the Fed funds rate, core inflation, and the output gap (proxied by -2 times the deviation of the unemployment rate from the natural rate, with the latter set to 4.8 as in Reifschneider 2016) for the period 1980-present, to extract a series for the empirical counterpart of $\varepsilon_{t}^{r *}$, to which we fit an $\operatorname{AR}(1)$ process. The resulting values are $\rho_{r}=0.25$ and $\sigma_{u}=0.20 / 100 .^{23}$

Turning to parameters governing international trade, we follow Erceg et al. (2007) (who rely on estimates by Hooper et al. 2000) and set the trade price elasticity $(1+\rho) / \rho$ to 1.5 . We impose the restriction that $\omega^{*}=\omega \xi / \xi^{*}$, as frequently done in the literature (e.g. Blanchard et al. 2016). We set $\omega=0.20$, implying that 20 percent of the home economy's output is exported in steady state. This value is somewhat lower than the ratio of Mexico's exports to the United States as a fraction of GDP (which equaled 0.28 in 2017) but higher than in other EMs (for example, aggregating across the major EMs in Asia and Latin America leads to a ratio of around 0.10 for 2017). ${ }^{24}$ The trade adjustment cost parameter $\varphi_{M}$ is set to 10, as in Erceg et al. (2005) and Erceg et al. (2006). This value implies a price elasticity of slightly below unity after four quarters, consistent with the evidence that the short-run elasticity is lower than the long-run one.

Regarding the parameters governing financial market frictions, we set the survival rate

\footnotetext{
${ }^{23}$ If we instead estimate a rule for the Fed funds rate with core inflation and unemployment as arguments (rather than calibrating the coefficients on these variables ex-ante), the resulting residual has a similar standard deviation, but lower persistence.

${ }^{24}$ These statistics refer only to merchandise trade, so do not include services. Source: IMF Direction of Trade statistics.
} 
$\sigma_{b}$ to 0.95 , implying an expected horizon of 6 years. The remaining three parameters are set to hit three targets: a steady-state credit spread of 200 basis points annually, a leverage ratio of 5 , and a ratio of foreign-currency debt to domestic debt $\left(\mathcal{Q}_{t} D_{t}^{*} / D_{t}\right)$ of 30 percent. The target for the credit spread reflects the average value of 5-year BBB corporate bond spreads in major emerging market economies (including both Asian and Latin American EMs) over the period 1999-2017 (excluding the global financial crisis period). The target leverage ratio is a rough average of leverage across different sectors. Leverage ratios in the banking sector are typically greater than five, ${ }^{25}$ but the corporate sector features a much lower ratio of assets to equity (between two and three in emerging markets). ${ }^{26}$ Our target of five reflects a rough compromise between these two values. Finally, evidence in Hahm et al. (2013) on ratios of foreign-currency deposits to domestic deposits in EMs suggests an average of about 30 percent. This value is also consistent with evidence presented in Chui et al. (2016), showing that average private-sector foreign currency debt across EMs (for the period 2006-2014) as a percent of total (i.e. domestic- plus foreign-currency denominated) debt is a little over 20 percent. These targets imply $\theta=0.41, \xi_{b}=0.07$, and $\gamma=2.58$. The implied value for steady-sate ratio of foreign liabilities to assets is $x=0.18$ (note that $x$ follows from our targets for $\phi$ and $\mathcal{Q} D^{*} / D$, via the balance sheet identity.)

\section{Cross-Border Spillovers of Monetary Policy}

This section uses the medium-scale model presented above to explore the transmission of monetary policy across borders. We begin by discussing the channels of spillovers in a frictionless complete markets economy, with an emphasis on the role of the familiar expenditureswitching and expenditure-reducing effects. Next, we examine spillovers in our baseline model with imperfect international financial markets. We conclude the section by analyzing the implications of dollar trade invoicing - an empirically relevant trade pricing assumption for EMs - for the spillovers from a U.S. monetary tightening.

\subsection{Spillovers in a Frictionless Economy}

We begin by considering monetary spillovers in an economy featuring a complete set of contingent claims traded internationally, and no financing frictions. We also set $\beta^{*}=\beta$.

\footnotetext{
${ }^{25}$ For example, bank assets to capital averaged around 10 for Mexico in recent years. Source: IMF Global Financial Stability Report.

${ }^{26}$ See e.g. IMF Global Financial Stability Report October 2015, Chapter 3.
} 
The remaining features are as described in Section 3.

The green solid line in Figure 2 shows the effects of a 100 basis point rise in the Fed funds rate. Overall, the shock has empirically realistic effects on the United States, with U.S. GDP (third row, first column) falling by a little over 0.50 at the trough - very close to our structural vector autoregression (SVAR) estimate (shown in Appendix C), and broadly similar to those found by other authors, like Christiano et al. (2005). The key observation from Figure 2 is that the effect of the U.S. tightening on activity in the EM are modest, with EM GDP falling by less than 0.10 percent (second row, first column).

To understand the mechanics of the effects of the foreign monetary policy on domestic activity, it is helpful to consider the following expression linking home's GDP to the sum of consumption, investment, and net exports, obtained by combining (48), (61), and (66) and log-linearizing:

$$
\widehat{y}_{t}=\alpha_{c y} \widehat{c}_{t}+\left(1-\alpha_{c y}\right) \widehat{i}_{t}+\omega\left(\widehat{m}_{t}^{*}-\widehat{m}_{t}\right)
$$

where $\widehat{z}_{t}$ denotes the $\log$ deviation of any variable $Z_{t}$ from its steady-state value, $\alpha_{c y} \equiv$ $C / Y=0.77$ is the steady-state share of consumption in output, and $\widehat{m}_{t}^{*}=\alpha_{c y} \widehat{m}_{c t}^{*}+(1-$ $\left.\alpha_{c y}\right) \widehat{m}_{i t}^{*}$ and $\widehat{m}_{t}=\alpha_{c y} \widehat{m}_{c t}+\left(1-\alpha_{c y}\right) \widehat{m}_{i t}$ are total exports and imports respectively. Equation (70) indicates that log-deviations of output from steady state can be decomposed into domestic absorption, $\alpha_{c y} \widehat{c}_{t}+\left(1-\alpha_{c y}\right) \widehat{i}_{t}$, plus net exports, $\omega\left(\widehat{m}_{t}^{*}-\widehat{m}_{t}\right)$.

The 100 basis point Fed funds rate hike raises the U.S. real rate (not shown) by around 120 basis points, given some decline in U.S. expected inflation. Through the familiar UIP condition (which holds in its standard form in this frictionless setting), the ensuing differential in long-run real interest rates puts downward pressure on home's real exchange rate (top left panel), which depreciates 1 percent on impact and then gradually appreciates. The expected appreciation then works to depress home's expected CPI inflation, accounting for a rise in the home real interest rate $R_{t}$ of about 25 basis points - roughly one fifth the size of the increase in the U.S. real rate. The rising home real rate accounts for the drops in consumption and investment (middle row, second and third columns respectively), each falling by around one-fifth of the size of the decline in the same variables in the United States - in line with the relative size of the increase in the real rate compared with the United States. Thus, in light of (70), the drop in home GDP reflects the drag from domestic absorption, along with some offset from net exports, which increase somewhat - as imports fall by more than exports do, as the middle and right panels in the top row indicate. 
The model permits illustrating how the small response of home's GDP to the foreign monetary shock ultimately reflects the offsetting influences of the expenditure-switching and the expenditure-reducing channels, which move home GDP in opposite directions. The expenditure-switching channel captures the shift in spending toward home goods and away from U.S. goods driven by the decline in the relative price of the former. We capture this channel by setting the habit and investment adjustment cost parameters to very high values, with the consequence that that households and firms in both countries keep consumption and investment spending constant despite the rise in real interest rates. The resulting dynamics (shown by the blue dash-dotted line in Figure 2, where we have re-sized the shock so it generates the same depreciation upon impact) reflect that consumers and firms at home and abroad reallocate expenditure toward home's goods and away from U.S. goods, while keeping overall expenditure constant. Accordingly, home's net exports improve, engendering a rise in home GDP of about 0.15 percent.

The expenditure-reducing channel, on the other hand, refers to the decline in the overall demand for both home and foreign products resulting from the rise in real interest rates. We capture this channel by setting the parameter $\phi_{M}$ (capturing the cost of adjusting the share of imports in both consumption and investment) to a very high value - effectively imposing Leontief preferences across domestic- and foreign-produced goods, which implies that agents do not alter the share of imports in total consumption or investment despite the relative price change. Under these conditions, the movement in home output can be shown to equal a weighted average of the change in home and U.S. absorption, with weights $(1-\omega)$ and $\omega$ respectively. ${ }^{27}$ In this case, the drop in home's GDP is more sizable - around 0.20 percent, with two thirds of the decline accounted for by the U.S. absorption component.

Under the baseline calibration, both the expenditure-reducing and the expenditureswitching effects are present: there is a decline in overall spending, but also some reallocation of spending toward home goods. Home output still declines a bit as the expenditure-reducing channel is somewhat more powerful, but the drop is quantitatively modest.

\footnotetext{
${ }^{27}$ Given $\phi_{M} \rightarrow \infty$, imports move in proportion with home absorption and exports move in proportion with U.S. absorption, so that equation (70) becomes simply

$$
\widehat{y}_{t}=(1-\omega)\left[\alpha_{c y} \widehat{c}_{t}+\left(1-\alpha_{c y}\right) \widehat{i}_{t}\right]+\omega\left[\alpha_{c y} \widehat{c}_{t}^{*}+\left(1-\alpha_{c y}\right) \widehat{i}_{t}^{*}\right]
$$
}




\subsection{Imperfect Financial Markets}

Unlike the frictionless complete markets models studied above, our model with imperfect financial markets and dollar debt implies sizable spillover effects from the U.S. monetary tightening. The blue solid line in Figure 3 shows the effects of the same 100 basis point U.S. tightening in our baseline model with financial market frictions. GDP in the EM (bottom left panel) falls almost 0.3 percent, more than three times as much as in the frictionless model, and the real exchange rate (second row, first column) depreciates by fifty percent more than without financial frictions. The bigger decline in GDP is driven by a much steeper drop in domestic absorption, with investment falling by more than 2 percent-eight times as much as in the complete markets economy - and consumption by about twice as much as in the frictionless model. At the same time, there is a stronger offset from net exports - with exports actually rising a bit, due to the the much sharper depreciation.

Both the presence of an endogenous currency premium and of dollar liabilities in balance sheets play a key role in driving the financial amplification responsible for the much stronger effects just described. To clarify the mechanics, it is helpful to consider the loglinearized versions of equations (43) and (34), respectively given by the following:

$$
\begin{aligned}
& \widehat{n}_{t} \approx \sigma_{b}\left\{\phi\left[\left(\widehat{r}_{k t}-\widehat{r}_{t}\right)-x\left(\widehat{r}_{t}^{*}+\Delta \widehat{\mathcal{Q}}_{t}-\widehat{r}_{t}\right)\right]+\widehat{r}_{t}+\widehat{n}_{t-1}\right\} \\
& \widehat{\mathcal{Q}}_{t} \approx \Gamma \mathbb{E}_{t}\left\{\widehat{r}_{k t+1}-\widehat{r}_{t+1}\right\}+\left(\widehat{r}_{t+1}^{*}-\widehat{r}_{t+1}\right)+\mathbb{E}_{t}\left\{\widehat{\mathcal{Q}}_{t+1}\right\}
\end{aligned}
$$

where $\phi=5$ and $x=0.18$ are the steady-state leverage ratio and the ratio of dollar debt to assets respectively, and where the coefficient $\Gamma$ (itself an increasing function of both $x$ and parameter $\gamma$ ) is $\Gamma=0.5 .^{28}$

Equation (71) shows the evolution of aggregate net worth, which depends positively on the realized return to capital $\widehat{r}_{k t}$ (a variable that moves in tandem with Tobin's $q$ ) and inversely on the ex-post real exchange rate depreciation $\Delta \widehat{\mathcal{Q}}_{t}$, where the latter effect is more powerful the larger the steady-state dollar debt share $x$. Equation (72) is the equivalent of the uncovered interest parity condition in our model, which links the real exchange rate to the spread between the domestic return on capital and the domestic deposit rate (the first term) as well as to real interest rate differential between the two countries and to the expectation of the following-period exchange rate (as in standard versions of UIP). The first

\footnotetext{
${ }^{28}$ The expression for $\Gamma$ is $\Gamma(x, \gamma)=\frac{x}{\gamma^{-1}-x^{2} / 2}$. For expositional convenience, equations (71) and (72) abstract from terms that involve coefficients $\left(R_{K}-R\right),\left(R-R^{*}\right)$ or $\left(1-\sigma_{b}\right) \xi_{b}$, all of which are orders of magnitude smaller than the coefficients on the terms shown in (71) and (72).
} 
term captures the deviation from UIP, in a manner analogous to the simple model of Section 2 (with the coefficient $\Gamma$ now replacing $\gamma$, due to $\Theta\left(x_{t}\right)$ being quadratic rather than linear).

As made clear by (71) and (72), to the extent that $x>0$, the model involves two-way feedback between $\widehat{n}_{t}$ and the real exchange rate $\widehat{\mathcal{Q}}_{t}$, over and above the adverse feedback between net worth and Tobin's $q$ usually present in financial accelerator models: as net worth deteriorates, the term $\mathbb{E}_{t}\left\{\widehat{r}_{k t+1}-r_{t+1}\right\}$ in (72) rises, pushing up $\widehat{\mathcal{Q}}_{t}$ (i.e. depreciating the currency), which in turn feeds back into net worth through the term $\Delta \widehat{\mathcal{Q}}_{t}$. Thus, the model features both mutual feedback between $\widehat{\mathcal{Q}}_{t}$ and $\widehat{n}_{t}$ (for given $\hat{q}_{t}$ ) and between $\hat{q}_{t}$ and $\widehat{n}_{t}$ (for a given exchange rate). This three-way interaction lies at the heart of the strength of financial amplification.

These considerations help understand how the dynamics presented in Figure 3 arise. The drop in Tobin's $q$ and the exchange rate depreciation following the U.S. rate hike (which would take place even in a frictionless setting, as made clear in the previous subsection) work to initiate losses in domestic net worth. This triggers the three-way amplification described previously. The end result is a drop in net worth of almost 9 percent, a drop in Tobin's $q$ that is eight times larger than in the frictionless setting, and a much sharper depreciation. The accompanying rise in the domestic credit spread raises the effective cost of investment and effectively underlies the sharp drop in that variable. ${ }^{29}$

To illustrate the quantitative role of the interaction between dollar debt in balance sheets and the endogenous deviation from UIP, we consider the effects of the U.S. rate hike in an alternative economy in which $\tau$ is set such that $x=0$ (i.e. no steady-state dollar debt), which amounts to setting $\tau=\beta^{*} / \beta-1$. This also implies $\Gamma=0$ in (72) - that is, standard UIP holds. The blue dashed lines in Figure 3 show the resulting responses. The net worth deterioration is now only about one-third that in the baseline model with dollar debt. The domestic credit spread still rises somewhat, accounting for a sharper drop in investment than in the frictionless model, but ultimately the drop in GDP continues to be relatively modest. Thus, the endogenous UIP deviation in the presence of foreign debt works to magnify considerably the effects of the foreign monetary policy shock.

The results from our baseline model are broadly consistent with those found by the SVAR literature that estimates the dynamic effects of a U.S. monetary policy innovation. To illustrate this point, we augment a SVAR model similar to that in Christiano et al. (2005)

\footnotetext{
${ }^{29}$ For comparability with empirical measures, we report the credit spread as a five-year maturity equivalent (with yields expressed in annual terms). That is, we show $\mathbb{E}_{t}\left(\sum_{i=1}^{20} r_{k t+i}-r_{t+i}\right) / 5$, and similarly for the currency premium.
} 
to include GDP from advanced and emerging economies. The results are shown in Appendix C. A monetary policy innovation that raises the U.S. federal funds rate by 100 basis points induces U.S. output to decrease by almost 0.5 percent at the trough, very close in magnitude to those implied by our model (though the SVAR-implied GDP response is somewhat more sluggish than the model-implied one). In response to the same shock, results from the SVAR suggest a decline in output in EMs that is broadly of comparable size to the decline in U.S. GDP over a horizon of one to two years. Our model also produces a substantial fall in home output, consistent with the evidence, though its overall decline still falls a bit short of the decline in the United States. Lastly, the effect of the U.S. monetary policy shock on other advanced economy output is more muted (and closer to the effects predicted by the model without dollar debt).

\subsection{Dominant Currency Pricing}

In this section we investigate the spillovers from U.S. monetary policy under the dominant currency paradigm (DCP) proposed by Gopinath et al. (2018). The DCP pricing assumption is motivated by empirical evidence suggesting that a large fraction of international trade is invoiced in a small number of dominant currencies, with the U.S. dollar playing an outsized role (see, for example, Goldberg and Tille 2008 and Gopinath et al. 2018).

Under DCP, firms in both countries set export prices in U.S. dollars. Thus, U.S. exporters continue to practice PCP as in the model above, but now EM producers set one price in domestic currency for goods sold in the domestic market, and another in dollars for goods sold in the United States. Home import prices continue to satisfy $P_{M t}=e_{t} P_{D t}^{*}$, but now each domestic firm $j$ also sets a dollar export price $P_{M t}^{*}(j)$ subject to the Calvo pricesetting friction. If firm $j$ is not able to reset its export price, it follows indexation rule $P_{M t}^{*}(j)=P_{M t-1}^{*}(j) \pi_{M t-1}^{* \iota_{p}}$, where $\pi_{M t}^{*}=P_{M t}^{*} / P_{M t-1}^{*}$ is export price inflation. ${ }^{30}$

Figure 4 shows the effects of the U.S. monetary shock under DCP. In our baseline model with financial market frictions, the drop in home GDP is now almost 0.4 percentconsiderably larger than under PCP, and in fact nearing the drop in U.S. GDP itself. The key reason for the larger hit to EM activity is that under DCP, the currency depreciation of the home currency fails to translate into lower prices of home goods abroad, and thus its benefits in terms of boosting exports are sharply diminished: note that exports decline by almost 0.4 percent, in spite of the (real) currency's persistent depreciation by more than 1.5

\footnotetext{
${ }^{30}$ See Appendix B.3 for the detailed set of equilibrium conditions under DCP.
} 
percent. At the same time, for the reasons described in the previous subsection, the sharp financial tightening continues to induce a large drag on GDP via lower domestic absorption. Put differently, under DCP the home economy's output suffers the costs of a depreciating currency (which work to depress domestic absorption via the financial feedback effects described earlier) without any of the potential benefits (arising due to a boost in exports).

The previous analysis thus underscores how the interaction between dollar debt in balance sheets and the dollar's role in trade pricing are ultimately responsible much larger spillover effects from U.S. monetary policy than in conventional models. Note that even under DCP, the spillovers effects on domestic output with frictionless financial markets (the green dotted line in Figure 4) and without dollar debts in balance sheets (the blue dotted line) continue to be relatively modest. It is when both DCP and dollar debt are present that spillovers become large, and closer to the SVAR estimates described previously.

\section{Monetary Spillovers and Exchange Rate Policy}

The previous section has shown that with financial market frictions and U.S. dollar debt in domestic balance sheets, U.S. monetary policy can exert considerable spillovers, consistent with the actual experience in many EMs and with the findings from SVAR analyses. In this section, we investigate whether these conditions provide grounds for a domestic monetary policy rule that focuses on stabilizing the nominal exchange rate (NER henceforth) to some extent. We are interested in this question because currency mismatches in balance sheets are frequently highlighted as an important reason why policymakers in EMs favor managing the exchange rate (e.g. Reinhart 2000).

To this end, we assume that instead of following (69), domestic monetary policy is conducted according to a rule that includes the NER:

$$
R_{t}^{n}=\left(R_{t-1}^{n}\right)^{\gamma_{r}}\left(\frac{1}{\beta} \pi_{t}^{\frac{1-\gamma_{e}}{\gamma_{e}}}\left(e_{t} / e\right)^{\frac{\gamma_{e}}{1-\gamma_{e}}}\right)^{1-\gamma_{r}} \varepsilon_{t}^{r}
$$

where $e$ (without a time subscript) denotes the NER in steady state and where $\gamma_{e} \in[0,1]$ : the central bank is assumed to respond to the NER in addition to domestic inflation, and higher values of $\gamma_{e}$ represent cases in which the exchange rate stabilization motive is more important. ${ }^{31}$ This specification nests the two polar cases of strict inflation targeting (when

\footnotetext{
${ }^{31}$ The specific formulation in equation (73) is taken from from Gali and Monacelli (2016).
} 
$\left.\gamma_{e}=0\right)$ and an exchange rate peg $\left(\gamma_{e}=1\right)$, and allows the parameterization of hybrid regimes of managed exchange rates.

We begin by analyzing the consequences for welfare and for volatility of following rule (73) in the face of shocks to U.S. monetary policy. We next focus on the case of an economy with high financial fragility, in which the interaction between balance sheets and UIP deviations is particularly strong. Finally, we analyze the implications of exchange rate policy for banks' portfolio choice.

\subsection{Should Central Banks Target the Exchange Rate?}

We begin by calculating welfare under different values of $\gamma_{e}$. In particular, letting household $i$ 's welfare $\mathcal{W}_{i t}$ be

$$
\mathcal{W}_{i t}=\frac{\sigma}{\sigma-1}\left(C_{t}-h C_{t-1}\right)^{\frac{\sigma-1}{\sigma}}-\frac{\chi_{0}}{1+\chi} L_{i t}^{1+\chi}+\beta \mathbb{E}_{t}\left(\mathcal{W}_{i t+1}\right)
$$

we calculate social welfare $\mathcal{W}_{t}$ as

$$
\mathcal{W}_{t}=\int_{0}^{1} \mathcal{W}_{i t} d i
$$

We then compute the unconditional expectation $\mathbb{E}\left(\mathcal{W}_{t}\right)$ for each value of $\gamma_{e} \in[0,1]$. We express welfare in terms consumption-equivalent losses relative to an economy with $\gamma_{e}=0$ : that is, for each $\gamma_{e} \in(0,1]$ we find the percent fall in consumption each period such that $\mathbb{E}\left(\mathcal{W}_{t}\right)$ is the same as in the economy with $\gamma_{e}=0$. Thus, positive values indicate lower welfare than in the pure inflation-targeting regime $\gamma_{e}=0$ (and regime $\gamma_{e}=0$ has zero welfare losses by construction). As in Schmitt-Grohé and Uribe (2007), Gali and Monacelli (2016), and others, we compute $\mathbb{E}\left(\mathcal{W}_{t}\right)$ by first computing a second-order approximation of the model around the non-stochastic steady state.

The left panel of Figure 5 shows the welfare losses for each $\gamma_{e}$ in the frictionless economy. The vertical line indicates the optimal $\gamma_{e}$, denoted $\gamma_{e}^{*}$, for which welfare losses are minimized. The main observation is that the $\gamma_{e}^{*}$ is very close to zero: the welfare criterion dictates nearly no NER stabilization, and instead recommends focusing almost exclusively on domestic inflation. Further, the welfare gains of setting $\gamma_{e}=\gamma_{e}^{*}$ (relative to $\gamma_{e}=0$ ) are very small. Similar to Gali and Monacelli (2005), NER stabilization is not desirable in this economy. ${ }^{32}$

\footnotetext{
${ }^{32}$ The presence of wage rigidities can make it welfare-improving to partially stabilize the exchange rate, as argued in Campolmi (2014) and Gali and Monacelli (2016), while it is never desirable to do so in the
} 
Does the presence of financial frictions and partly dollarized balance sheets make stabilizing the NER more desirable? The right panel of Figure 5 shows welfare losses in our baseline model with frictions. Similar to the frictionless economy, $\gamma_{e}^{*}$ is nearly zero: the optimal policy rule within the class (73) again targets almost exclusively domestic inflation. In addition, the welfare losses now rise much more steeply in $\gamma_{e}$ than in the frictionless case: while the latter features overall modest welfare losses (they peak at around 0.08 percent of quarterly consumption), the welfare losses from raising $\gamma_{e}$ in our baseline economy are enormous, reaching more than 4 percent of quarterly consumption when $\gamma_{e}$ approaches unity.

Figure 6 complements the welfare analysis by showing business cycle properties of several key variables as a function of $\gamma_{e}$, in both the frictionless model (green dotted line) and in our baseline model with financial frictions (blue solid line). As seen in the top row, the standard deviations of home output (denoted $\sigma\left(Y_{t}\right)$ in the Figure) and of domestic price and wage inflation all rise much more steeply with $\gamma_{e}$ in our baseline model, compared to the frictionless economy. ${ }^{33}$ By contrast, the standard deviation of the nominal depreciation rate, $\sigma\left(\Delta e_{t}\right)$, falls less steeply in the baseline model as $\gamma_{e}$ rises, relative to the frictionless model; ${ }^{34}$ for example, cutting $\sigma\left(\Delta e_{t}\right)$ by half relative to its value when $\gamma_{e}=0$ requires setting $\gamma_{e}=0.3$ in the frictionless economy, but $\gamma_{e}=0.7$ in the model with frictions. Thus, a given reduction in exchange rate instability entails a much larger rise in output and inflation volatility in the economy with frictions, compared with the frictionless one. In the model with financial frictions, raising $\gamma_{e}$ is also less successful in bringing down the volatility of CPI inflation $\pi_{c t}=P_{t} / P_{t-1}$ (which depends positively on both domestic inflation and on the change in the terms of trade): as seen in the right panel of the middle row, $\sigma\left(\pi_{c t}\right)$ eventually turns nearly flat in $\gamma_{e}$, as the lower terms-of-trade volatility is offset by much higher volatility in domestic inflation.

Figure 7 provides intuition for the results just described, by showing the effects of a 1 percentage point hike in the domestic policy rate (engineered via a one-time rise in $\varepsilon_{t}^{r}$, and assuming the baseline policy rule 69). Because it lowers the domestic price of capital (i.e. Tobin's q), the tighter domestic policy reduces banks' net worth, triggering a rise in the credit spread and in the currency's UIP premium. As a consequence of the latter, the nominal and real exchange rate appreciate by much less in the short run in our baseline

simpler model with only price rigidities. Consistent with this result, when we set $\theta_{w}=0$ we find that welfare in the frictionless model is maximized at exactly $\gamma_{e}=0$.

${ }^{33}$ Since the only exogenous disturbance is U.S monetary shocks, the standard deviations of output and of the output gap coincide in this setting.

${ }^{34}$ Because $e_{t}$ can be nonstationary in our model, we report the volatility of its percent change. 
economy, compared to the frictionless case. The rise in credit spreads leads to a steeper fall in investment and, as a consequence, in output. Thus, a domestic monetary tightening induces greater output effects compared to a frictionless model, while at the same time its effectiveness in engineering an exchange rate appreciation is diminished.

The top and middle rows in Figure 8 provide a complementary perspective by showing the effects of a U.S. monetary tightening under different policy regimes in the frictionless model (top row) and in our baseline economy (middle row). The lines without markers in Figure 8 display the outcomes conditional on a very small weight on the NER $\left(\gamma_{e}=0.05\right.$, the welfare-maximizing value) and the lines with round markers show the same outcomes conditional on a relatively high weight on NER stabilization $\left(\gamma_{e}=0.40\right)$. In the frictionless economy, the rule that gives a higher weight to NER is quite successful in moderating the depreciation: the home currency depreciates about 1.5 percent on impact under the rule with $\gamma_{e}=0.05$, compared to just 0.5 percent under the rule with $\gamma_{e}=0.40$. The smaller exchange rate movement, however, comes at the cost of a significantly larger output contraction, of over 0.4 percent. In our baseline economy with frictions, the NER-targeting rule still helps moderate the movement in the nominal exchange rate, but the gain is now much smaller: the NER depreciates about 2 percent on impact under the high- $\gamma_{e}$ rule, compared to 1.5 percent when $\gamma_{e}$ is small. This is a consequence of the weaker effects of domestic policy rate hikes on exchange rates in our framework with endogenous UIP deviations: because a domestic monetary tightening raises the currency premium, the policy rate needs to rise by more, ceteris paribus, to engineer a given appreciation. In addition, the output drop is now much larger, which follows from the fact that the policy rate rises much more as just described, and also from the fact that a rate hike of a given size has more-adverse output effects (due to the accompanying financial tightening).

The last panel in Figure 6 shows the standard deviation of home's real interest rate $R_{t+1}$, as a function of $\gamma_{e}$. The horizontal line marks the standard deviation of the U.S. real interest rate. Note that in the frictionless model, the standard deviation of the domestic real rate rises slowly with $\gamma_{e}$, eventually matching the standard deviation of the U.S. real rate as $\gamma_{e} \rightarrow 1$. By contrast, in our baseline model, $\sigma\left(R_{t+1}\right)$ rises much faster, and is eventually over five times as large as $\sigma\left(R_{t+1}^{*}\right)$ when $\gamma_{e}$ is near unity. Again, this reflects the weaker effects of domestic policy on the exchange rate, given the counterveiling movements in currency premia. The much higher real rate instability is ultimately the key driver of the much steeper rises in macroeconomic instability, and of the larger welfare losses, resulting from policy rules that set large values of $\gamma_{e}$. 


\subsection{An Economy with High Financial Fragility}

The analysis above has illustrated how the endogeneity of the currency premium to domestic net worth works to dampen the influence of domestic monetary policy on the exchange rate. This section explores an alternative calibration of the model in which this basic force plays out much more dramatically: we parameterize an economy featuring "high financial fragility," in which the elasticity of the UIP deviation to domestic net worth is much larger than in our baseline model. This example permits illustrating how the model can produce cases in which the basic transmission of domestic monetary policy to the exchange rate changes qualitatively, with the exchange rate depreciating in the short run-rather than appreciating as predicted by conventional models - following a domestic rate hike. ${ }^{35}$

Specifically, we modify two of the targets from our baseline calibration. First, the home discount factor is assumed to be 4 percent - a value close to the upper bound found in Magud and Tsounta (2012), who report a range of values for this parameter between 2 and 5 percent across EMs. Accordingly, we calibrate $\beta$ to 0.99 , implying that home economy is more impatient compared to the baseline calibration. Second, we target a steady-state ratio of foreign-currency debt to domestic debt of 40 percent, a more realistic description of countries considered highly vulnerable to exchange rate fluctuations, like Turkey. The remaining targets for leverage and for the credit spread are kept unchanged. The resulting parameter values are $\theta=0.45, \xi_{b}=0.04$, and $\gamma=3.91$. The steady-state ratio $x$ now is 0.23 , and the coefficient $\Gamma=1$. As made clear by equations (71) and (72), this calibration gives rise to higher elasticity of both (i) banks' net worth to an exchange rate depreciation, and (ii) the UIP deviation to the credit spread. The two-way feedback between net worth and the exchange rate turns more powerful as a result.

Figure 9 compares the effects of a one percent domestic monetary tightening in this example with those in the baseline model. For the same hike in the policy rate, the currency premium now rises more than twice as much on impact, and remains above the response in the baseline model for more than a year. As shown in the bottom right panel, the rise in the currency premium is so large that the nominal exchange rate depreciates on impact by 0.5 percent, compared to a 0.6 percent appreciation in the baseline model; and does not start appreciating relative to its pre-shock value until two quarters after the shock.

The bottom row of Figure 7 illustrates the consequences of following a NER-targeting rule under the high financial vulnerability calibration. Because raising the domestic policy

\footnotetext{
${ }^{35}$ Definitive evidence that tighter monetary policy leads to currency appreciation in EMs has proved elusive in the empirical literature. See, for example, Gould and Kamin (2001).
} 
rate now induces short-run depreciation in the short run, attempting to defend the currency turns out to be disastrous in this case. With high $\gamma_{e}$ the domestic monetary authority raises policy rates sharply (by over 300 basis points) in the face of a 100 basis rise in the U.S. policy rate, thereby inducing an enormous output decline; and it still does not succeed in halting the depreciation, with the currency falling by more than five percent in the short run, over fifty percent more than under the baseline rule with a smaller weight on the NER.

Taken together, the findings above cast doubt on the desirability of policy rules that target the exchange rate, despite the presence of dollar debts in balance sheets. Even if the home monetary authority values NER stability in itself (e.g. as an additional argument in its objective function), our baseline model implies that NER-targeting rules stabilizes the NER by quantitatively less (compared to frictionless frameworks), at the cost of a larger declines in output. In the more extreme case of high financial vulnerability, the rule implies an enormous output drop, and actually fails at moderating the short-run depreciation.

\subsection{Exchange Rate Policy and Banks' Portfolio Choice}

We next turn to examining the consequences of the monetary regime followed by the domestic authority for banks' liability portfolio choice. In particular, we use our framework to ask whether a monetary regime with significant exchange rate stability motives may induce banks to hold larger quantities of dollar debt. As we document below, this turns out to be the case in our model. Thus, somewhat ironically, the analysis raises the possibility that EM central banks, by targeting the exchange rate - perhaps motivated by the presence of dollar debt in domestic balance sheets - may actually be themselves encouraging domestic borrowers to finance a higher fraction of their balance sheets using dollar liabilities. This analysis complements recent literature exploring mechanisms given rise to dollar debts from a portfolio perspective, like Bocola and Lorenzoni (2017) and Gopinath and Stein (2018).

Start by rearranging banks' optimal portfolio condition, equation (34), to obtain ${ }^{36}$

$$
x_{t}=f\left(\frac{\mu_{t}^{*}}{\mu_{t}}\right)
$$

with $f^{\prime}>0$, and where

$$
\mu_{t}^{*}=\mathbb{E}_{t}\left\{\Omega_{B t, t+1}\left(R_{t}-R_{t+1}^{*} \mathcal{Q}_{t+1} / \mathcal{Q}_{\sqcup}\right)\right\}
$$

\footnotetext{
${ }^{36}$ The expression for $f$ is $f\left(\mu_{t}^{*} / \mu_{t}\right)=\left(\mu_{t}^{*} / \mu_{t}\right)^{-1}\left(-1+\sqrt{1+\frac{2}{\gamma}\left(\mu_{t}^{*} / \mu_{t}\right)^{2}}\right)$.
} 


$$
\mu_{t}=\mathbb{E}_{t}\left\{\Omega_{B t, t+1}\left(R_{K t+1}-R_{t+1}\right)\right\}
$$

with $\Omega_{B t, t+1} \equiv \Lambda_{t, t+1} \Omega_{t+1}$. The bank's optimal choice of $x_{t}$ depends positively on $\mu_{t}^{*}$, and inversely on $\mu_{t}$. The intuition is straightfoward: $\mu_{t}^{*}$ captures the marginal benefit of borrowing from abroad, relative to borrowing from domestic depositors; at the same time, recall that borrowing from abroad tightens the bank's incentive constraint, and so it entails foregone profit given by $\mu_{t}$ - the marginal value of asset funding.

Next, we explore how the average ratio of banks' dollar liabilities changes as we the monetary authority targets the exchange rate to a greater extent. To this end, we again compute a second-order approximation of the model, and use the resulting system to calculate the mean of the ratio $x_{t}$. The top panel in Figure 10 shows that $E\left(x_{t}\right)$ is an increasing function of the parameter $\gamma_{e}$ : for values of $\gamma_{e}$ close to zero, the average dollar liability ratio is 0.18 , similar to its value in the nonstochastic steady state. As $\gamma_{e}$ turns higher, $\mathbb{E}\left(x_{t}\right)$ rises steeply: for example, when $\gamma_{e}=0.75, \mathbb{E}\left(x_{t}\right)$ is 0.4 , more than double its value in the nonstochastic steady state.

The behavior of the second moments $\operatorname{Cov}\left(\Omega_{B t}, R_{t}-R_{t}^{*} \mathcal{Q}_{t} / \mathcal{Q}_{t-1}\right)$ and $\operatorname{Cov}\left(\Omega_{B t}, R_{K t}-R_{t}\right)$ along $\gamma_{e}$ is critical in accounting for the sharp rise in $E\left(x_{t}\right) \cdot{ }^{37}$ As shown in the bottom panels of Figure 10, the first covariance rises as $\gamma_{e}$ increases, while the second one falls sharply. The first effect works to push up $\mathbb{E}\left(\mu_{t}^{*}\right)$, while the second depresses $\mathbb{E}_{t}\left(\mu_{t}\right)$. Both forces work to increase $\mathbb{E}_{t}\left(x_{t}\right)$, through equation (76). The intuition is straightforward: when the ex-post return differential $R_{t}-R_{t}^{*} \mathcal{Q}_{t} / \mathcal{Q}_{t-1}$ covaries more positively with the banker's marginal value of wealth, $\Omega_{B t}$, borrowing from foreigners becomes a better hedge (as it delivers gains when the value of funds is high); similarly, if the comovement between $\Omega_{B t}$ and the ex-post excess return $R_{K t}-R_{t}$ falls, the bank's value of lending declines.

Figure 11 clarifies how the shift in $\gamma_{e}$ alters the second moments just described, by showing the effects of a 1 percent rise in the federal funds rate for $\gamma_{e}=0.05$ (a very low value, shown by the blue solid line) and for $\gamma_{e}=0.75$ (a high value, shown by the orange dashed line). Note first that the behavior of the banker's stochastic discount factor is essentially the mirror

${ }^{37}$ Note that the unconditional means of $\mu_{t}, \mu_{t}^{*}$ can be written

$$
\begin{aligned}
& \mathbb{E}\left(\mu_{t}^{*}\right)=\mathbb{E}\left(\Omega_{B t}\right) \mathbb{E}\left(R_{t}-R_{t}^{*} \mathcal{Q}_{t} / \mathcal{Q}_{t-1}\right)+\operatorname{Cov}\left(\Omega_{B t}, R_{t}-R_{t}^{*} \mathcal{Q}_{t} / \mathcal{Q}_{t-1}\right) \\
& \mathbb{E}\left(\mu_{t}\right)=\mathbb{E}\left(\Omega_{B t}\right) \mathbb{E}\left(R_{K t}-R_{t}\right)+\operatorname{Cov}\left(\Omega_{B t}, R_{K}-R_{t}\right)
\end{aligned}
$$

where we have employed a second-order approximation around the unconditional mean. In turn, a secondorder approximation of (76) indicates that $E\left(x_{t}\right)$ is increasing in the ratio $\mathbb{E}\left(\mu_{t}^{*}\right) / \mathbb{E}\left(\mu_{t}\right)$. The latter declines as $\gamma_{e}$ rises, with the decline driven by both rising $\operatorname{Cov}\left(\Omega_{B t}, R_{t}-R_{t}^{*} \mathcal{Q}_{t} / \mathcal{Q}_{t-1}\right)$ and falling $\operatorname{Cov}\left(\Omega_{B t}, R_{K}-R_{t}\right)$. 
image of that of net worth: when aggregate banker wealth is low, banks' constraints are tight. Consequently, an additional unit of net worth is highly valuable.

Consider the behavior of $\mathcal{Q}_{t}$ and $R_{t}$ and when $\gamma_{e}=0.05$. In response to the Fed's tightening, the real exchange rate depreciates sharply ( $\mathcal{Q}_{t}$ rises) and $R_{t}$ moves up just a bit. The large upward movement in $\mathcal{Q}_{t}$ makes $R_{t}^{*} \mathcal{Q}_{t} / \mathcal{Q}_{t-1}$ (the ex-post cost of foreign loans) rise sharply - precisely when bankers' value of funds is high $\left(\Omega_{B t}\right.$ is up). This explains why $\operatorname{Cov}\left(\Omega_{B t}, R_{t}-R_{t} \mathcal{Q}_{t} / \mathcal{Q}_{t-1}\right)$ is negative for low values of $\gamma_{e}$, as seen in the bottom left panel of Figure 10. Next consider what happens when $\gamma_{e}=0.75$. The response of $\mathcal{Q}_{t}$ is now more muted, and at the same time there is a sharper rise in $R_{t}$. Thus, we expect $\operatorname{Cov}\left(\Omega_{B t}, R_{t}-R_{t} \mathcal{Q}_{t} / \mathcal{Q}_{t-1}\right)$ to rise with $\gamma_{e}$ and eventually turn positive, as confirmed by Figure 10 .

In addition, $\operatorname{Cov}\left(\Omega_{B t}, R_{K}-R_{t}\right)$ (which is always negative, as $R_{K t}-R_{t}$ is procyclical and $\Omega_{B t}$ countercyclical) turns more negative when $\gamma_{e}$ is high. The reason is that the rise in $\Omega_{B t}$ is sharper, and the decline in $R_{K t}$ is also amplified, as a consequence of the now more powerful financial accelerator.

The analysis just described thus highlights that exchange-rate targeting regimes may have the byproduct of encouraging domestic banks to take on more dollar debt. Conversely, it suggests that moving toward inflation-targeting regimes might also imply less-dollarized balance sheets of domestic borrowers.

\section{Exchange Rates and Credit Spreads: Some Evidence}

Unlike conventional open economy macroeconomic models such as Gali and Monacelli (2005) and subsequent literature, the model described above features endogenous deviations from UIP, with the currency premium moving in tandem with the credit spread facing domestic borrowers. In this section, we examine empirical evidence from several EMs to test this basic model prediction. Our approach relies on estimating versions of the forwardlooking exchange rate equation implied by the model, as frequently done in the (large) empirical literature on the determinants of exchange rates. ${ }^{38}$

We begin with the equation linking the exchange rate to the premium $\mu_{t}$ from the simple

\footnotetext{
${ }^{38}$ See, for example, Engel and West (2004), Engel and West (2005), Engel et al. (2007), Faust et al. (2007), Clarida and Waldman (2008), and more recently Galí (2018). Our approach follows Galí (2018)'s most closely. In earlier versions we followed the approach based on Fama (1984) and also found evidence linking UIP deviations with credit spreads, as we find here.
} 
model in Section 2. Combining equations (3), (4), and (7) and loglinearizing,

$$
Q_{t}=\gamma \mathbb{E}_{t}\left\{r_{k t+1}-r_{t+1}\right\}+r_{t+1}^{*}-r_{t+1}+\mathbb{E}_{t}\left\{Q_{t+1}\right\}
$$

where $Q_{t}, r_{k t+1}, r_{t+1}$, and $r_{t+1}^{*}$ denote the $\operatorname{logs}$ of $\mathcal{Q}_{t}, R_{K t+1}, R_{t+1}$, and $R_{t+1}^{*}$, respectively. ${ }^{39}$ Equation (79) resembles the familiar UIP condition for the real exchange rate present in conventional macroeconomic frameworks, but in addition to the real interest rate differential $r_{t+1}^{*}-r_{t+1}$, the right hand side also includes the term $\gamma \mathbb{E}_{t}\left\{r_{k t+1}-r_{t+1}\right\}$, capturing the foregone excess return on domestic lending $\left(\mathbb{E}_{t}\left\{r_{k t+1}-r_{t+1}\right\}\right)$ due to a tighter constraint multiplied by the parameter $\gamma$ determining how much the constraint tightens with increased foreign borrowing.

We follow Galí (2018) and iterate (79) forward $T$ periods:

$$
Q_{t}=\gamma \sum_{j=1}^{T} \mathbb{E}_{t}\left\{r_{k t+j}-r_{t+j}\right\}+\sum_{j=1}^{T} \mathbb{E}_{t}\left\{r_{t+j}^{*}-r_{t+j}\right\}+\mathbb{E}_{t}\left\{Q_{t+T+1}\right\}
$$

Let

$$
\begin{aligned}
s_{t} & \equiv \sum_{j=1}^{T} \mathbb{E}_{t}\left\{r_{k t+j}-r_{t+j}\right\} \\
r_{t}^{d i f f} & \equiv \sum_{j=1}^{T} \mathbb{E}_{t}\left\{r_{t+j}^{*}-r_{t+j}\right\}
\end{aligned}
$$

Next, assume that $Q_{t}=f_{t}+\widehat{Q}_{t}$, where $f_{t}$ is a deterministic time trend and $\widehat{Q}_{t}$ is stationary, so that if $T$ is large enough, $\mathbb{E}_{t}\left\{\widehat{Q}_{t+T+1}\right\} \approx 0$. Below we verify that these assumptions are reasonable approximations for our data. Under these assumptions, (80) can be rewritten

$$
Q_{t}=\gamma s_{t}+r_{t}^{\text {diff }}+f_{t+T+1}
$$

Equation (83) forms the basis for our empirical analysis. Our baseline estimation uses monthly data from South Korea. We then repeat the analysis for Brazil and Mexico. These are three major EMs for which there is considerable availability of corporate bond yield data, a necessary series for our analysis, as we explain below. We measure $Q_{t}$ by the $(\log )$ bilateral real exchange rate against the (real) dollar. We calculate the real exchange rate by

\footnotetext{
${ }^{39}$ In deriving this equation we let $R \rightarrow R^{*}$ and $R_{K} \rightarrow R$.
} 
multiplying the nominal exchange rate (the price of the dollar in terms of local currency) times the ratio of the U.S. CPI price level to the local price level.

To approximate $s_{t}$, we use data on yields on Korean 3-year won-denominated corporate bonds (rated AA-) minus yields on government bonds of the same maturity. The resulting corporate bond spread is a widely used proxy for the "external finance premium" (Bernanke et al. 1999) stemming from financial market frictions. ${ }^{40}$ Thus, we measure $s_{t}$ as

$$
s_{t}=\frac{T}{12}\left(r_{t}^{\text {corp }}-r_{t}^{g o v}\right)
$$

where $r_{t}^{\text {corp }}$ is the Korean corporate bond yield (in annual terms) and $r_{t}^{g o v}$ is the Korean yield on 3-year Treasury bonds, and $T=36$ months. Similarly, we construct a measure of $r_{t}^{\text {diff }}$ as

$$
r_{t}^{\text {diff }}=\frac{T}{12}\left(r_{t}^{g o v *}-r_{t}^{g o v}\right)
$$

where $r_{t}^{\text {gov* }}$ is the (real) 3-year U.S. Treasury yield. In (85) real yields are constructed by subtracting from nominal yields the expected inflation rate in each month, calculated as the average inflation rate over the past year. ${ }^{41}$ These calculations make the simplifying assumption that the expected sum of one-period yields differentials in (81) and (82) are well approximated by the $T$-month maturity bond yields. ${ }^{42}$

Unlike for Korea, there is no available data for domestic-currency corporate yields form Mexico and Brazil with long enough duration. For these two countries, instead, we measure $s_{t}$ by the spread between 5-year dollar-denominated BBB corporate bonds and U.S. Treasury bonds of the same maturity. ${ }^{43}$ Accordingly, we set $T=60$ for Mexico and Brazil, and measure $r_{t}^{\text {diff }}$ by using 5-year local and U.S. government bond yields.

We found that the assumption above that real exchange rates are approximately back to trend, in expectation, after $T$ months (with $T=36$ for Korea and $T=60$ for Mexico and Brazil), is a reasonable approximation in our data. By fitting autoregressive models to detrended real exchange rates, we find that over 85 percent of the effects of the typical shock

\footnotetext{
${ }^{40}$ E.g. Christiano et al. (2014), Gertler and Karadi (2015).

${ }^{41}$ Note that expected inflation terms cancel in (84) given that $r_{t}^{\text {corp }}$ and $r_{t}^{g o v}$ are in the same currency, so we can calculate $s_{t}$ simply by using the difference of nominal yields.

${ }^{42}$ Thus, if the $T$-month maturity bonds include a term premium in addition to the expected path of short-term yields, our assumption is that the term premium term is part of the regression error term.

${ }^{43}$ While in our baseline model $R_{K t}$ is denominated in local currency, Appendix A.5 shows that a relation similar to (83) emerges when local firms issue dollar bonds to domestic banks (with the corporate spread calculated relative to the U.S. government yield in 81), so long as the agency friction continues to apply with greater severity to banks' foreign borrowing.
} 
to $\widehat{Q}_{t}$ dissipate after 36 months for Korea, and virtually all of the effects dissipate after 60 months for Mexico and Brazil, thus providing some reassuring evidence for the assumption used in (83) that $\mathbb{E}_{t}\left\{\widehat{Q}_{t+T+1}\right\} \approx 0$.

Below, we report OLS estimates of the regression equation

$$
Q_{t}=\alpha_{0}+\alpha_{1} t+\alpha_{2} t^{2}+\beta_{s} s_{t}+\beta_{r} r^{d i f f}+\varepsilon_{t}
$$

where the coefficient $\alpha_{2}$ is set to zero for both Korea and Mexico, as the quadratic trend is not found to be significant for neither of these countries (we do include it for Brazil as it is highly significant in that case). Comparing equations (86) and (83), note that our theory predicts $\beta_{s}=\gamma>0$ and $\beta_{r}=1$.

The left part of Table 2 reports the results using Korean data. For reference, column (1) shows results when setting $\beta_{s}=0$ in (86), resulting in the equation implied by conventional models in which UIP holds. Note that the coefficient in the interest rate differential is positive, as predicted by UIP, but is somewhat above unity, and is statistically significant (at $1 \%$ confidence).

Column (2) shows our baseline specification with both the interest differential and the corporate bond spread. The first key observation is that the coefficient on the spread is highly statistically significant, and large in magnitude - more than twice as large as the coefficient on the interest rate differential. The second observation is that the presence of the spread improves the equation fit considerably: $R^{2}$ rises from less than 0.2 to over 0.5 . Finally, note also that once the spread is present, the coefficient on the interest differential drops a bit, and is essentially equal to unity - exactly as predicted by the theory.

Columns (3) and (4) perform robustness by including additional regressors in equation (86). In column (3) we add a crisis dummy to ensure that the results are not driven by the large movements in exchange rates during times of extreme financial stress. ${ }^{44}$ The coefficient on the corporate spread continues to be significant despite the presence of the dummy, and in fact its magnitude becomes larger. Column (4) adds the VIX to proxy for global risk aversion. Again, the spread continues to be significant even when the regression includes this variable.

The middle and right columns of Table 2 repeat the analysis for Brazil and Mexico. The coefficient on the corporate spread is highly significant for these two countries as well, and continues to be so when we add the crisis dummy and the VIX. For Brazil, the spread

\footnotetext{
${ }^{44} D_{\text {crisis }}$ equals unity in the months 1998:8-1999:3 and 2008:9-2009:3, and zero otherwise.
} 
also improves the fit considerably relative to the "standard UIP" regression from column (1), while for Mexico much less so. The coefficient on the spread is considerably smaller for Brazil than for Korea, and lower still for Mexico. Turning to the interest differential, we find a positive and significant coefficient for Brazil (though smaller than one) while the coefficient is generally insignificant for Mexico. Thus, evidence for the standard UIP condition predicting a coefficient of unity is weaker for these two countries. Note also that the coefficient on the VIX appears to have the "wrong" sign (that is, the price of the domestic currency rises when the VIX rises) but this result appears linked to the fact that the VIX and the corporate bond spreads are quite highly correlated (we find that running the regressions in column (4) but excluding the corporate bond spread yields a positive and significant coefficient for the VIX).

One possible problem with regressions like equation (86) that has been noted in the literature is that the presence of non-stationary components in the real exchange rate and in the regressors not fully captured by the deterministic trend can lead to spurious regression results. To address this problem we estimate equation (86) in first differences:

$$
\Delta Q_{t}=\alpha_{0}+\alpha_{1} t+\beta_{s} \Delta s_{t}+\beta_{r} \Delta r_{t}^{\text {diff }}+\varepsilon_{t}
$$

where, again, the time trend term is included for Brazil only (i.e. $\alpha_{1}=0$ for both Korea and Mexico).

Table 3 reports the corresponding results. The key finding that the corporate spread is highly significant reemerges here, as does the fact that the presence of the spread adds considerable explanatory power relative to a regression with the interest differential only, now including for Mexico as well. Except for Mexico, the coefficients on the spread are now somewhat lower in magnitude, compared to the levels specification. On the other hand, coefficients on the interest rate differential are insignificant and often have the wrong sign. The VIX now has a positive sign for both Korea and Mexico (and is insignificant for Brazil).

Overall, we conclude that the empirical analysis above finds considerable support for the link between exchange rates and credit spreads implied by the theory. The results also suggest that the calibration of the parameter $\gamma$ in our model (or the equivalent elasticity $\Gamma$ in the medium-scale model) of 0.5 is relatively conservative in light of the empirical evidence just documented, as this value is at the lower end of the range of coefficients found in Tables 2 and 3. 


\section{Conclusion}

This paper develops a two-country model with imperfect financial markets to study the spillovers from U.S. monetary policy to EMs. The model features strong financial amplification due to the interaction between endogenous deviations from UIP - through which deteriorating balance sheets exert downward pressure on the currency - and the presence of dollar-denominated debt. Consistent with recent empirical evidence, this mechanism leads to large spillovers from U.S. monetary shocks, particularly when export prices are set in dollars.

Despite strong amplification when domestic balance sheets are dollarized, the model calls into question the common view that it is desirable to use domestic monetary policy to mitigate exchange rate flucuations. In fact, under some conditions (specifically, when the two-way feedback between domestic balance sheets and the exchange rate is particularly strong) attempting to defend the exchange rate can actually exacerbate its short-run volatility, while at the same time inducing large output volatility. In addition, monetary regimes that target the exchange rate to a greater extent tend to make the balance sheet mismatch

problem worse, by creating incentives for domestic borrowers to take on larger amounts of dollar debt.

Looking forward, it would be useful to use the model developed here to consider the implications of foreign reserve holdings and foreign exchange interventions on the part of EM central banks. Given the endogenous deviation from UIP present in the model, there may be a role for interventions in foreign exchange over and above conventional interest rate policy. This extension is left for future research. 


\section{References}

Aghion, Philippe, Philippe Bacchetta, and Abhijit Banerjee, "Currency crises and monetary policy in an economy with credit constraints," European economic review, 2001, $45(7), 1121-1150.9$

_ , _, and _, "A corporate balance-sheet approach to currency crises," Journal of Economic theory, 2004, 119 (1), 6-30. 9

Akinci, Ozge and Albert Queralto, "Credit Spreads, Financial Crises, and Macroprudential Policy," 2017. 8

Ammer, John, Michiel De Pooter, Christopher J. Erceg, and Steven B. Kamin, "International Spillovers of Monetary Policy," International Finance Discussion Papers (Board of Governors of the Federal Reserve) Published as an IFDP Note, 2016. 4

Aoki, Kosuke, Gianluca Benigno, and Nobuhiro Kiyotaki, "Monetary and financial policies in emerging markets," in "Economic Growth and Policy Conference" 2016. 1, 11

Bernanke, Ben S., "Federal Reserve Policy in an International Context," IMF Economic Review, 2017, 65 (1), 1-32. 2

_, Mark Gertler, and Simon Gilchrist, "The financial accelerator in a quantitative business cycle framework," in J. B. Taylor and M. Woodford, eds., Handbook of Macroeconomics, Vol. 1 of Handbook of Macroeconomics, Elsevier, 1999, chapter 21, pp. 1341-1393. 8,6

Blanchard, Olivier, "Currency Wars, Coordination, and Capital Controls," International Journal of Central Banking, June 2017, 13 (2), 283-308. 2

_, Christopher Erceg, and Jesper Linde, "Jump-Starting the Euro Area Recovery: Would a Rise in Core Fiscal Spending Help the Periphery?," in "NBER Macroeconomics Annual 2016, Volume 31," National Bureau of Economic Research, Inc, 2016, pp. 103-182. $11,3.2,3.8$

Bocola, Luigi and Guido Lorenzoni, "Financial Crises, Dollarization, and Lending of Last Resort in Open Economies," Working Paper 23984, National Bureau of Economic Research November 2017. 5.3 
Braggion, Fabio, Lawrence J. Christiano, and Jorge Roldos, "Optimal monetary policy in a 'sudden stop'," Journal of Monetary Economics, May 2009, 56 (4), 582-595. 9

Bräuning, Falk and Victoria Ivashina, "US monetary policy and emerging market credit cycles," Journal of Monetary Economics, 2019. 1

Bruno, Valentina and Hyun Song Shin, "Capital flows and the risk-taking channel of monetary policy," Journal of Monetary Economics, 2015, 71 (C), 119-132. 1

Burnside, Craig, Martin Eichenbaum, and Sergio Rebelo, "Prospective Deficits and the Asian Currency Crisis," Journal of Political Economy, 2001, 109 (6), 1155-1197. 20

Caballero, Ricardo J and Alp Simsek, "A model of fickle capital flows and retrenchment," 2016. 18

Calvo, Guillermo A and Carmen M Reinhart, "Fear of floating," The Quarterly Journal of Economics, 2002, 117 (2), 379-408. 3

Campolmi, Alessia, "Which inflation to target? A small open economy with sticky wages," Macroeconomic Dynamics, 2014, 18 (1), 145-174. 32

Carrillo, Julio A., Rocio Elizondo, Cid Alonso Rodriguez-Perez, and Jessica Roldan-Pena, "What Determines the Neutral Rate of Interest in an Emerging Economy?," 2017. 3.8

Céspedes, Luis Felipe, Roberto Chang, and Andres Velasco, "Balance sheets and exchange rate policy," American Economic Review, 2004, 94 (4), 1183-1193. 1

Christiano, Lawrence J., Martin Eichenbaum, and Charles L. Evans, "Nominal Rigidities and the Dynamic Effects of a Shock to Monetary Policy," Journal of Political Economy, February 2005, 113 (1), 1-45. 11, 3, 4.1, 4.2

Christiano, Lawrence J, Roberto Motto, and Massimo Rostagno, "Risk shocks," American Economic Review, 2014, 104 (1), 27-65. 40

Chui, Michael, Emese Kuruc, and Philip Turner, "A new dimension to currency mismatches in the emerging markets - non-financial companies," BIS Working Papers 550, Bank for International Settlements March 2016. 3.8 
Clarida, Richard H. and Daniel Waldman, "Is Bad News about Inflation Good News for the Exchange Rate? And, if So, Can That Tell Us Anything about the Conduct of Monetary Policy?," in "Asset Prices and Monetary Policy," University of Chicago Press, 2008, pp. 371-396. 38

Corsetti, Giancarlo and Paolo Pesenti, "Welfare and Macroeconomic Interdependence*," The Quarterly Journal of Economics, 05 2001, 116 (2), 421-445. 1

_, Luca Dedola, and Sylvain Leduc, "Exchange Rate Misalignment, Capital Flows, and Optimal Monetary Policy Trade-offs," 2018. 1

Daniel, Christine A Mc and Edward J Balistreri, "A review of Armington trade substitution elasticities," Economie internationale, 2003, (2), 301-313. 17

Dedola, Luca, Giulia Rivolta, and Livio Stracca, "If the Fed sneezes, who catches a cold?," Journal of International Economics, 2017, 108, S23-S41. 1

Devereux, Michael B, Eric R Young, and Changhua Yu, "A New Dilemma: Capital Controls and Monetary Policy in Sudden Stop Economies," Working Paper 21791, National Bureau of Economic Research December 2015. 1

di Giovanni, Julian, Sebnem Kalemli-Ozcan, Mehmet Fatih Ulu, and Yusuf Soner Baskaya, "International Spillovers and Local Credit Cycles," Working Paper 23149, National Bureau of Economic Research February 2017. 1

Diamond, Douglas, Yunzhi Hu, and Raghuram G. Rajan, "The Spillovers from Easy Liquidity and the Implications for Multilateralism," 2018 IMF Annual Research Conference: Mundell-Fleming Lecture, November 2018. 6

Engel, Charles and Kenneth D. West, "Accounting for Exchange-Rate Variability in Present-Value Models When the Discount Factor Is Near 1," American Economic Review, 2004, 94 (2), 119-125. 38

_ and _, "Exchange Rates and Fundamentals," Journal of Political Economy, 2005, 113 (3), 485-517. 38

_, Nelson C. Mark, and Kenneth D. West, "Exchange Rate Models Are Not as Bad as You Think," NBER Macroeconomics Annual, 2007, 22, 381-473. 38 
Erceg, Christopher, Christopher Gust, and David Lopez-Salido, The Transmission of Domestic Shocks in Open Economies, University of Chicago Press, June 1, 3, 3.8

Erceg, Christopher J., Dale W. Henderson, and Andrew T. Levin, "Optimal monetary policy with staggered wage and price contracts," Journal of Monetary Economics, 2000, $46(2), 281-313.3 .2$

Erceg, Christopher J, Luca Guerrieri, and Christopher Gust, "Expansionary fiscal shocks and the US trade deficit," International Finance, 2005, 8 (3), 363-397. 17, 3.8

_ , _, and _ , "SIGMA: A New Open Economy Model for Policy Analysis," International Journal of Central Banking, 2006. 11, 3.2, 21, 3.8

Fama, Eugene F., "Forward and spot exchange rates," Journal of Monetary Economics, 1984, $14(3), 319-338.38$

Farhi, Emmanuel and Ivan Werning, "Dilemma not Trilemma? Capital Controls and Exchange Rates with Volatile Capital Flows," IMF Economic Review (Special Volume in Honor of Stanley Fischer), 2014, 62, 569-605. 1

Faust, Jon, John H. Rogers, Shing-Yi B. Wang, and Jonathan H. Wright, "The high-frequency response of exchange rates and interest rates to macroeconomic announcements," Journal of Monetary Economics, 2007, 54 (4), 1051-1068. 38

Fornaro, Luca, "Financial crises and exchange rate policy," Journal of International Economics, 2015, 95 (2), 202-215. 1

Gabaix, Xavier and Matteo Maggiori, "International liquidity and exchange rate dynamics," The Quarterly Journal of Economics, 2015, 130 (3), 1369-1420. 10, 3.7

Galí, Jordi, "Forward Guidance and the Exchange Rate," Technical Report 2018. 38, 6

Gali, Jordi and Tommaso Monacelli, "Monetary Policy and Exchange Rate Volatility in a Small Open Economy," Review of Economic Studies, 2005, 72 (3), 707-734. 1, 3, 5.1, 6

_ and _, "Understanding the Gains from Wage Flexibility: The Exchange Rate Connection," American Economic Review, December 2016, 106 (12), 3829-68. 31, 5.1, 32 
Gertler, Mark and Nobuhiro Kiyotaki, "Financial Intermediation and Credit Policy in Business Cycle Analysis," in Benjamin M. Friedman and Michael Woodford, eds., Handbook of Monetary Economics, Vol. 3, Elsevier, 2010, chapter 11, pp. 547-599. 1

- and Peter Karadi, "A model of unconventional monetary policy," Journal of Monetary Economics, 2011, 58 (1), $17-34.8$

_ and _, "Qe 1 vs. 2 vs. 3...: A framework for analyzing large-scale asset purchases as a monetary policy tool," international Journal of central Banking, 2013, 9 (1), 5-53. 3.7, 45

_ and _., "Monetary policy surprises, credit costs, and economic activity," American Economic Journal: Macroeconomics, 2015, 7 (1), 44-76. 40

_, Nobuhiro Kiyotaki, and Albert Queralto, "Financial crises, bank risk exposure and government financial policy," Journal of Monetary Economics, 2012, 59, Supplement, S17 - S34. 8

_, Simon Gilchrist, and Fabio M Natalucci, "External constraints on monetary policy and the financial accelerator," Journal of Money, Credit and Banking, 2007, 39 (2-3), 295-330. 1

Goldberg, Linda S. and Cdric Tille, "Vehicle currency use in international trade," Journal of International Economics, December 2008, 76 (2), 177-192. 4.3

Gopinath, Gita and Jeremy C Stein, "Banking, Trade, and the making of a Dominant Currency," 2018. 5, 19, 5.3

_, Emine Boz, Camila Casas, Federico Diez, Pierre-Olivier Gourinchas, and Mikkel Plagborg-Møller, "Dominant Currency Paradigm," NBER Working Paper, 2018, (22943). 1, 4.3

Gould, David M and Steven B Kamin, "The impact of monetary policy on exchange rates during financial crises," Financial crises in emerging markets, 2001, pp. 384-420. 35

Gourinchas, Pierre-Olivier, "Monetary Policy Transmission in Emerging Markets: An Application to Chile," in Enrique G. Mendoza, Ernesto Pastn, and Diego Saravia, eds., Monetary Policy and Global Spillovers: Mechanisms, Effects and Policy Measures, Vol. 25 of Central Banking, Analysis, and Economic Policies Book Series, Central Bank of Chile, December 2018, chapter 8, pp. 279-324. 1 
_, Thomas Philippon, and Dimitri Vayanos, The Analytics of the Greek Crisis, University of Chicago Press, September 8

Hahm, Joon-Ho, Hyun Song Shin, and Kwanho Shin, "Noncore Bank Liabilities and Financial Vulnerability," Journal of Money, Credit and Banking, August 2013, 45, 3-36. 3.8

Hermalin, Benjamin E. and Andrew K. Rose, "Risks to lenders and borrowers in international capital markets," in "International Capital Flows," University of Chicago Press, 1999, pp. 363-420. 3.7

Holston, Kathryn, Thomas Laubach, and John C Williams, "Measuring the natural rate of interest: International trends and determinants," Journal of International Economics, 2017, 108, S59-S75. 3.8

Hooper, Peter, Karen Johnson, and Jaime R Marquez, "Trade elasticities for the G-7 countries," 2000. 17, 3.8

Iacoviello, Matteo and Gaston Navarro, "Foreign effects of higher U.S. interest rates," Journal of International Money and Finance, 2018. 1, C

Justiniano, Alejandro, Giorgio E Primiceri, and Andrea Tambalotti, "Investment shocks and business cycles," Journal of Monetary Economics, 2010, 57 (2), 132-145. 3.8

Krugman, Paul, "Balance sheets, the transfer problem, and financial crises," International finance and financial crises, 1999, 6 (4), 459-472. 1

Magud, Mr Nicolas E and Evridiki Tsounta, To cut or not to cut? That is the (central banks) question in search of the neutral interest rate in Latin America number 12-243, International Monetary Fund, 2012. 22, 5.2

Miranda-Agrippino, Silvia and Hélene Rey, "US Monetary Policy and the Global Financial Cycle," 2019. 1

Obstfeld, Maurice, "Trilemmas and Tradeoffs: Living with Financial Globalization," in Claudio Raddatz, Diego Saravia, and Jaume Ventura, eds., Global Liquidity, Spillovers to Emerging Markets and Policy Responses, Vol. 20 of Central Banking, Analysis, and Economic Policies Book Series, Central Bank of Chile, December 2015, chapter 2, pp. 013078. 2 
- and Alan M. Taylor, "International Monetary Relations: Taking Finance Seriously," Journal of Economic Perspectives, Summer 2017, 31 (3), 3-28. 2

- and Kenneth Rogoff, "Exchange Rate Dynamics Redux," Journal of Political Economy, June 1995, 103 (3), 624-660. 1

Rajan, Raghuram G. and Luigi Zingales, "Which Capitalism? Lessons from the East Asian Crisis," Journal of Applied Corporate Finance, 1998, 11 (3), 40-48. 3.7

Reifschneider, David, "Gauging the Ability of the FOMC to Respond to Future Recessions," 2016. 3.8

Reinhart, Carmen M, "Mirage of floating exchange rates," American Economic Review, $2000,90(2), 65-70.5$

Rey, Helene, "Dilemma not Trilemma: The Global Financial Cycle and Monetary Policy Independence," Working Paper 21162, National Bureau of Economic Research May 2015. 1

Rey, Hélène, "International Channels of Transmission of Monetary Policy and the Mundellian Trilemma," IMF Economic Review, May 2016, 64 (1), 6-35. 1

Schmitt-Grohé, Stephanie and Martin Uribe, "Optimal simple and implementable monetary and fiscal rules," Journal of monetary Economics, 2007, 54 (6), 1702-1725. 5.1

Smets, Frank and Rafael Wouters, "Shocks and Frictions in US Busines Cycle: A Bayesian DSGE Approach," American Economic Review, June 2007, 97 (3), 586-606. 11

Taylor, John B., "Discretion versus policy rules in practice," in "Carnegie-Rochester Conference Series on Public Policy," Vol. 39 Elsevier 1993, pp. 195-214. 3.8 
Table 1. Model Calibration

\begin{tabular}{lcc} 
Parameter & Symbol & Value \\
\hline Home discount factor & $\beta$ & 0.9925 \\
U.S. discount factor & $\beta^{*}$ & 0.9950 \\
IES & $\sigma$ & 1 \\
Habit parameter & $h$ & 0.78 \\
Inverse Frisch elasticity of labor supply & $\chi$ & 3.79 \\
Trade price elasticity & $\frac{1+\rho}{\rho}$ & 1.5 \\
Trade openness, home & $\omega$ & 0.2 \\
Trade openness, foreign & $\omega^{*}$ & $0.2 / 3$ \\
Relative home size & $\xi / \xi^{*}$ & $1 / 3$ \\
Trade adjustment cost parameter & $\varphi_{M}$ & 10 \\
Capital share & $\alpha$ & 0.33 \\
Capital depreciation & $\delta$ & 0.025 \\
Prob. of keeping price fixed & $\xi_{p}$ & 0.84 \\
Price indexation & $\iota_{p}$ & 0.24 \\
Price markup & $\theta_{p}$ & 0.20 \\
Prob. of keeping wage fixed & $\xi_{w}$ & 0.70 \\
Wage indexation & $\iota_{w}$ & 0.15 \\
Wage markup & $\theta_{w}$ & 0.20 \\
Investment adjustment cost & $\Psi_{I}$ & 2.85 \\
\hline Home Taylor rule coefficients & $\gamma_{r}$ & 0.82 \\
& $\gamma_{\pi}$ & 1.50 \\
U.S. Taylor rule coefficients & $\gamma_{r}^{*}$ & 0.82 \\
& $\gamma_{\pi}^{*}$ & 1.50 \\
& $\gamma_{x}^{*}$ & 0.125 \\
U.S. monetary shock persistence & $\rho_{r}$ & 0.25 \\
U.S. monetary shock standard deviation & $\sigma_{u}$ & $0.20 / 100$ \\
\hline Bank survival rate & $\sigma_{b}$ & 0.95 \\
Bank fraction divertable & $\theta$ & 0.41 \\
Bank transfer rate & $\xi_{b}$ & 0.07 \\
Home bias in bank funding & $\gamma$ & 2.58 \\
\hline & &
\end{tabular}


Table 2. Empirical exchange rate equation: Level specification

\begin{tabular}{|c|c|c|c|c|c|c|c|c|c|c|c|c|}
\hline & \multicolumn{4}{|c|}{ Korea } & \multicolumn{4}{|c|}{ Brazil } & \multicolumn{4}{|c|}{ Mexico } \\
\hline & $(1)$ & $(2)$ & $(3)$ & $(4)$ & $(1)$ & $(2)$ & $(3)$ & $(4)$ & $(1)$ & $(2)$ & $(3)$ & $(4)$ \\
\hline Interest diff. & $\begin{array}{l}1.27^{* * *} \\
(0.33)\end{array}$ & $\begin{array}{l}0.97^{* * *} \\
(0.27)\end{array}$ & $\begin{array}{l}0.98^{* * *} \\
(0.26)\end{array}$ & $\begin{array}{l}0.87^{* * *} \\
(0.25)\end{array}$ & $\begin{array}{l}0.62^{* * *} \\
(0.17)\end{array}$ & $\begin{array}{l}0.55^{* * *} \\
(0.11)\end{array}$ & $\begin{array}{l}0.52^{* * *} \\
(0.11)\end{array}$ & $\begin{array}{l}0.42^{* * *} \\
(0.09)\end{array}$ & $\begin{array}{l}-0.10 \\
(0.16)\end{array}$ & $\begin{array}{l}-0.11 \\
(0.14)\end{array}$ & $\begin{array}{l}-0.13 \\
(0.14)\end{array}$ & $\begin{array}{l}-0.11 \\
(0.13)\end{array}$ \\
\hline Corp. spread & & $\begin{array}{l}2.72^{* * *} \\
(0.53)\end{array}$ & $\begin{array}{l}3.56^{* * *} \\
(0.99)\end{array}$ & $\begin{array}{l}2.17^{* * *} \\
(0.33)\end{array}$ & & $\begin{array}{l}1.09^{* * *} \\
(0.14)\end{array}$ & $\begin{array}{l}1.25^{* * *} \\
(0.16)\end{array}$ & $\begin{array}{l}1.61^{* * *} \\
(0.13)\end{array}$ & & $\begin{array}{l}0.47^{* * *} \\
(0.13)\end{array}$ & $\begin{array}{l}0.37^{*} \\
(0.19)\end{array}$ & $\begin{array}{l}0.93^{* * *} \\
(0.29)\end{array}$ \\
\hline$D_{\text {crisis }}$ & & & $\begin{array}{l}-0.16^{*} \\
(0.09)\end{array}$ & & & & $\begin{array}{l}-0.09^{* *} \\
(0.05)\end{array}$ & & & & $\begin{array}{l}0.05 \\
(0.04)\end{array}$ & \\
\hline VIX/100 & & & & $\begin{array}{l}0.43^{* * *} \\
(0.16)\end{array}$ & & & & $\begin{array}{l}-0.66^{* * *} \\
(0.11)\end{array}$ & & & & $\begin{array}{l}-0.34^{* *} \\
(0.17)\end{array}$ \\
\hline trend & linear & linear & linear & linear & quadratic & quadratic & quadratic & quadratic & linear & linear & linear & linear \\
\hline$R^{2}$ & 0.19 & 0.53 & 0.55 & 0.58 & 0.63 & 0.87 & 0.88 & 0.91 & 0.58 & 0.62 & 0.62 & 0.63 \\
\hline Observations & 281 & 281 & 281 & 281 & 148 & 148 & 148 & 148 & 219 & 219 & 219 & 219 \\
\hline
\end{tabular}

Note: Dependent variable: Monthly bilateral real exchange rate against the United States. Regressions estimated by OLS. Standard errors shown in parentheses, computed using the Newey-West adjustment. ${ }^{* * *},{ }^{* *}$, and ${ }^{*}$ denote significance at the 1,5 , and 10 percent levels, respectively. Sample periods: 1995:5-2018:9 (Korea), 2006:7-2018:10 (Brazil), 2000:8-2018:10 (Mexico). The baseline regression equation (column (2)) is

$$
Q_{t}=\alpha_{0}+\alpha_{1} t+\alpha_{2} t^{2}+\beta_{s} s_{t}+\beta_{r} r_{t}^{d i f f}+\varepsilon_{t}
$$

with $\alpha_{2}=0$ for Korea and Mexico, and where $Q_{t}$ is the $\log$ real bilateral exchange rate against the dollar, $s_{t}$ is the corporate bond spread, and $r_{t}^{\text {diff }}$ is the government bond yield differential between the U.S. and the respective country. 
Table 3. Empirical exchange rate equation: First-difference specification

\begin{tabular}{|c|c|c|c|c|c|c|c|c|c|c|c|c|}
\hline & \multicolumn{4}{|c|}{ Korea } & \multicolumn{4}{|c|}{ Brazil } & \multicolumn{4}{|c|}{ Mexico } \\
\hline & $(1)$ & $(2)$ & $(3)$ & $(4)$ & $(1)$ & $(2)$ & $(3)$ & $(4)$ & $(1)$ & $(2)$ & $(3)$ & $(4)$ \\
\hline$\Delta$ Interest diff. & $\begin{array}{l}0.04 \\
(0.10)\end{array}$ & $\begin{array}{l}0.02 \\
(0.11)\end{array}$ & $\begin{array}{l}-0.07 \\
(0.09)\end{array}$ & $\begin{array}{l}0.07 \\
(0.11)\end{array}$ & $\begin{array}{l}-0.21^{*} \\
(0.11)\end{array}$ & $\begin{array}{l}0.00 \\
(0.09)\end{array}$ & $\begin{array}{l}-0.06 \\
(0.08)\end{array}$ & $\begin{array}{l}0.00 \\
(0.09)\end{array}$ & $\begin{array}{l}-0.12 \\
(0.08)\end{array}$ & $\begin{array}{l}-0.10^{* *} \\
(0.04)\end{array}$ & $\begin{array}{l}-0.13^{* * *} \\
(0.04)\end{array}$ & $\begin{array}{l}-0.09^{*} \\
(0.05)\end{array}$ \\
\hline$\Delta$ Corp. spread & & $\begin{array}{l}1.27^{* * *} \\
(0.13)\end{array}$ & $\begin{array}{l}1.21^{* * *} \\
(0.06)\end{array}$ & $\begin{array}{l}1.26^{* * *} \\
(0.15)\end{array}$ & & $\begin{array}{l}0.88^{* * *} \\
(0.07)\end{array}$ & $\begin{array}{l}0.81^{* * *} \\
(0.08)\end{array}$ & $\begin{array}{l}0.93^{* * *} \\
(0.13)\end{array}$ & & $\begin{array}{l}0.82^{* * *} \\
(0.14)\end{array}$ & $\begin{array}{l}0.74^{* * *} \\
(0.14)\end{array}$ & $\begin{array}{l}0.58^{* * *} \\
(0.15)\end{array}$ \\
\hline$D_{\text {crisis }}$ & & & $\begin{array}{l}0.05^{* * *} \\
(0.01)\end{array}$ & & & & $\begin{array}{l}0.03^{* * *} \\
(0.01)\end{array}$ & & & & $\begin{array}{l}0.02^{* *} \\
(0.01)\end{array}$ & \\
\hline$\Delta \mathrm{VIX} / 100$ & & & & $\begin{array}{l}0.21^{* * *} \\
(0.05)\end{array}$ & & & & $\begin{array}{l}-0.05 \\
(0.08)\end{array}$ & & & & $\begin{array}{l}0.16^{* *} \\
(0.06)\end{array}$ \\
\hline trend & no & no & no & no & linear & linear & linear & linear & no & no & no & no \\
\hline$R^{2}$ & 0.00 & 0.45 & 0.53 & 0.51 & 0.06 & 0.48 & 0.51 & 0.48 & 0.03 & 0.33 & 0.35 & 0.37 \\
\hline Observations & 280 & 280 & 280 & 280 & 147 & 147 & 147 & 147 & 218 & 218 & 218 & 218 \\
\hline
\end{tabular}

Note: Dependent variable: log of change in monthly bilateral real exchange rate against the United States. Regressions estimated by OLS. Standard errors shown in parentheses, computed using the Newey-West adjustment. ${ }^{* * *}$, ${ }^{* *}$, and ${ }^{*}$ denote significance at the 1,5 , and 10 percent levels, respectively. Sample periods: 1995:6-2018:9 (Korea), 2006:8-2018:10 (Brazil), 2000:9-2018:10 (Mexico). The baseline regression equation (column (2)) is

$$
Q_{t}=\alpha_{0}+\alpha_{1} t+\beta_{s} \Delta s_{t}+\beta_{r} \Delta r_{t}^{\text {diff }}+\varepsilon_{t}
$$

with $\alpha_{1}=0$ for Korea and Mexico, and where $Q_{t}$ is the log real bilateral exchange rate against the dollar, $s_{t}$ is the corporate bond spread, and $r_{t}^{d i f f}$ is the government bond yield differential between the U.S. and the respective country. 
Figure 1. Negative $\xi$ shock in the simple model
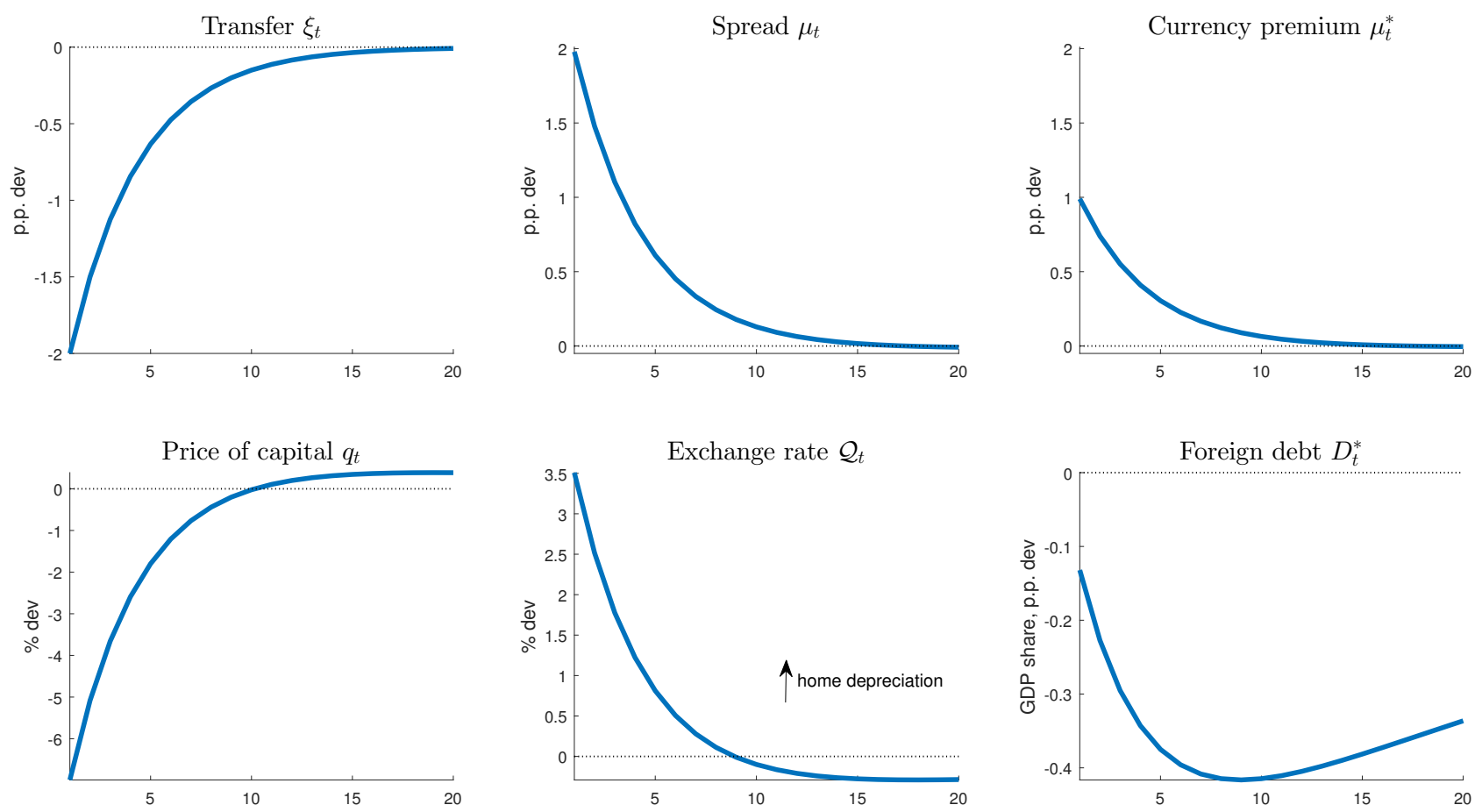

Note: The Figure shows the effects of a 2 percent drop in bankers' equity endowment $\xi_{t}$ in the simple model of Section 2. Parameter values: $\beta=0.9925, \beta^{*}=0.995, \gamma=0.5, \theta=0.18, \xi=0.20, \chi_{m}=\chi_{x}=1$. 
Figure 2. U.S. Monetary Tightening in the Frictionless Model
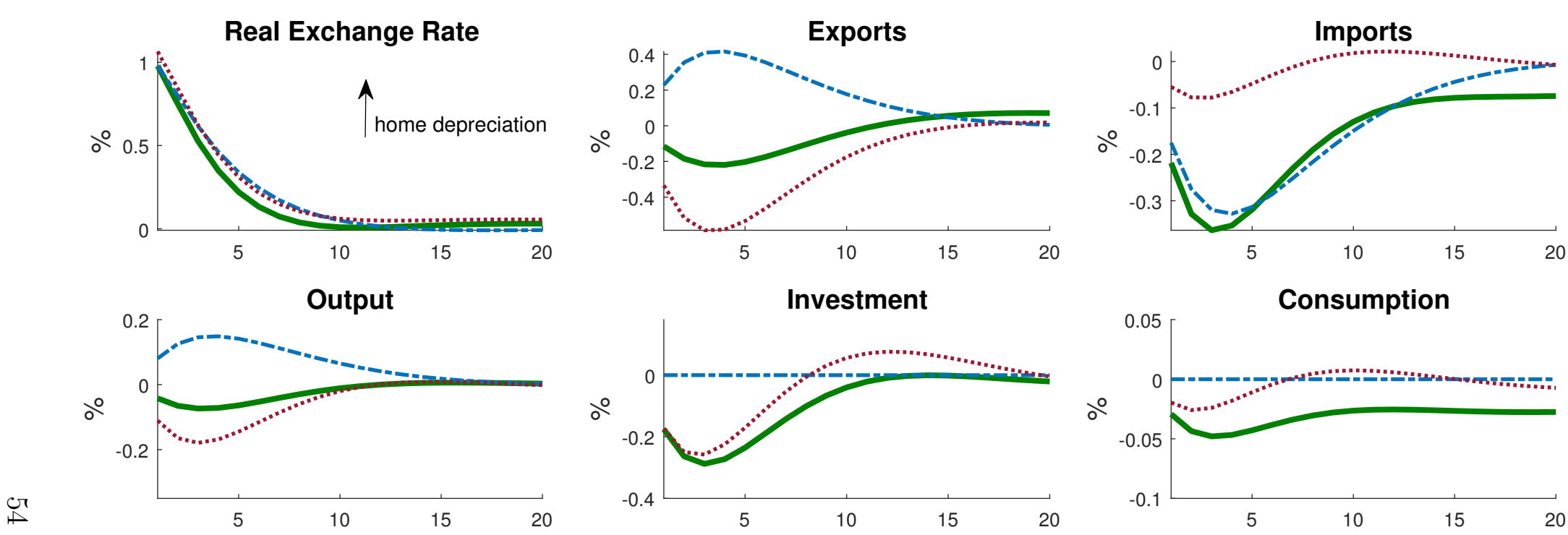

U.S. Output

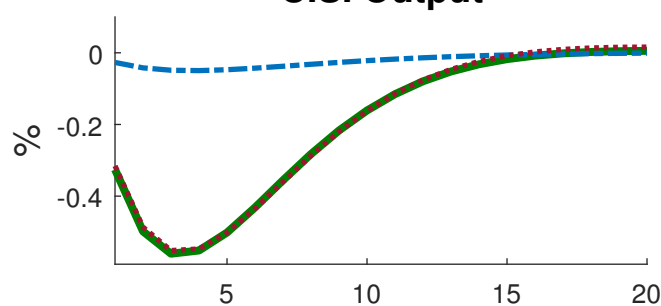

U.S. Investment

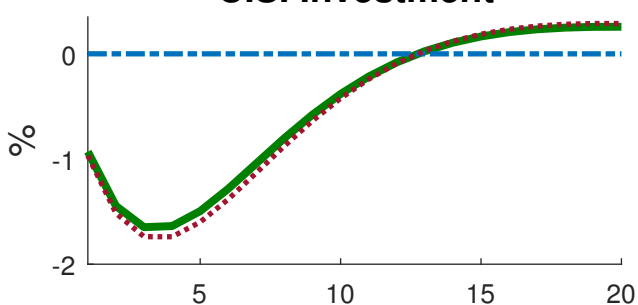

U.S. Consumption
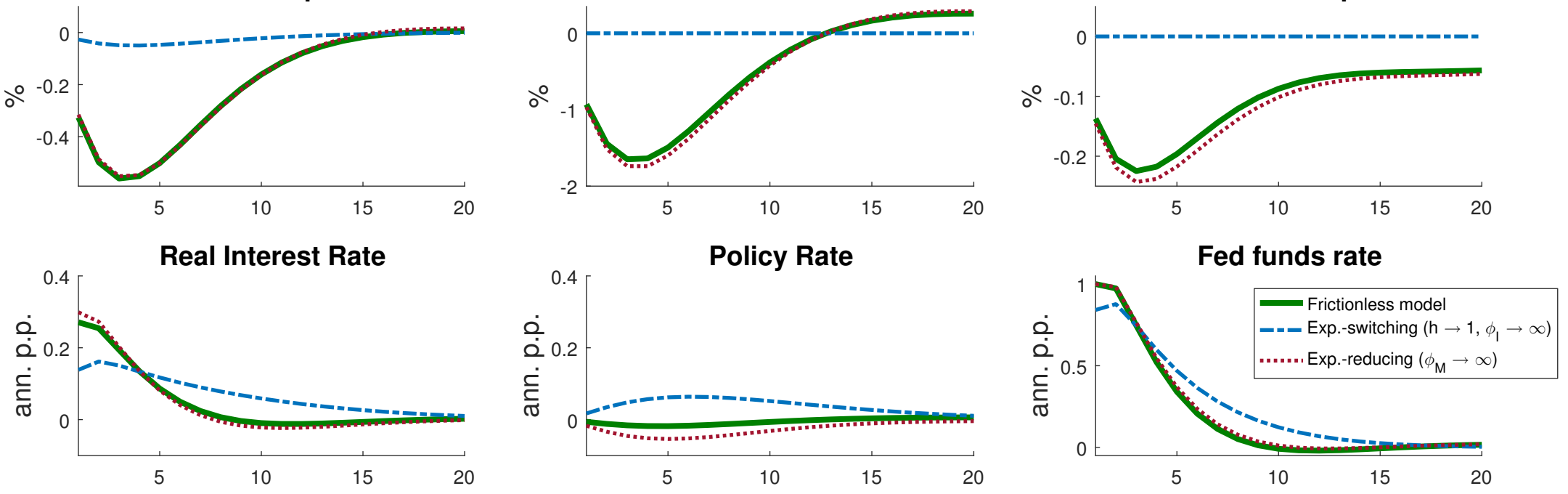

Note: The green solid line shows the effects of a 1 percent rise in the U.S. policy rate in the model with frictionless financial markets. The blue dash-dotted line sets the habit parameter $h$ very close to 1 and the investment adjustment cost parameter $\phi_{I}$ to a very high value, keeping world expenditure constant and thus capturing only the expenditure-switching effect. The dark red solid line sets the trade adjustment cost parameter to a very high value (and $h$ and $\phi_{I}$ back to their baseline values), thus capturing only the expenditure-reducing effect. All variables shown relative to steady state. 
Figure 3. U.S. Monetary Tightening with Imperfect Financial Markets
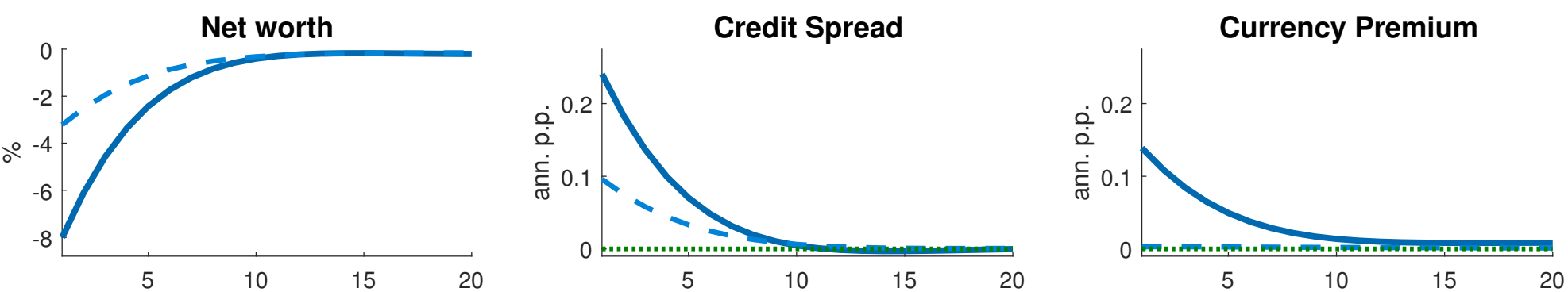

Real Exchange Rate
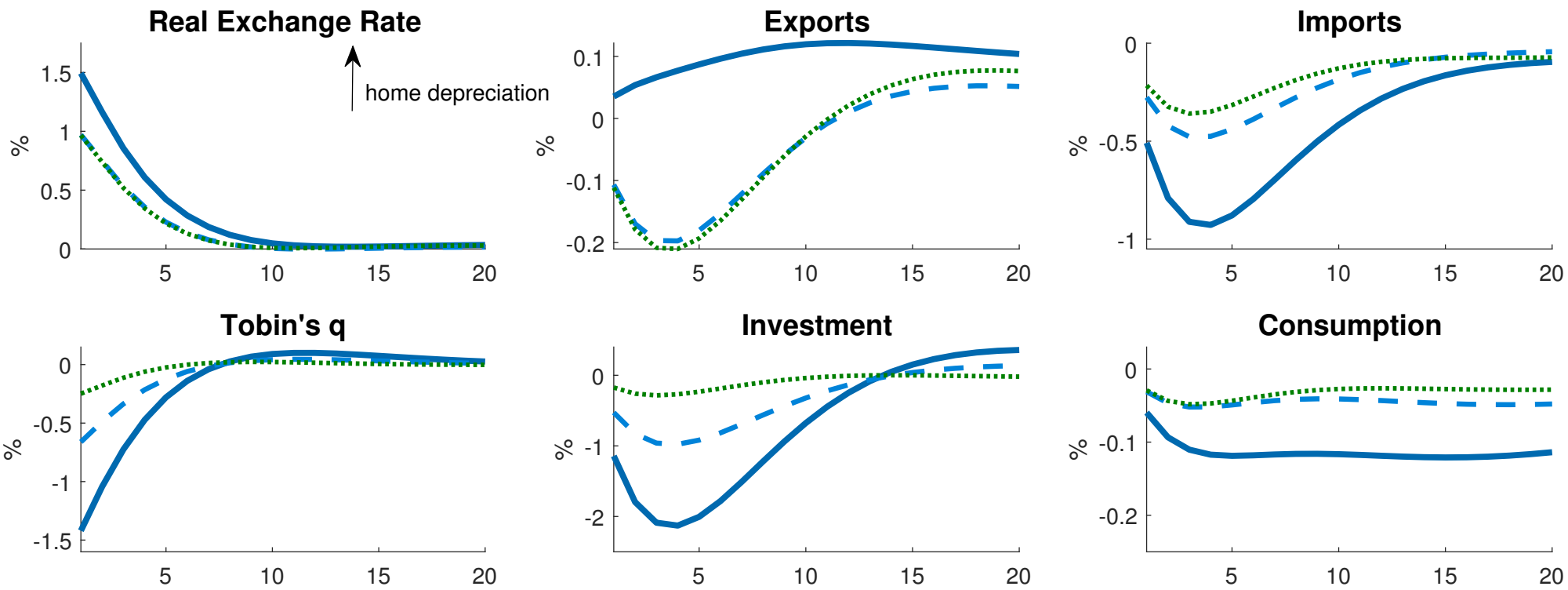

Output
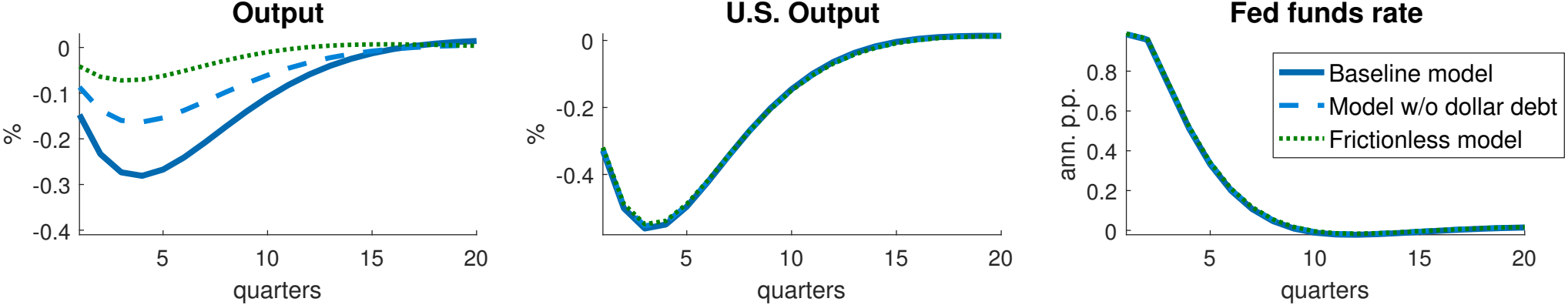

Note: The dark blue solid line shows the effects of 1 percent rise in the U.S. policy rate in our baseline model with frictions in financial markets. The light blue dashed line shows the effects in our baseline model with a tax on foreign borrowing such that steady-state domestic dollar debt is zero. The green dotted line shows the effects in the frictionless model. 
Figure 4. U.S. Monetary Tightening with Imperfect Financial Markets, Dominant Currency Pricing
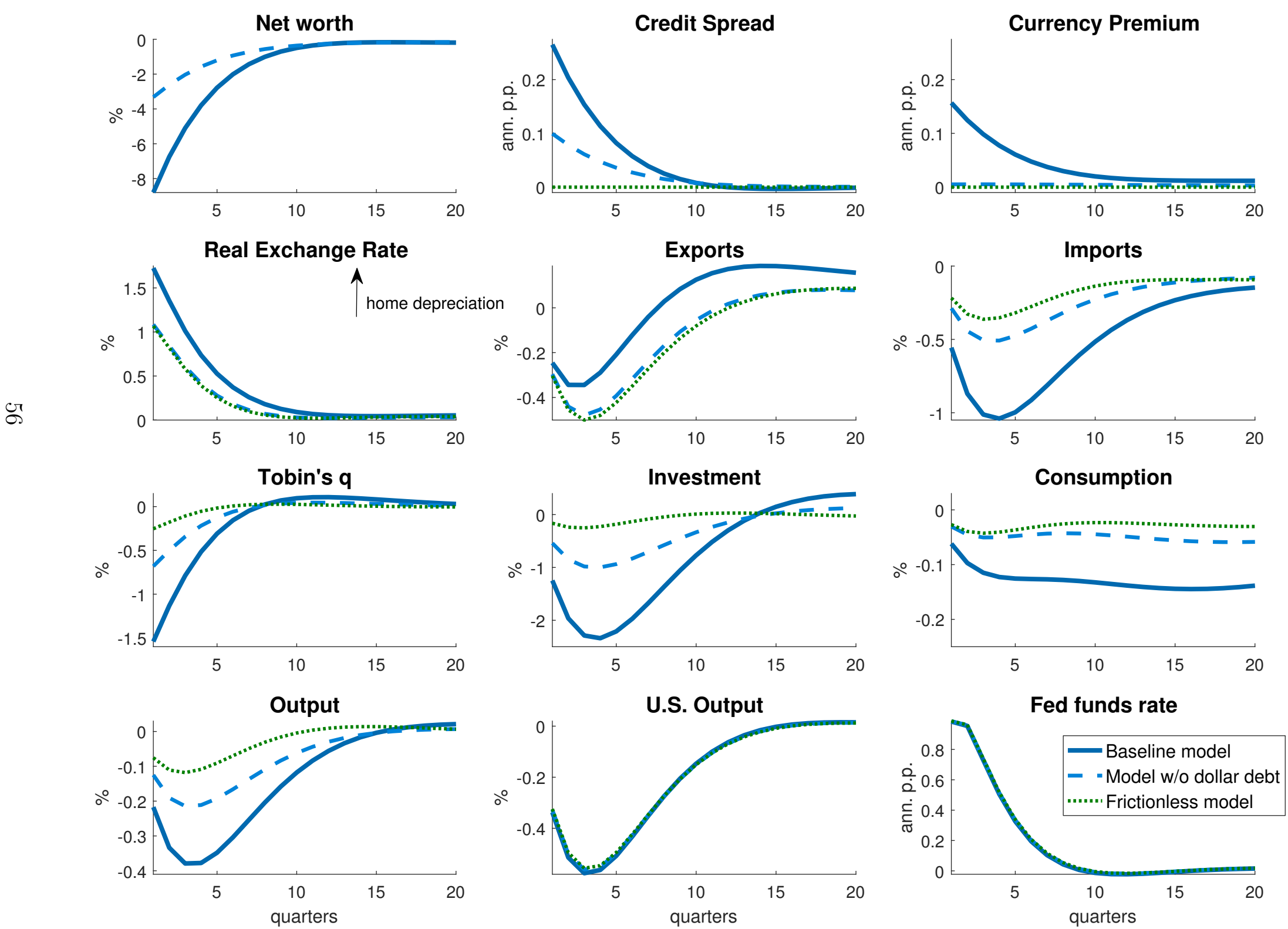

Note: The Figure performs the same experiment as in Figure 3 under the Dominant Currency Pricing (DCP) assumption. The dark blue solid line shows the effects of a 1 percent rise in the U.S. policy rate in the baseline model, the light blue dashed line shows the effects when steady-state dollar debt is zero, and the green dotted line shows the effects in the frictionless model. 
Figure 5. Exchange Rate Regimes and Welfare: Frictionless Model v. Baseline Model with Frictions
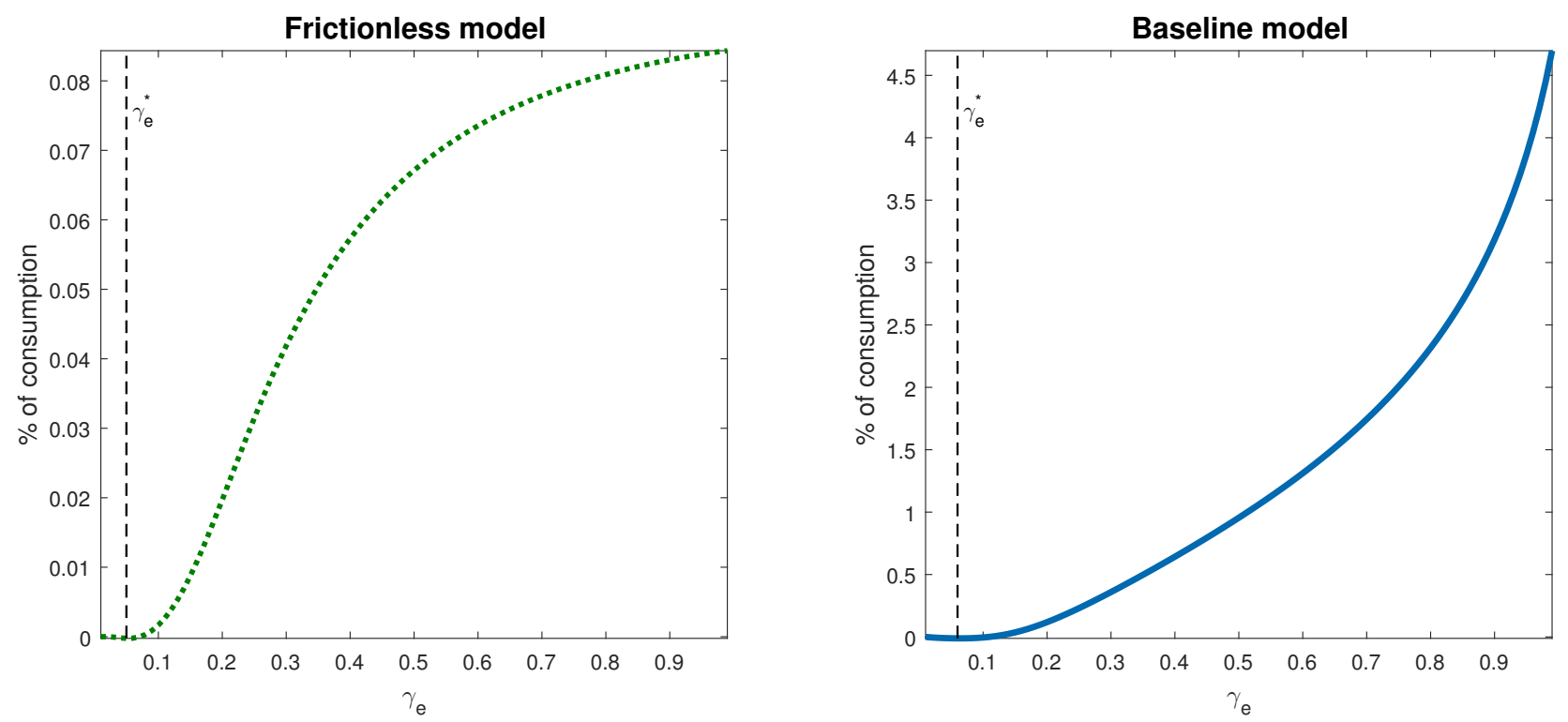

Note: The Figure shows the welfare losses associated with monetary regime $\gamma_{e}$ relative to $\gamma_{e}=0$, expressed as percent of quarterly consumption, in the frictionless model (left panel) and in our baseline model with frictions (right panel). Vertical lines mark the welfare-maximizing $\gamma_{e}$, denoted $\gamma_{e}^{*}$. 
Figure 6. Exchange Rate Regimes and Volatility: Frictionless Model v. Baseline Model with Frictions


\section{- Baseline model \\ ..... Frictionless model}

Note: The Figure shows the standard deviations of several variables under different values of $\gamma_{e}$ (indexing the weight on nominal exchange rate stabilization in the monetary rule), in the frictionless economy (green dotted line) and in the baseline economy with frictions (blue solid line). 
Figure 7. Domestic Monetary Tightening, Frictionless Model v. Baseline Model with Frictions
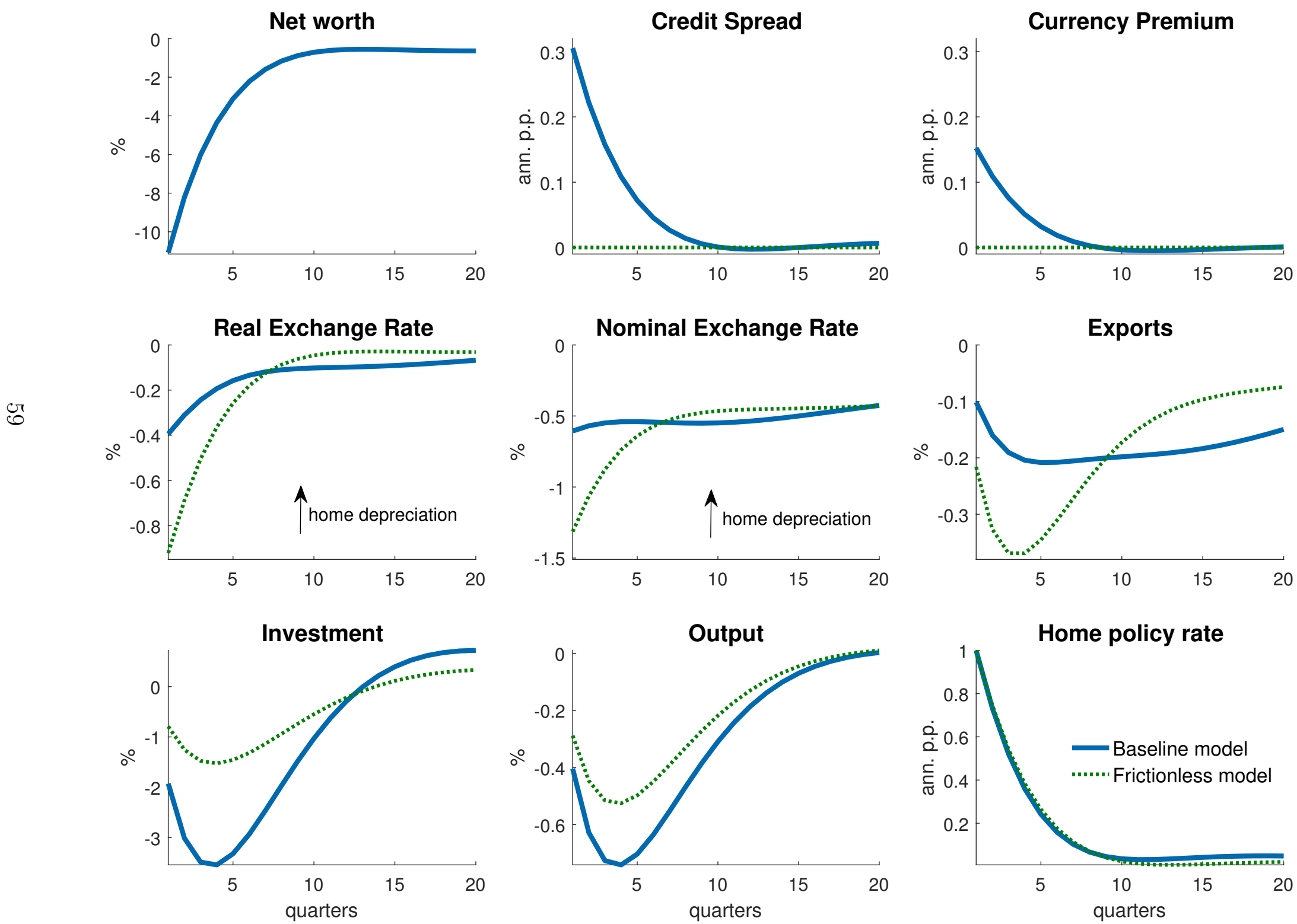

Note: The Figure shows the effects of a 1 percentage point increase in the domestic policy rate, in the frictionless model (green dotted line) and in the baseline model with frictions (blue solid line). 
Figure 8. U.S. Monetary Tightening and Exchange-Rate Regimes: Frictionless Model v. Baseline v. High Financial Fragility
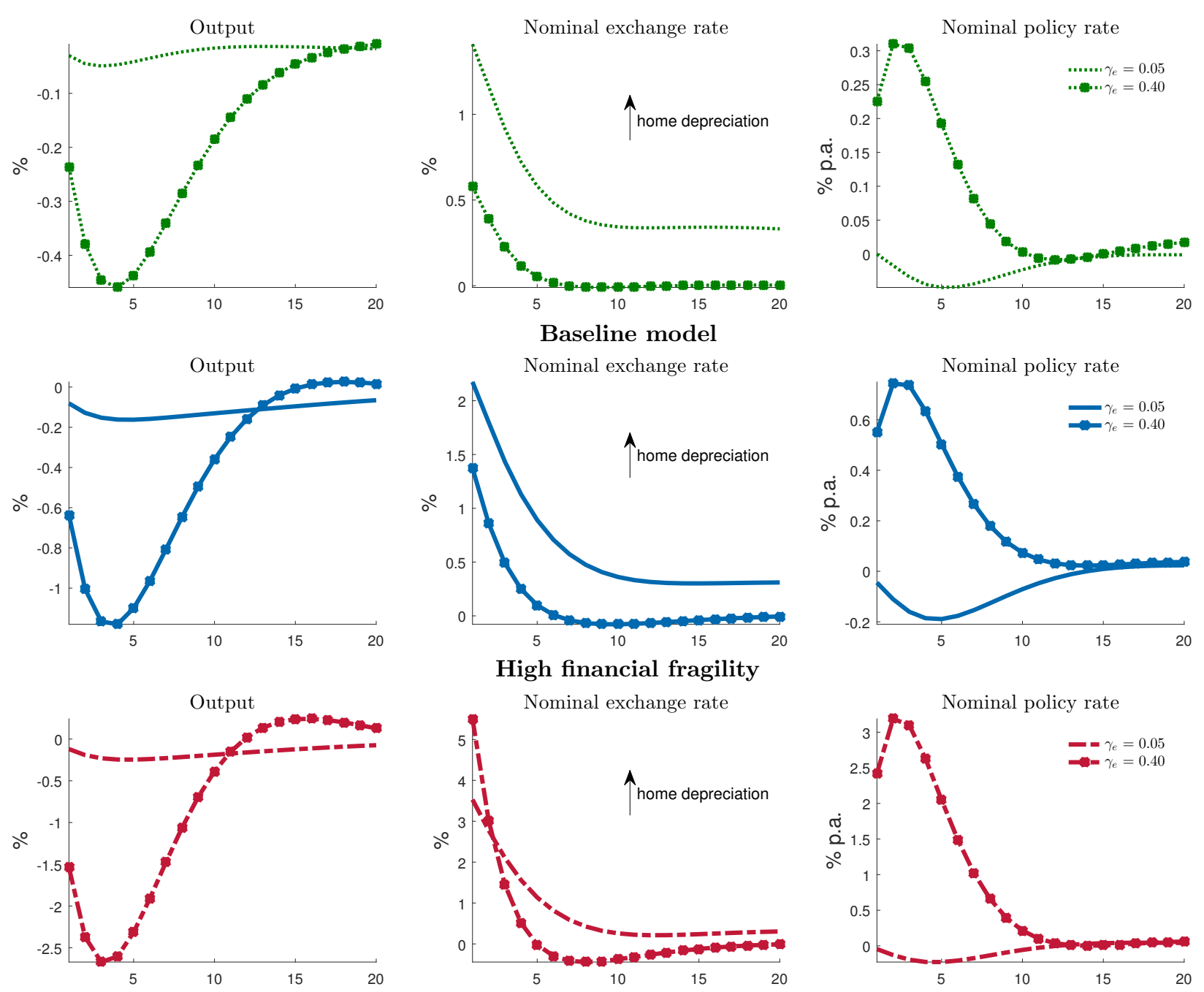

Note: The Figure shows the effects of U.S. monetary tightening under different policy regimes: $\gamma_{e}=0.05$ captures a regime characterized mostly by domestic inflation targeting, while $\gamma_{e}=0.40$ captures a regime with significant exchange-rate stabilization motives. The top, middle, and bottom rows refer to the frictionless, baseline, and high fragility economies, respectively. 
Figure 9. Domestic Monetary Tightening, Baseline v. High Financial Fragility
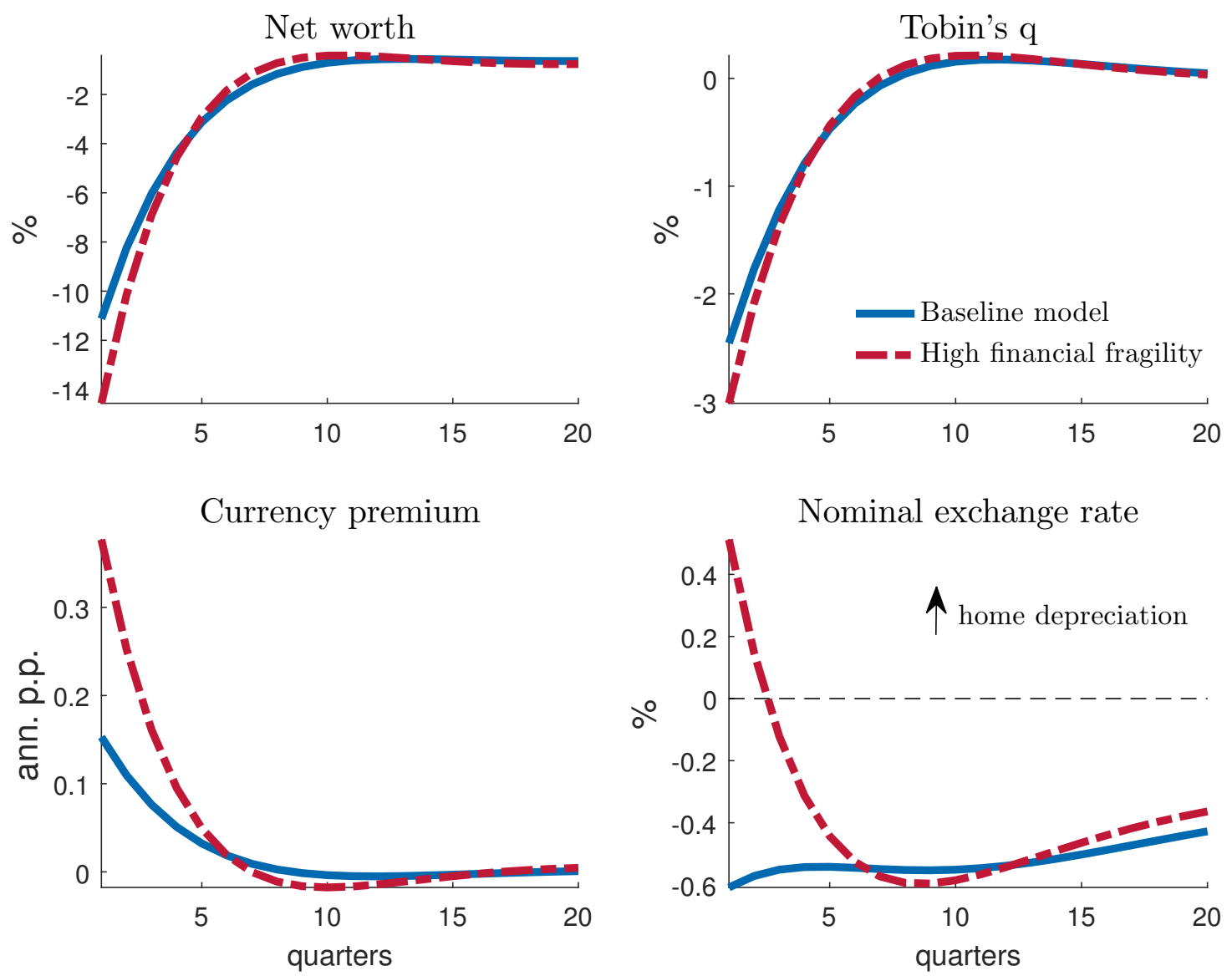

Note: The Figure shows the effects of a 1 percentage point rise in the domestic policy rate (as in Figure 7 , in our baseline calibration (blue solid line) and in the high financial fragility calibration (red dash-dotted line). 
Figure 10. Exchange Rate Regimes and Liability Dollarization
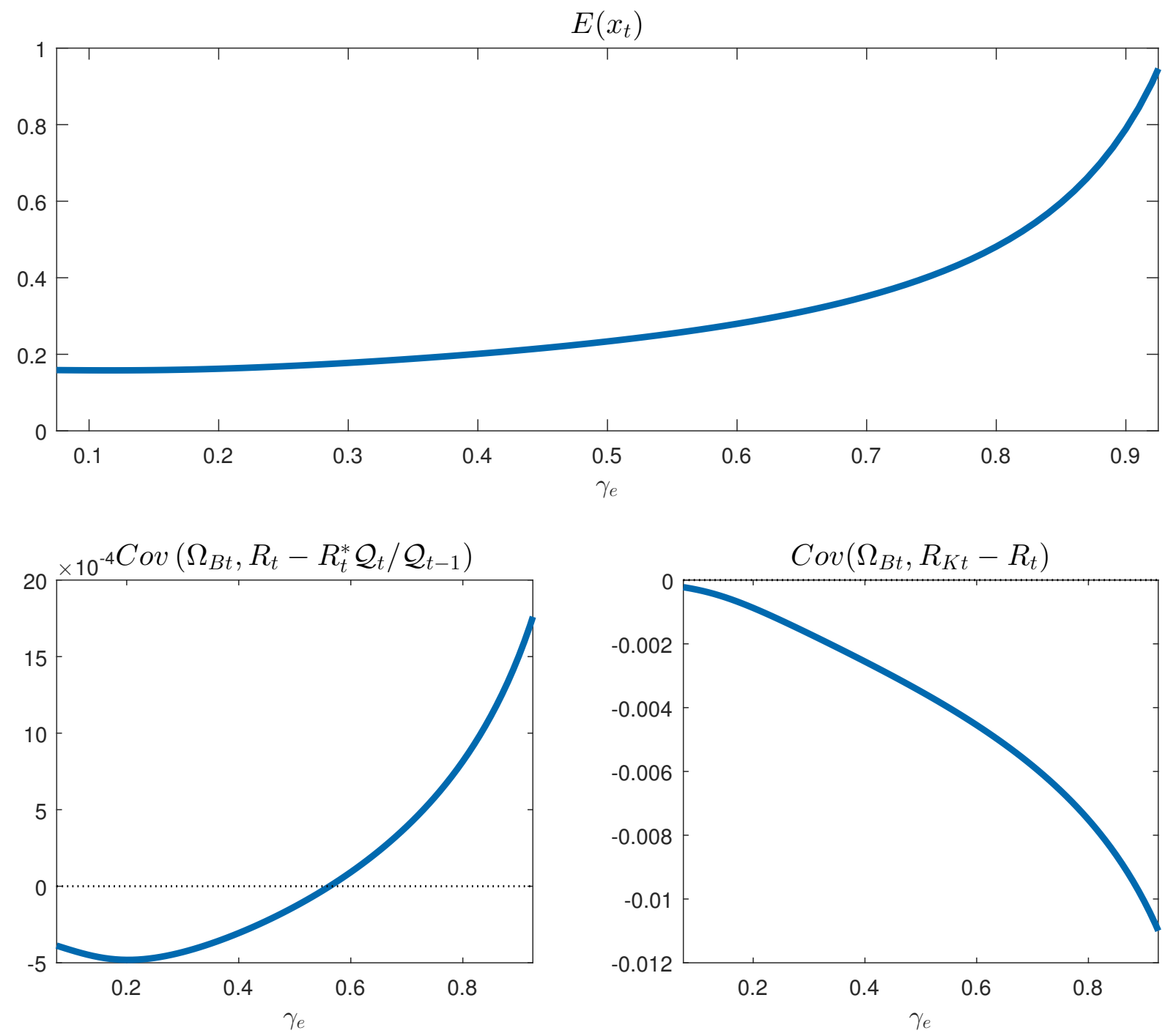

Note: The Figure shows the average value of the foreign liability ratio (top panel) and the covariances between the banker's SDF and the foreign-domestic yield differential (bottom left panel) and between the SDF and the spread between the domestic lending and deposit rate (bottom right panel). 
Figure 11. U.S. Monetary Tightening and Exchange Rate Regimes: Response of Financial Variables
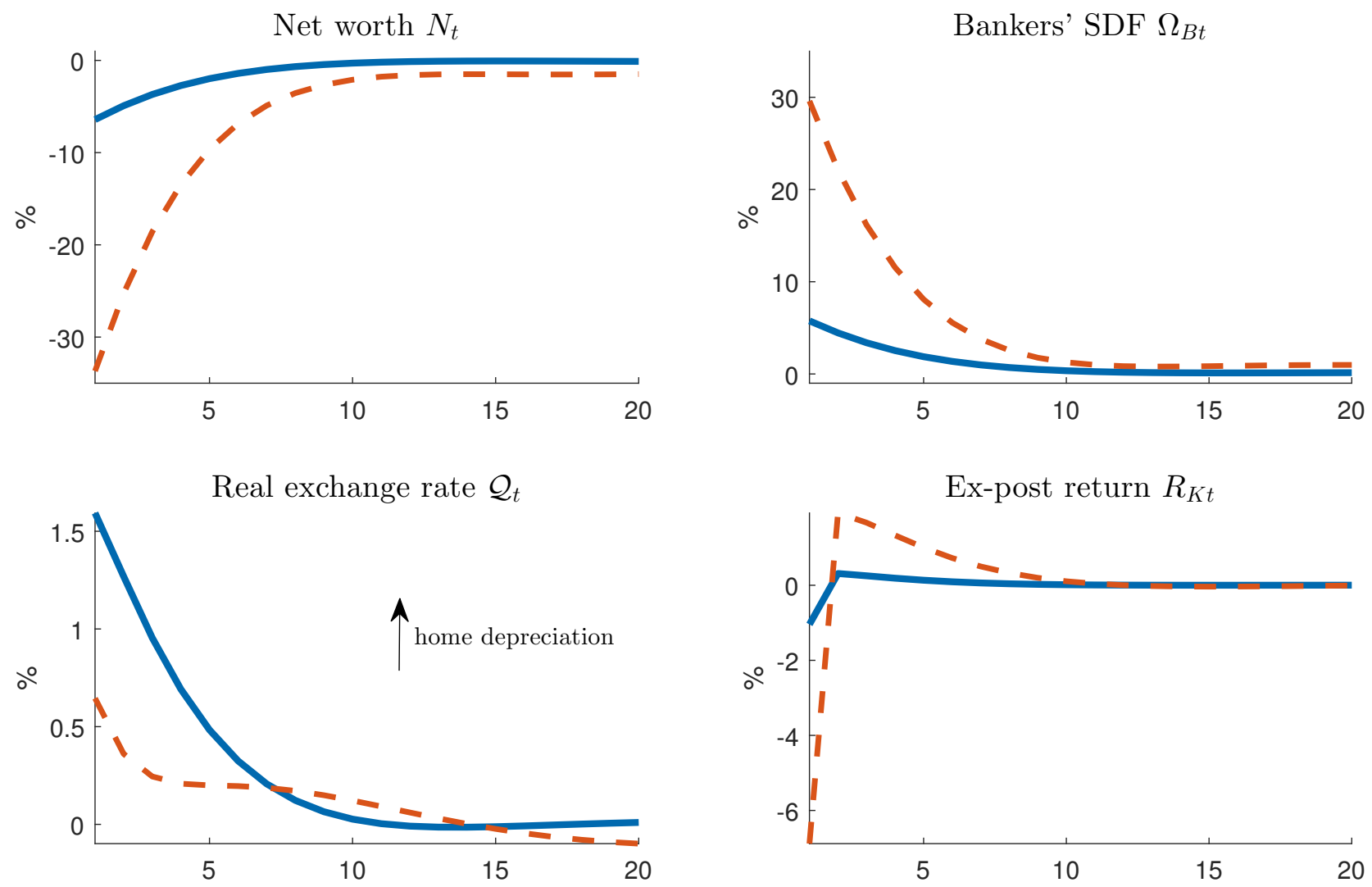

Domestic real rate $R_{t+1}$
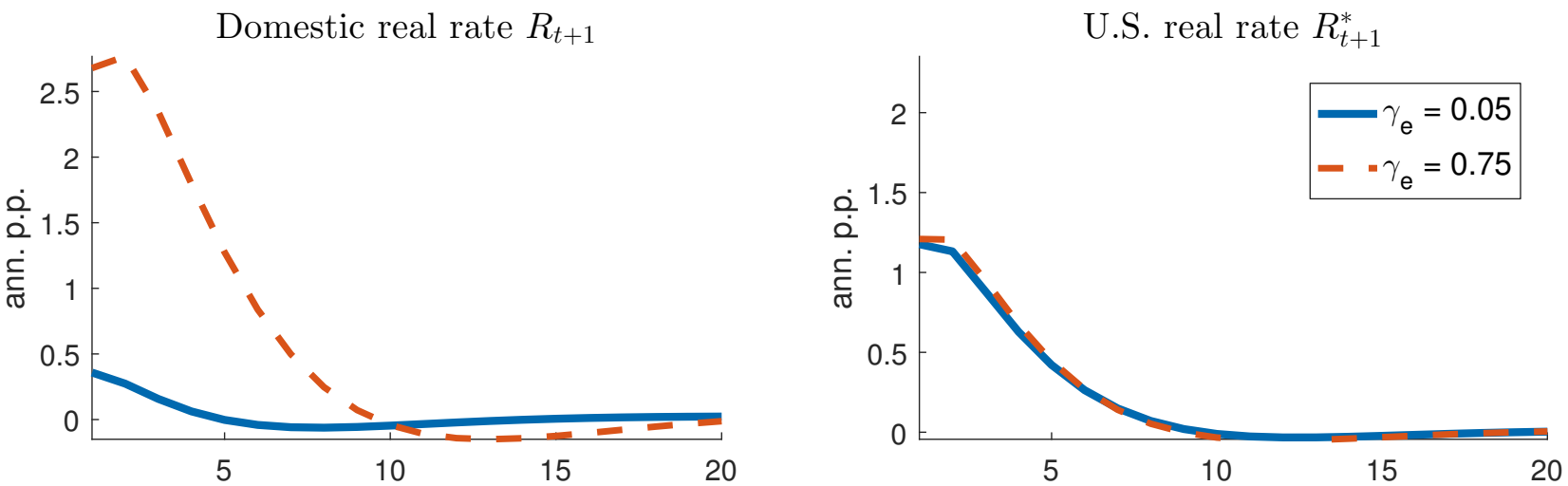

Note: The Figure shows the impulse responses of to a 1 percent rise in the federal funds rate of selected financial variables, under a domestic inflation-focused monetary regime (blue solid line) and under a regime with a strong weight on exchange rate stabilization (orange dashed line). 


\section{Appendix (For Online Publication)}

\section{A Simple model: Details and extension}

\section{A.1 Aggregate resource constraint}

Here we derive the balance of payments equations (15), (16) by aggregating domestic budget constraints. The term $\pi_{t}$ in (11) is

$$
\begin{aligned}
\pi_{t} & =\int\left\{\left(Z+q_{t}\right) S_{i t-1}-R D_{i t-1}-R^{*} \mathcal{Q}_{t} D_{i t-1}^{*}-\xi_{i t}\right\} d i \\
& =\left(Z+q_{t}\right) \bar{K}-R D_{t-1}-R^{*} \mathcal{Q}_{t} D_{t-1}^{*}-\int \xi_{i t} d i \\
& =Z \bar{K}-R D_{t-1}-R^{*} \mathcal{Q}_{t} D_{t-1}^{*}+D_{t}+\mathcal{Q}_{t} D_{t}^{*}
\end{aligned}
$$

where the second equality uses the bank's budget constraint (1). Substituting the above equation into households' budget constraint at equality yields

$$
C_{D t}+\mathcal{Q}_{t} M_{C t}=W_{t} \bar{L}+Z \bar{K}-R^{*} \mathcal{Q}_{t} D_{t-1}^{*}+\mathcal{Q}_{t} D_{t}^{*}
$$

Using the market-clearing condition for the home good $C_{D t}+M_{C t}^{*}=Y_{t}$ and the zero-profit condition for home firms $Y_{t}=W_{t} \bar{L}+Z \bar{K}$ in the equation above yields (15) and (16).

\section{A.2 Steady state}

The deterministic steady state can be solved in closed form:

$$
\begin{aligned}
\mu & =\left(1-\frac{\beta}{\beta^{*}}\right) \frac{1}{\gamma} \\
x & =\left(\frac{\xi}{\theta-\mu}-1\right) \frac{1}{\gamma} \\
q & =\frac{\frac{\beta}{1+\mu}}{1-\frac{\beta}{1+\mu}} Z \\
\mathcal{Q} & =\frac{\left(\beta^{*-1}-1\right) x q \bar{K}+\chi_{m}}{\chi_{x}}
\end{aligned}
$$


From (A.1), $\beta<\beta^{*}$ ensures $\mu>0$. A binding incentive constraint requires

$$
\theta-\mu=\theta-\left(1-\frac{\beta}{\beta^{*}}\right) \frac{1}{\gamma}>0
$$

i.e. $\theta$ must be large enough, given $\beta, \beta^{*}$, and $\gamma$. For the foreign borrowing ratio $x$ to be positive in steady state, the parameters need to satisfy

$$
\xi>\theta-\mu=\theta-\left(1-\frac{\beta}{\beta^{*}}\right) \frac{1}{\gamma}
$$

i.e. $\xi$ (the steady-state net worth transfer, as a fraction of the capital stock) must be large enough. In addition, for $x$ to be smaller than 1 the condition

$$
\xi<(1+\gamma)(\theta-\mu)=(1+\gamma)\left(\theta-\left(1-\frac{\beta}{\beta^{*}}\right) \frac{1}{\gamma}\right)
$$

must be satisfied, i.e. $\xi$ cannot be too large.

\section{A.3 Loglinearized equilibrium conditions}

Let $\widehat{y}_{t} \equiv \log \left(\frac{y_{t}}{y}\right)$ and $\widetilde{y}_{t} \equiv y_{t}-y$ for any variable $y_{t}$, where variables without time subscripts refer to the non-stochastic steady state. A first-order approximation to (17)-(21) yields the following system of difference equations:

$$
\begin{aligned}
\widetilde{\mu}_{t} & =-\frac{\theta-\mu}{\xi} \widetilde{\xi}_{t}+\frac{\gamma x \xi}{(1+\gamma x)^{2}} \widehat{x}_{t} \\
\widehat{x}_{t} & =\widehat{\mathcal{Q}}_{t}+\widehat{D}_{t}^{*}-\widehat{q}_{t} \\
\widehat{\mathcal{Q}}_{t} & =\gamma \frac{\beta^{*}}{\beta} \widetilde{\mu}_{t}+\mathbb{E}_{t}\left\{\widehat{\mathcal{Q}}_{t+1}\right\} \\
\widehat{q}_{t} & =-\frac{1}{1+\mu} \widetilde{\mu}_{t}+\frac{\beta}{1+\mu} \mathbb{E}_{t}\left\{\widehat{q}_{t+1}\right\} \\
\widehat{D}_{t}^{*} & =-\varepsilon \widehat{\mathcal{Q}}_{t}+\frac{1}{\beta^{*}} \widehat{D}_{t-1}^{*}
\end{aligned}
$$

where

$$
\varepsilon \equiv \frac{\chi_{m}\left(\frac{1}{\beta^{*}}-1\right)}{\chi_{x} \mathcal{Q}-\chi_{m}}
$$


Next let $\beta \rightarrow \beta^{*}$ from below (implying $\mu \rightarrow 0$ from above, from (A.1)), and assume $\chi_{x}=$ $\chi_{m} \equiv \chi$ (symmetric preferences over the foreign good). In addition, normalize $\bar{K}$ such that $\varepsilon=\frac{1}{\beta^{*}}-1$, which from (A.10) entails ensuring that $\mathcal{Q}=2$, in turn requiring from (A.3),(A.4) that $\bar{K}$ be set so as to satisfy

$$
\alpha \bar{K}^{\alpha}=\frac{\chi}{x}
$$

with $x$ given by (A.2), where we have made use of the expression for the capital return $Z=\alpha(\bar{K} / \bar{L})^{\alpha-1}$ and the normalization $\bar{L}=1$. Note from (16) that $\mathcal{Q}=2$ makes the elasticity of net exports to $\mathcal{Q}_{t}$ equal to unity. Under these assumptions, equations (A.5), (A.7)-(A.9) simplify to

$$
\begin{aligned}
\widetilde{\mu}_{t} & =-\frac{\theta}{\xi} \widetilde{\xi}_{t}+\frac{\theta}{\xi}(\xi-\theta) \widehat{x}_{t} \\
\widehat{\mathcal{Q}}_{t} & =\gamma \widetilde{\mu}_{t}+\mathbb{E}_{t}\left\{\widehat{\mathcal{Q}}_{t+1}\right\} \\
\widehat{q}_{t} & =-\widetilde{\mu}_{t}+\beta \mathbb{E}_{t}\left\{\widehat{q}_{t+1}\right\} \\
\widehat{D}_{t}^{*} & =-r^{*} \widehat{\mathcal{Q}}_{t}+\left(1+r^{*}\right) \widehat{D}_{t-1}^{*}
\end{aligned}
$$

where $r^{*} \equiv \frac{1}{\beta^{*}}-1$ denotes the net foreign interest rate, and where we have made use of (A.2) in going from (A.5) to (A.11).

\section{A.4 Extension with household participation in foreign exchange}

Our baseline model assumes full market segmentation in dollar funding, whereby only banks have access to foreign credit markets. Here we extend the simple model of Section 2 to allow households to also borrow from foreigners, subject to a transaction cost. We use this extended model to illustrate that as long as there is some cost to participating in foreign exchange on the part of the household sector, our main result that a decrease in bankers' equity pushes up the currency premium continues to hold.

Let the representative household's dollar debt be $D_{H t}^{*}$. The household's budget constraint is

$$
C_{D t}+Q_{t} M_{C t}+D_{t}-\mathcal{Q}_{t} D_{H t}^{*}+f\left(\mathcal{Q}_{t} D_{H t}^{*}\right) \leq R_{t} D_{t-1}-R_{t}^{*} \mathcal{Q}_{t} D_{H t-1}^{*}+W_{t} \bar{L}+\pi_{t}
$$


where $f(\cdot)$ is an increasing convex function of the value of household dollar financing $\mathcal{Q}_{t} D_{H t}^{*}$. The function $f(\cdot)$ captures transaction costs to participating in foreign exchange markets (terms of the home good). This formulation represents a reduced-form way of capturing household heterogeneity in financial sophistication, whereby only a limited supply of households is sophisticated enough to monitor international financial markets and engage in foreign exchange. ${ }^{45}$ The household thus solves

$$
\max _{\substack{\left\{C_{D t+j}, M_{C t+j}, D_{t+j}, D_{H t+j}^{*}\right\}_{j=0}^{\infty}}} \mathbb{E}_{t} \sum_{j=0}^{\infty} \beta^{j} U\left(C_{D t+j}, M_{C t+j}\right)
$$

subject to (A.15) for all $t$. The rest of the model setup is exactly as in Section 2.

The household's first-order condition for $D_{H t}^{*}$ is

$$
1=\beta \mathbb{E}_{t}\left(\frac{R_{t+1}^{*} \mathcal{Q}_{t+1}}{\mathcal{Q}_{t}}\right)+f^{\prime}\left(\mathcal{Q}_{t} D_{H t}^{*}\right)
$$

The marginal benefit of borrowing an additional unit is the marginal utility of consumption today (equal to unity), while the marginal cost is the discounted cost of repayment (expressed in terms of the domestic good) plus the marginal transaction cost $f^{\prime}\left(\mathcal{Q}_{t} D_{H t}^{*}\right)$.

Suppose the transaction cost takes the form

$$
f\left(\mathcal{Q}_{t} D_{H t}^{*}\right)=\frac{\kappa}{2}\left(\mathcal{Q}_{t} D_{H t}^{*}\right)^{2}
$$

Proceeding exactly as before, the model's equilibrium conditions are

$$
\begin{aligned}
\mu_{t} & =\theta-\frac{\xi_{t}}{1+\gamma x_{t}} \\
x_{t} & =\frac{\mathcal{Q}_{t} D_{t}^{*}}{q_{t} \bar{K}} \\
q_{t} & =\beta \frac{\mathbb{E}_{t}\left(Z+q_{t+1}\right)}{1+\mu_{t}} \\
\mathcal{Q}_{t} & =\frac{\frac{\beta}{\beta^{*}} \mathbb{E}_{t}\left(\mathcal{Q}_{t+1}\right)}{1-\gamma \mu_{t}} \\
\mathcal{D}_{t}^{*} & =\chi_{m} \mathcal{Q}_{t}^{-1}-\chi_{x}+R^{*} \mathcal{D}_{t-1}^{*}
\end{aligned}
$$

\footnotetext{
${ }^{45}$ Gertler and Karadi (2013) make a similar assumption, in the context of motivating limited participation by households in the markets for private securities and for long-term government bonds.
} 


$$
\begin{aligned}
\mathcal{D}_{t}^{*} & =D_{t}^{*}+D_{H t}^{*} \\
\mathcal{Q}_{t} D_{H t}^{*} & =\frac{\gamma}{\kappa} \mu_{t}
\end{aligned}
$$

where $\mathcal{D}_{t}$ is the economy's aggregate foreign debt (the sum of households' and bankers' dollar debt) and where (A.24) combines (A.16) with (A.21). The above system determines variables $\mu_{t}, x_{t}, q_{t}, \mathcal{Q}_{t}, \mathcal{D}_{t}^{*}, D_{t}^{*}$, and $D_{H t}^{*}$.

The system (A.18)-(A.24) clarifies how the presence of household participation may dampen the effects of lower bank net worth $\xi$ on the exchange rate. The initial rise in $\mu_{t}$ will work to push up $D_{H t}^{*}$ through (A.24), as households take advantage of the lower relative cost of dollar credit. Everything else equal, a rise in $D_{H t}^{*}$ implies a smaller decline in aggregate foreign debt $\mathcal{D}_{t}^{*}$, through (A.23). In turn, the latter effect will work to moderate the downward pressure on the currency through the balance of payments condition (A.22), allowing for a smaller depreciation than without household participation.

Figure A.1 illustrates the effects of a 2 percent drop in the equity endowment $\xi$ for two different calibrations of the parameter $\kappa$, a high and a low value. The high $\kappa$ value is set by targeting a steady-state ratio of household-to-total foreign debt of 10 percent. The low value targets a much higher ratio of household debt, 25 percent. ${ }^{46}$ As the Figure makes clear, when $\kappa$ is high (i.e. when steady-state household debt is low) the effects are close to our baseline case without household participation. Even when $\kappa$ is such that in steady state $D_{H}^{*}$ is 25 percent of $\mathcal{D}^{*}$, the drop in banker equity still delivers a substantial exchange rate depreciation - about half as large as the case without household participation. One final observation is that the presence of household participation works by damping the overall effects on all aggregate variables, but it does not alter the basic result that the currency premium $\mu_{t}^{*}$ is proportional to the spread $\mu_{t}$.

\section{A.5 Version with dollar-denominated loans}

Suppose that domestic non-financial firms now also issue dollar-denominated claims, and for simplicity suppose that all bank lending to non-financial firms is done in the form of these claims. Bank $i$ 's constraint is now

$$
\mathcal{Q}_{t} q_{t}^{f} S_{i t}^{f}=D_{i t}+\mathcal{Q}_{t} D_{i t}^{*}+\xi_{i t}
$$

\footnotetext{
${ }^{46}$ In each case we re-calibrate $\bar{K}$ to ensure the elasticity of $\mathcal{D}_{t}$ to $\mathcal{Q}_{t}$ is $-r^{*}$, as done earlier.
} 
Figure A.1. Negative $\xi$ shock in the extended model with household participation in forex


Note: The Figure shows the effects of lower bank equity in the extended model, for a high (orange dashed line) and a low (yellow dotted line) value of the participation cost parameter $\kappa$. For comparison, the blue solid line shows the effects without household participation from Figure 1. The remaining parameters are calibrated as in Section 2.2: $\beta=0.9925, \beta^{*}=0.995, \gamma=0.5, \theta=0.18, \xi=0.20, \chi_{m}=\chi_{x}=1$.

where $S_{i t}^{*}$ is holdings of dollar-denominated claims issued by domestic non-corporations, and $q_{t}^{f}$ is the (dollar) price of those claims. Each of these claims pays gross returns $R_{K t+1}^{f} \equiv$ $\left(Z_{t+1}^{f}+q_{t+1}^{f}\right) / q_{t}^{f}$ in $t+1$, with $Z_{t+1}^{f}$ denoting the claim's dividend. The bank's payoff in $t+1$, denoted $\pi_{i t+1}$, is

$$
\pi_{i t+1}=\mathcal{Q}_{t+1} R_{K t+1} q_{t}^{f} S_{i t}^{f}-R_{t+1} D_{i t}-R_{t+1}^{*} \mathcal{Q}_{t+1} D_{i t}^{*}
$$

We assume that the amount of assets the bank can divert is

$$
\theta\left[(1-\gamma) D_{i t}+\mathcal{Q}_{t} D_{i t}^{*}+\xi_{i t}\right]
$$


i.e. we modify slightly the formulation of the agency problem, by assuming that $\gamma$ captures the degree to which domestic deposits are less divertable than foreign ones. This change makes the algebra simpler but is otherwise immaterial. Define the excess returns

$$
\begin{aligned}
\mu_{t}^{f} & \equiv \beta \mathbb{E}_{t}\left[\frac{\mathcal{Q}_{t+1}}{\mathcal{Q}_{t}}\left(R_{K t+1}^{f}-\frac{R_{t+1}}{\mathcal{Q}_{t+1} / \mathcal{Q}_{t}}\right)\right] \\
\varrho_{t}^{f} & \equiv \beta \mathbb{E}_{t}\left[\frac{\mathcal{Q}_{t+1}}{\mathcal{Q}_{t}}\left(R_{K t+1}^{f}-R_{t+1}^{*}\right)\right]
\end{aligned}
$$

Let also $y_{i t} \equiv D_{i t} \bar{S}_{i t}$ with $\bar{S}_{i t} \equiv \mathcal{Q}_{t} q_{t}^{f} S_{i t}^{f}$ for ease of notation. The bank's problem is

$$
\max _{y_{i t}, \bar{S}_{i t}}\left[\mu_{t}^{f} y_{i t}+\varrho_{t}^{f}\left(1-y_{i t}\right)\right] \bar{S}_{i t}+\beta \mathbb{E}_{t}\left(\mathcal{Q}_{t+1} / \mathcal{Q}_{t}\right) R_{t+1}^{*} \xi_{i t}
$$

subject to

$$
\left[\mu_{t}^{f} y_{i t}+\varrho_{t}^{f}\left(1-y_{i t}\right)\right] \bar{S}_{i t}+\beta \mathbb{E}_{t}\left(\mathcal{Q}_{t+1} / \mathcal{Q}_{t}\right) R_{t+1}^{*} \xi_{i t} \geq \theta\left(1-\gamma y_{i t}\right) \bar{S}_{i t}
$$

In an interior solution, the following optimal portfolio condition must hold

$$
\mu_{t}^{f}=(1-\gamma) \rho_{t}^{f}
$$

Similar to the baseline case, the excess return relative to the domestic deposit rate is lower than relative to the foreign rate. Thus, we have $\varrho_{t}^{f}-\mu_{t}^{f}=\gamma \varrho_{t}^{f}$, or

$$
\mathbb{E}_{t}\left[\frac{\mathcal{Q}_{t+1}}{\mathcal{Q}_{t}}\left(\frac{R_{t+1}}{\mathcal{Q}_{t+1} / \mathcal{Q}_{t}}-R_{t+1}^{*}\right)\right]=\gamma \mathbb{E}_{t}\left[\frac{\mathcal{Q}_{t+1}}{\mathcal{Q}_{t}}\left(R_{K t+1}^{f}-R_{t+1}^{*}\right)\right]
$$

Loglinearizing the equation above, we arrive at the "modified" UIP condition

$$
Q_{t}=\gamma \mathbb{E}_{t}\left\{r_{k t+1}^{f}-r_{t+1}^{*}\right\}+r_{t+1}^{*}-r_{t+1}+\mathbb{E}_{t}\left\{Q_{t+1}\right\}
$$

where $Q_{t}, r_{k t+1}^{f}, r_{t+1}$, and $r_{t+1}^{*}$ denote the logs of $\mathcal{Q}_{t}, R_{K t+1}^{f}, R_{t+1}$, and $R_{t+1}^{*}$, respectively. Thus, the UIP deviation (the first term on the right-hand side) is now captured by the return on the (dollar-denominated) domestic claim over the safe dollar rate. 


\section{B Medium-scale model: Additional material}

\section{B.1 Derivation of solution to bankers' problem}

To solve the banker's problem, we first guess that the value function is linear in net worth, $V_{i t}=\alpha_{t} N_{i t}$. We then let the coefficients $\mu_{t}, \mu_{t}^{*}, \nu_{t}$ be given by

$$
\begin{aligned}
\mu_{t} & =\mathbb{E}_{t}\left[\Lambda_{t, t+1}\left(1-\sigma_{b}+\sigma_{b} \alpha_{t+1}\right)\left(R_{K t+1}-R_{t+1}\right)\right] \\
\mu_{t}^{*} & =\mathbb{E}_{t}\left[\Lambda_{t, t+1}\left(1-\sigma_{b}+\sigma_{b} \alpha_{t+1}\right)\left(R_{t+1}-R_{t+1}^{*} \mathcal{Q}_{t+1} / \mathcal{Q}_{t}\right)\right] \\
\nu_{t} & =\mathbb{E}_{t}\left[\Lambda_{t, t+1}\left(1-\sigma_{b}+\sigma_{b} \alpha_{t+1}\right) R_{t+1}\right]
\end{aligned}
$$

Given the definition of leverage ratio: $\phi_{i t} \equiv \frac{q_{i t} S_{i t}}{N_{i t}}$, banker $i$ 's problem can be written as:

$$
\alpha_{t}=\max _{\phi_{i t}, x_{i t}}\left(\mu_{t}+x_{i t} \mu_{t}^{*}\right) \phi_{i t}+\nu_{t}
$$

subject to

$$
\left(\mu_{t}+x_{t} \mu_{t}^{*}\right) \phi_{i t}+\nu_{t} \geq \Theta\left(x_{t}\right) \phi_{i t}
$$

The first-order conditions from the corresponding Lagrangian (with multiplier on (B.5) denoted $\lambda_{i t}$ ) yield

$$
\begin{aligned}
\mu_{t}^{*} & =\frac{\lambda_{t}}{1+\lambda_{i t}} \Theta^{\prime}\left(x_{i t}\right) \\
\mu_{t}+x_{i t} \mu_{t}^{*} & =\frac{\lambda_{i t}}{1+\lambda_{i t}} \Theta\left(x_{i t}\right)
\end{aligned}
$$

Combining the above equations yields (34) in the main text. Given that $\mu_{t}$ and $\mu_{t}^{*}$ are not bank-specific, $x_{i t}=x_{t}$ is common across banks. Given a binding incentive constraint, the leverage ratio $\phi_{i t}=\phi_{t}$ is also common across banks, and given by

$$
\phi_{t}=\frac{\nu_{t}}{\Theta\left(x_{t}\right)-\left(\mu_{t}+x_{t} \mu_{t}^{*}\right)}
$$

We can then solve for the undetermined coefficient $\alpha_{t}$ using (B.4):

$$
\alpha_{t}=\left(\mu_{t}+x_{t} \mu_{t}^{*}\right) \phi_{t}+\nu_{t}
$$




\section{B.2 Full set of equilibrium conditions}

\section{Home country}

$$
\begin{aligned}
& 1=\mathbb{E}_{t}\left(\frac{\Lambda_{t, t+1}}{\pi_{c t+1}}\right) R_{t+1}^{n} \\
& 1=\mathbb{E}_{t}\left(\Lambda_{t, t+1}\right) R_{t+1} \\
& \Lambda_{t, t+1}=\beta U_{C t+1} / U_{C t} \\
& U_{C t}=\left(C_{t}-h C_{t-1}\right)^{-1 / \sigma}-\beta h \mathbb{E}_{t}\left\{\left(C_{t+1}-h C_{t}\right)^{-1 / \sigma}\right\} \\
& p_{D t}=(1-\omega)^{\frac{\rho}{1+\rho}}\left(\frac{C_{t}}{C_{D t}}\right)^{\frac{\rho}{1+\rho}}+\omega^{\frac{\rho}{1+\rho}}\left(\frac{C_{t}}{M_{C t}^{A}}\right)^{\frac{\rho}{1+\rho}} \varphi_{M} x_{M C t}\left(\frac{x_{M C t}}{x_{M C t-1}}-1\right) \frac{x_{M C t}}{x_{M C t-1}} \\
& -\mathbb{E}_{t}\left\{\Lambda_{t, t+1} \pi_{c t+1} \omega^{\frac{\rho}{1+\rho}}\left(\frac{C_{t+1}}{M_{C t+1}^{A}}\right)^{\frac{\rho}{1+\rho}} \frac{C_{D t+1}}{C_{D t}} \varphi_{M} x_{M C t+1}\left(\frac{x_{M C t+1}}{x_{M C t}}-1\right) \frac{x_{M C t+1}}{x_{M C t}}\right\} \\
& p_{D t} \mathcal{T}_{t}=\omega^{\frac{\rho}{1+\rho}}\left(\frac{C_{t}}{M_{C t}^{A}}\right)^{\frac{\rho}{1+\rho}}\left[1-\frac{\varphi_{M}}{2}\left(\frac{x_{M C t}}{x_{M C t-1}}-1\right)^{2}-\varphi_{M}\left(\frac{x_{M C t}}{x_{M C t-1}}-1\right) \frac{x_{M C t}}{x_{M C t-1}}\right] \\
& +\mathbb{E}_{t}\left\{\Lambda_{t, t+1} \pi_{c t+1} \omega^{\frac{\rho}{1+\rho}}\left(\frac{C_{t+1}}{M_{C t+1}^{A}}\right)^{\frac{\rho}{1+\rho}} \frac{M_{C t+1}}{M_{C t}} \varphi_{M}\left(\frac{x_{M C t+1}}{x_{M C t}}-1\right) \frac{x_{M C t+1}}{x_{M C t}}\right\} \\
& M_{C t}^{A}=M_{C t}\left[1-\frac{\varphi_{M}}{2}\left(\frac{x_{M C t}}{x_{M C t-1}}-1\right)^{2}\right] \\
& x_{M C t}=\frac{M_{C t}}{C_{D t}} \\
& p_{D t}=(1-\omega)^{\frac{\rho}{1+\rho}}\left(\frac{I_{t}}{I_{D t}}\right)^{\frac{\rho}{1+\rho}}+\omega^{\frac{\rho}{1+\rho}}\left(\frac{I_{t}}{M_{I t}^{A}}\right)^{\frac{\rho}{1+\rho}} \varphi_{M} x_{M I t}\left(\frac{x_{M I t}}{x_{M I t-1}}-1\right) \frac{x_{M I t}}{x_{M I t-1}} \\
& -\mathbb{E}_{t}\left\{\Lambda_{t, t+1} \pi_{c t+1} \omega^{\frac{\rho}{1+\rho}}\left(\frac{I_{t+1}}{M_{I t+1}^{A}}\right)^{\frac{\rho}{1+\rho}} \frac{I_{D t+1}}{I_{D t}} \varphi_{M} x_{M I t+1}\left(\frac{x_{M I t+1}}{x_{M I t}}-1\right) \frac{x_{M I t+1}}{x_{M I t}}\right\} \\
& p_{D t} \mathcal{T}_{t}=\omega^{\frac{\rho}{1+\rho}}\left(\frac{I_{t}}{M_{I t}^{A}}\right)^{\frac{\rho}{1+\rho}}\left[1-\frac{\varphi_{M}}{2}\left(\frac{x_{M I t}}{x_{M I t-1}}-1\right)^{2}-\varphi_{M}\left(\frac{x_{M I t}}{x_{M I t-1}}-1\right) \frac{x_{M I t}}{x_{M I t-1}}\right] \\
& +\mathbb{E}_{t}\left\{\Lambda_{t, t+1} \pi_{c t+1} \omega^{\frac{\rho}{1+\rho}}\left(\frac{I_{t+1}}{M_{I t+1}^{A}}\right)^{\frac{\rho}{1+\rho}} \frac{M_{I t+1}}{M_{I t}} \varphi_{M}\left(\frac{x_{M I t+1}}{x_{M I t}}-1\right) \frac{x_{M I t+1}}{x_{M I t}}\right\} \\
& M_{I t}^{A}=M_{I t}\left[1-\frac{\varphi_{M}}{2}\left(\frac{x_{M I t}}{x_{M I t-1}}-1\right)^{2}\right]
\end{aligned}
$$




$$
\begin{aligned}
& x_{M I t}=\frac{M_{I t}}{I_{D t}} \\
& p_{D t}^{\frac{1}{\rho}}=1-\omega+\omega \mathcal{T}_{t}^{-\frac{1}{\rho}} \\
& Y_{t}=K_{t}^{\alpha} L_{t}^{1-\alpha} / \Delta_{p t} \\
& \Delta_{p t}=\left(1-\xi_{p}\right)\left(\pi_{t}^{o} / \pi_{t}\right)^{-\left(1+\theta_{p}\right) / \theta_{p}}+\xi_{p} \pi_{t}^{\left(1+\theta_{p}\right) / \theta_{p}} \pi_{t-1}^{-\iota_{p}\left(1+\theta_{p}\right) / \theta_{p}} \Delta_{p t-1} \\
& w_{t}=\frac{(1-\alpha)}{\alpha} \frac{K_{t}}{L_{t}} r_{k t} \\
& m c_{t}=\left(\frac{w_{t}}{1-\alpha}\right)^{1-\alpha}\left(\frac{r_{k t}}{\alpha}\right)^{\alpha} \\
& \pi_{t}=\left(\left(1-\xi_{p}\right)\left(\pi_{t}^{o}\right)^{-\frac{1}{\theta_{p}}}+\xi_{p}\left(\pi_{t-1}\right)^{-\frac{\iota p}{\theta_{p}}}\right)^{-\theta_{p}} \\
& \pi_{t}^{o}=\left(1+\theta_{p}\right) \frac{x_{1 t}}{x_{2 t}} \pi_{t} \\
& x_{1 t}=C_{t}^{-1 / \sigma} m c_{t} Y_{t}+\beta \xi_{p} \pi_{t}^{-\iota_{p} \frac{1+\theta_{p}}{\theta_{p}}} \mathbb{E}_{t}\left\{x_{1 t+1} \pi_{t+1}^{\frac{1+\theta_{p}}{\theta_{p}}}\right\} \\
& x_{2 t}=C_{t}^{-1 / \sigma} p_{D t} Y_{t}+\beta \xi_{p} \pi_{t}^{1-\iota_{p} \frac{1+\theta_{p}}{\theta_{p}}} \mathbb{E}_{t}\left\{x_{2 t+1} \pi_{t+1}^{\frac{1+\theta_{p}}{\theta_{p}}-1}\right\} \\
& \pi_{c t}=\frac{\pi_{t}}{p_{D t} / p_{D t-1}} \\
& Y_{t}=C_{D t}+I_{D t}+\frac{\xi^{*}}{\xi}\left(M_{C t}^{*}+M_{I t}^{*}\right)+\frac{\psi_{I}}{2}\left(I_{t} / I_{t-1}-1\right)^{2} I_{t} \\
& R_{t+1}^{n}=\left(R_{t}^{n}\right)^{\gamma_{r}}\left(\beta^{-1} \pi_{t}^{\gamma_{\pi}}\right)^{1-\gamma_{r}} \varepsilon_{t}^{r} \\
& K_{t}=(1-\delta) K_{t-1}+I_{t-1} \\
& q_{t}=1+p_{D t}\left[\psi_{I}\left(\frac{I_{t}}{I_{t-1}}-1\right) \frac{I_{t}}{I_{t-1}}+\frac{\psi_{I}}{2}\left(\frac{I_{t}}{I_{t-1}}-1\right)^{2}\right]-\mathbb{E}_{t}\left\{\Lambda_{t, t+1} p_{D t+1} \psi_{I}\left(\frac{I_{t+1}}{I_{t}}-1\right)\left(\frac{I_{t+1}}{I_{t}}\right)^{2}\right\} \\
& x_{t}=\left(\mu_{t}^{*} / \mu_{t}\right)^{-1}\left(-1+\sqrt{1+\frac{2}{\gamma}\left(\mu_{t}^{*} / \mu_{t}\right)^{2}}\right) \\
& N_{t}=\sigma_{b}\left[\left(R_{K t}-R_{t}\right) q_{t-1} S_{t-1}+\left(R_{t}-R_{t}^{*} \mathcal{Q}_{t} / \mathcal{Q}_{t-1}\right) \mathcal{Q}_{t-1} D_{t-1}^{*}+R_{t} N_{t-1}\right]+\left(1-\sigma_{b}\right) \xi_{b} q_{t-1} S_{t-1} \\
& \phi_{t}=\frac{\nu_{t}}{\theta\left(1+\frac{\gamma}{2} x_{t}^{2}\right)-\left(\mu_{t}+\mu_{t}^{*} x_{t}\right)} \\
& q_{t} S_{t}=\phi_{t} N_{t} \\
& \mathcal{Q}_{t} D_{t}^{*}=x_{t} \phi_{t} N_{t} \\
& \mu_{t}=\mathbb{E}_{t}\left[\Lambda_{t, t+1} \Omega_{t+1}\left(R_{K t+1}-R_{t+1}\right)\right]
\end{aligned}
$$




$$
\begin{aligned}
\mu_{t}^{*} & =\mathbb{E}_{t}\left[\Lambda_{t, t+1} \Omega_{t+1}\left(R_{t+1}-R_{t+1}^{*} \mathcal{Q}_{t+1} / \mathcal{Q}_{t}\right)\right] \\
\Omega_{t} & =1-\sigma_{b}+\sigma_{b}\left[\nu_{t}+\left(\mu_{t}+\mu_{t}^{*} x_{t}\right) \phi_{t}\right] \\
\nu_{t} & =\mathbb{E}_{t}\left(\Lambda_{t, t+1} \Omega_{t+1}\right) R_{t+1} \\
S_{t} & =(1-\delta) K_{t}+I_{t} \\
R_{K t} & =\frac{r_{k t}+(1-\delta) q_{t}}{q_{t-1}} \\
w_{t}^{o} & =\left(1+\theta_{w}\right) \frac{x_{1 w t}}{x_{2 w t}} \\
x_{1 w t} & =L_{t}^{o} U_{C t} M R S_{t}+\beta \xi_{w} \mathbb{E}_{t}\left\{x_{1 w t+1}\right\} \\
x_{2 w t} & =L_{t}^{o} U_{C t}+\beta \xi_{w} \pi_{w t}^{\iota w} \mathbb{E}_{t}\left\{x_{2 w t+1} \pi_{c t+1}^{-1}\right\} \\
w_{t} & =\left(\left(1-\xi_{w}\right)\left(w_{t}^{o}\right)^{-\frac{1}{\theta_{w}}}+\xi_{w}\left(\pi_{w t-1}^{\iota_{w}} w_{t-1} \pi_{c t}^{-1}\right)^{-\frac{1}{\theta_{w}}}\right)^{-\theta_{w}} \\
M R S_{t} & =\frac{\chi_{0}\left(L_{t}^{o}\right)^{\chi}}{U_{C t}} \\
L_{t}^{o} & =\left(\frac{w_{t}^{o}}{w_{t}}\right)^{-\frac{1+\theta_{w}}{\theta_{w}}} L_{t} \\
\pi_{w t} & =\frac{w_{t}}{w_{t-1}} \pi_{c t}
\end{aligned}
$$

Above, $p_{D t}=P_{D t} / P_{t}$ is the relative price of the home-produced good in terms of the home basket; $\pi_{c t}=P_{t} / P_{t-1}$ is CPI inflation; $\mathcal{T}_{t}=P_{M t} / P_{D t}$ is the terms of trade; $\Delta_{p t}$ is price dispersion; $m c_{t}$ is firms' real marginal cost; and $\pi_{w t}$ is nominal wage inflation.

Equations (B.10)-(B.11) are the Euler equations for the nominal and real safe rate. Equations (B.14)-(B.21) characterize optimality of the choice of domestic and imported consumption and investment goods. Note that these conditions simplify to the standard CES demand equations when $\varphi_{M}=0$ : for example, (B.14) becomes $C_{D t}=(1-\omega) p_{D t}^{-(1+\rho) / \rho} C_{t}$. Equations (B.23)-(B.30) characterize domestic intermediate producers' optimality, including price-setting. Equations (B.47)-(B.52) characterize optimal wage setting.

\section{Terms of trade and balance of payments}

$$
\begin{aligned}
\mathcal{Q}_{t} & =\mathcal{T}_{t}\left(\frac{1-\omega+\omega\left(\frac{1}{\mathcal{T}_{t}}\right)^{-\frac{1}{\rho}}}{1-\omega+\omega\left(\mathcal{T}_{t}\right)^{-\frac{1}{\rho}}}\right)^{-\rho} \\
\mathcal{Q}_{t}\left(D_{t}^{*}-R_{t}^{*} D_{t-1}^{*}\right) & =C_{t}+I_{t}+p_{D t} \frac{\psi_{I}}{2}\left(I_{t} / I_{t-1}-1\right)^{2} I_{t}-p_{D t} Y_{t}
\end{aligned}
$$


Equation (B.55) characterizes the (positive) relationship between the terms of trade $\mathcal{T}_{t}$ and the real exchange rate $\mathcal{Q}_{t}$. It can be obtained by combining the expression for the real exchange rate, $\mathcal{Q}_{t}=e_{t} P_{t}^{*} / P_{t}$, with the PCP conditions (50),(51) and the price level expression (49) in each country. The balance of payments equation (B.55) can be obtained by combining budget constraints in each country with equilibrium conditions.

\section{Foreign country}

$$
\begin{aligned}
& 1=\mathbb{E}_{t}\left(\frac{\Lambda_{t, t+1}^{*}}{\pi_{c t+1}^{*}}\right) R_{t+1}^{n *} \\
& 1=\mathbb{E}_{t}\left(\Lambda_{t, t+1}^{*}\right) R_{t+1}^{*} \\
& 1=\mathbb{E}_{t}\left(\Lambda_{t, t+1}^{*} R_{K t+1}^{*}\right) \\
& \Lambda_{t, t+1}^{*}=\beta^{*} U_{C t+1}^{*} / U_{C t}^{*} \\
& U_{C t}^{*}=\left(C_{t}^{*}-h C_{t-1}^{*}\right)^{-1 / \sigma}-\beta^{*} h \mathbb{E}_{t}\left\{\left(C_{t+1}^{*}-h C_{t}^{*}\right)^{-1 / \sigma}\right\} \\
& p_{D t}^{*}=\left(1-\omega^{*}\right)^{\frac{\rho}{1+\rho}}\left(\frac{C_{t}^{*}}{C_{D t}^{*}}\right)^{\frac{\rho}{1+\rho}}+\omega^{* \frac{\rho}{1+\rho}}\left(\frac{C_{t}^{*}}{M_{C t}^{A *}}\right)^{\frac{\rho}{1+\rho}} \varphi_{M} x_{M C t}^{*}\left(\frac{x_{M C t}^{*}}{x_{M C t-1}^{*}}-1\right) \frac{x_{M C t}^{*}}{x_{M C t-1}^{*}} \\
& -\mathbb{E}_{t}\left\{\Lambda_{t, t+1}^{*} \pi_{c t+1}^{*} \omega^{* \frac{\rho}{1+\rho}}\left(\frac{C_{t+1}^{*}}{M_{C t+1}^{A *}}\right)^{\frac{\rho}{1+\rho}} \frac{C_{D t+1}^{*}}{C_{D t}^{*}} \varphi_{M} x_{M C t+1}^{*}\left(\frac{x_{M C t+1}^{*}}{x_{M C t}^{*}}-1\right) \frac{x_{M C t+1}^{*}}{x_{M C t}^{*}}\right\} \\
& p_{D t}^{*} \mathcal{T}_{t}^{-1}=\omega^{* \frac{\rho}{1+\rho}}\left(\frac{C_{t}^{*}}{M_{C t}^{A *}}\right)^{\frac{\rho}{1+\rho}}\left[1-\frac{\varphi_{M}}{2}\left(\frac{x_{M C t}^{*}}{x_{M C t-1}^{*}}-1\right)^{2}-\varphi_{M}\left(\frac{x_{M C t}^{*}}{x_{M C t-1}^{*}}-1\right) \frac{x_{M C t}^{*}}{x_{M C t-1}^{*}}\right] \\
& +\mathbb{E}_{t}\left\{\Lambda_{t, t+1}^{*} \pi_{c t+1}^{*} \omega^{* \frac{\rho}{1+\rho}}\left(\frac{C_{t+1}^{*}}{M_{C t+1}^{A *}}\right)^{\frac{\rho}{1+\rho}} \frac{M_{C t+1}^{*}}{M_{C t}^{*}} \varphi_{M}\left(\frac{x_{M C t+1}^{*}}{x_{M C t}^{*}}-1\right) \frac{x_{M C t+1}^{*}}{x_{M C t}^{*}}\right\} \\
& M_{C t}^{A *}=M_{C t}^{*}\left[1-\frac{\varphi_{M}}{2}\left(\frac{x_{M C t}^{*}}{x_{M C t-1}^{*}}-1\right)^{2}\right] \\
& x_{M C t}^{*}=\frac{M_{C t}^{*}}{C_{D t}^{*}} \\
& p_{D t}^{*}=\left(1-\omega^{*}\right)^{\frac{\rho}{1+\rho}}\left(\frac{I_{t}^{*}}{I_{D t}^{*}}\right)^{\frac{\rho}{1+\rho}}+\omega^{* \frac{\rho}{1+\rho}}\left(\frac{I_{t}^{*}}{M_{I t}^{A *}}\right)^{\frac{\rho}{1+\rho}} \varphi_{M} x_{M I t}^{*}\left(\frac{x_{M I t}^{*}}{x_{M I t-1}^{*}}-1\right) \frac{x_{M I t}^{*}}{x_{M I t-1}^{*}} \\
& -\mathbb{E}_{t}\left\{\Lambda_{t, t+1}^{*} \pi_{c t+1}^{*} \omega^{* \frac{\rho}{1+\rho}}\left(\frac{I_{t+1}^{*}}{M_{I t+1}^{A *}}\right)^{\frac{\rho}{1+\rho}} \frac{I_{D t+1}^{*}}{I_{D t}^{*}} \varphi_{M} x_{M I t+1}^{*}\left(\frac{x_{M I t+1}^{*}}{x_{M I t}^{*}}-1\right) \frac{x_{M I t+1}^{*}}{x_{M I t}^{*}}\right\}
\end{aligned}
$$




$$
\begin{aligned}
& p_{D t}^{*} \mathcal{T}_{t}^{-1}=\omega^{*} \frac{\rho}{1+\rho}\left(\frac{I_{t}^{*}}{M_{I t}^{A *}}\right)^{\frac{\rho}{1+\rho}}\left[1-\frac{\varphi_{M}}{2}\left(\frac{x_{M I t}^{*}}{x_{M I t-1}^{*}}-1\right)^{2}-\varphi_{M}\left(\frac{x_{M I t}^{*}}{x_{M I t-1}^{*}}-1\right) \frac{x_{M I t}^{*}}{x_{M I t-1}^{*}}\right] \\
& +\mathbb{E}_{t}\left\{\Lambda_{t, t+1}^{*} \pi_{c t+1}^{*} \omega^{* \frac{\rho}{1+\rho}}\left(\frac{I_{t+1}^{*}}{M_{I t+1}^{A *}}\right)^{\frac{\rho}{1+\rho}} \frac{M_{I t+1}^{*}}{M_{I t}^{*}} \varphi_{M}\left(\frac{x_{M I t+1}^{*}}{x_{M I t}^{*}}-1\right) \frac{x_{M I t+1}^{*}}{x_{M I t}^{*}}\right\} \\
& M_{I t}^{A *}=M_{I t}^{*}\left[1-\frac{\varphi_{M}}{2}\left(\frac{x_{M I t}^{*}}{x_{M I t-1}^{*}}-1\right)^{2}\right] \\
& x_{M I t}^{*}=\frac{M_{I t}^{*}}{I_{D t}^{*}} \\
& p_{D t}^{* 1 / \rho}=1-\omega^{*}+\omega^{*} \mathcal{T}_{t}^{1 / \rho} \\
& Y_{t}^{*}=K_{t}^{* \alpha} L_{t}^{* 1-\alpha} / \Delta_{p t}^{*} \\
& \Delta_{p t}^{*}=\left(1-\xi_{p}\right)\left(\pi_{t}^{o *} / \pi_{t}^{*}\right)^{-\left(1+\theta_{p}\right) / \theta_{p}}+\xi_{p} \pi_{t}^{*\left(1+\theta_{p}\right) / \theta_{p}} \pi_{t-1}^{*}{ }^{-\iota_{p}\left(1+\theta_{p}\right) / \theta_{p}} \Delta_{p t-1}^{*} \\
& w_{t}^{*}=\frac{(1-\alpha)}{\alpha} \frac{K_{t}^{*}}{L_{t}^{*}} r_{k t}^{*} \\
& m c_{t}^{*}=\left(\frac{w_{t}^{*}}{1-\alpha}\right)^{1-\alpha}\left(\frac{r_{k t}^{*}}{\alpha}\right)^{\alpha} \\
& \pi_{t}^{*}=\left(\left(1-\xi_{p}\right)\left(\pi_{t}^{o *}\right)^{-\frac{1}{\theta_{p}}}+\xi_{p}\left(\pi_{t-1}^{*}\right)^{-\frac{\iota p}{\theta_{p}}}\right)^{-\theta_{p}} \\
& \pi_{t}^{o *}=\left(1+\theta_{p}\right) \frac{x_{1 t}^{*}}{x_{2 t}^{*}} \pi_{t}^{*} \\
& x_{1 t}^{*}=C_{t}^{*-1 / \sigma} m c_{t}^{*} Y_{t}^{*}+\beta^{*} \xi_{p} \pi_{t}^{*-\iota_{p} \frac{1+\theta_{p}}{\theta_{p}}} \mathbb{E}_{t}\left\{x_{1 t+1}^{*} \pi_{t+1}^{*} \frac{1+\theta_{p}}{\theta_{p}}\right\} \\
& x_{2 t}^{*}=C_{t}^{*-1 / \sigma} p_{D t}^{*} Y_{t}^{*}+\beta^{*} \xi_{p} \pi_{t}^{* 1-\iota_{p} \frac{1+\theta_{p}}{\theta_{p}}} \mathbb{E}_{t}\left\{x_{2 t+1}^{*} \pi_{t+1}^{*} \frac{1+\theta_{p}}{\theta_{p}}-1\right\} \\
& \pi_{c t}^{*}=\frac{\pi_{t}^{*}}{p_{D t}^{*} / p_{D t-1}^{*}} \\
& Y_{t}^{*}=C_{D t}^{*}+I_{D t}^{*}+\frac{\xi}{\xi^{*}}\left(M_{C t}+M_{I t}\right)+\frac{\psi_{I}}{2}\left(I_{t}^{*} / I_{t-1}^{*}-1\right)^{2} I_{t}^{*} \\
& R_{t+1}^{n *}=\left(R_{t}^{n *}\right)^{\gamma_{r}}\left(\beta^{-1}\left(\pi_{t}^{*}\right)^{\gamma_{\pi}^{*}}\left(Y_{t}^{*} / Y_{t}^{\text {pot* }}\right)^{\gamma_{y}^{*}}\right)^{1-\gamma_{r}} \varepsilon_{t}^{r} \\
& K_{t}^{*}=(1-\delta) K_{t-1}^{*}+I_{t-1}^{*} \\
& q_{t}^{*}=1+p_{D t}^{*}\left[\psi_{I}\left(\frac{I_{t}^{*}}{I_{t-1}^{*}}-1\right) \frac{I_{t}^{*}}{I_{t-1}^{*}}+\frac{\psi_{I}}{2}\left(\frac{I_{t}^{*}}{I v_{t-1}}-1\right)^{2}\right]-\mathbb{E}_{t}\left\{\Lambda_{t, t+1}^{*} p_{D t+1}^{*} \psi_{I}\left(\frac{I_{t+1}^{*}}{I_{t}^{*}}-1\right)\left(\frac{I_{t+1}^{*}}{I_{t}^{*}}\right)^{2}\right\} \\
& R_{K t}^{*}=\frac{r_{k t}^{*}+(1-\delta) q_{t}^{*}}{q_{t-1}^{*}}
\end{aligned}
$$




$$
\begin{aligned}
w_{t}^{* o} & =\left(1+\theta_{w}\right) \frac{x_{1 w t}^{*}}{x_{2 w t}^{*}} \\
x_{1 w t}^{*} & =L_{t}^{* o} U_{C t}^{*} M R S_{t}^{*}+\beta^{*} \xi_{w} \mathbb{E}_{t}\left\{x_{1 w t+1}^{*}\right\} \\
x_{2 w t}^{*} & =L_{t}^{* o} U_{C t}^{*}+\beta^{*} \xi_{w} \pi_{w t}^{* \iota_{w}} \mathbb{E}_{t}\left\{x_{2 w t+1}^{*} \pi_{c t+1}^{*}{ }^{-1}\right\} \\
w_{t}^{*} & =\left(\left(1-\xi_{w}\right)\left(w_{t}^{* o}\right)^{-\frac{1}{\theta_{w}}}+\xi_{w}\left(\pi_{w t-1}^{* \iota_{w}} w_{t-1}^{*} \pi_{c t}^{*-1}\right)^{-\frac{1}{\theta_{w}}}\right)^{-\theta_{w}} \\
M R S_{t}^{*} & =\frac{\chi_{0}\left(L_{t}^{* o}\right)^{\chi}}{U_{C t}^{*}} \\
L_{t}^{* o} & =\left(\frac{w_{t}^{* o}}{w_{t}}\right)^{-\frac{1+\theta_{w}}{\theta_{w}}} L_{t}^{*} \\
\pi_{w t}^{*} & =\frac{w_{t}^{*}}{w_{t-1}^{*}} \pi_{c t}^{*}
\end{aligned}
$$

The "pot" superscript in (B.80) refers to the potential economy, given by the system above without price or wage rigidities: $\xi_{p}=\xi_{w}=0$.

The system (B.10)-(B.90) characterizes the behavior of the 44 home variables $C_{t}, L_{t}$, $\Lambda_{t, t+1}, U_{C t}, C_{D t}, M_{C t}, I_{D t}, M_{I t}, x_{M C t}, x_{M I t}, M_{C t}^{A}, M_{I t}^{A}, p_{D t}, Y_{t}, \Delta_{p t}, r_{k t}, m c_{t}, \pi_{t}, \pi_{t}^{o}, x_{1 t}, x_{2 t}, \pi_{c t}, R_{t}$, $R_{t}^{n}, I_{t}, K_{t}, q_{t}, x_{t}, N_{t}, \phi_{t}, S_{t}, D_{t}^{*}, \mu_{t}, \mu_{t}^{*}, \Omega_{t}, \nu_{t}, R_{K t}, w_{t}, w_{t}^{o}, x_{1 w t}, x_{2 w t}, M R S_{t}, L_{t}^{o}, \pi_{w t}$, the 35 foreign variables $C_{t}^{*}, L_{t}^{*}, \Lambda_{t, t+1}^{*}, U_{C t}^{*}, C_{D t}^{*}, M_{C t}^{*}, I_{D t}^{*}, M_{I t}^{*}, x_{M C t}^{*}, x_{M I t}^{*}, M_{C t}^{A *}, M_{I t}^{A *}, p_{D t}^{*}, Y_{t}^{*}, \Delta_{p t}^{*}, r_{k t}^{*}, m c_{t}^{*}$, $\pi_{t}^{*}, \pi_{t}^{o *}, x_{1 t}^{*}, x_{2 t}^{*}, \pi_{c t}^{*}, R_{t}^{*}, R_{t}^{* n}, I_{t}^{*}, K_{t}^{*}, q_{t}^{*}, R_{K t}^{*}, w_{t}^{*}, w_{t}^{* o}, x_{1 w t}^{*}, x_{2 w t}^{*}, M R S_{t}^{*}, L_{t}^{* o}, \pi_{w t}^{*}$, and the two international prices $\mathcal{Q}_{t}, \mathcal{T}_{t}$.

\section{B.3 Dominant Currency Pricing}

Let the relative export price be $p_{M t}^{*} \equiv P_{M t}^{*} / P_{t}^{*}$, let $\pi_{M t}^{o *}$ denote reset export price inflation, and let $z_{1 t}, z_{2 t}$ be the auxiliary Calvo variables for home firms' export prices. We use $p_{M t} \equiv$ $P_{M t} / P_{t}$ for the price of the U.S. good at home, and drop the terms of trade variable $\mathcal{T}_{t}$ and replace it appropriately in the demand equations (e.g. $p_{M t}$ in place of $p_{D t} \mathcal{T}_{t}$ in (B.15)). We drop equation (B.54) and instead use the PCP condition for U.S. goods prices:

$$
p_{M t}=\mathcal{Q}_{t} p_{D t}^{*}
$$

We also replace (B.22)and (B.69) with

$$
\begin{aligned}
& 1=(1-\omega) p_{D t}^{-1 / \rho}+\omega p_{M t}^{-1 / \rho} \\
& 1=\left(1-\omega^{*}\right) p_{D t}^{*-1 / \rho}+\omega^{*} p_{M t}^{*-1 / \rho}
\end{aligned}
$$


The additional equations for the home economy characterizing export price setting are as follows:

$$
\begin{aligned}
\left(\pi_{M t}^{*}\right)^{-\frac{1}{\theta_{p}}} & =\left(1-\xi_{p}\right)\left(\pi_{M t}^{* o}\right)^{-\frac{1}{\theta_{p}}}+\xi_{p}\left(\pi_{M t-1}^{*}\right)^{-\frac{\iota_{p}}{\theta_{p}}} \\
\pi_{M t}^{* o} & =\left(1+\theta_{p}\right) \frac{z_{1 t}}{z_{2 t}} \pi_{M t}^{*} \\
z_{1 t} & =U_{C t}\left(M_{C t}^{*}+M_{I t}^{*}\right) m c_{t}+\beta \xi_{p} \mathbb{E}_{t}\left\{\left(\frac{\pi_{M t+1}^{*}}{\left.\left.\pi_{M t}^{* \iota_{p}}\right)^{\frac{1+\theta_{p}}{\theta_{p}}} z_{1 t+1}\right\}}\right.\right. \\
z_{2 t} & =U_{C t}\left(M_{C t}^{*}+M_{I t}^{*}\right) p_{M t}^{*} \mathcal{Q}_{t}+\beta \xi_{p} \mathbb{E}_{t}\left\{\left(\frac{\pi_{M t+1}^{*}}{\pi_{M t}^{* t_{p}}}\right)^{\frac{1+\theta_{p}}{\theta_{p}}-1} z_{2 t+1}\right\} \\
p_{M t}^{*} & =\frac{\pi_{M t}^{*}}{\pi_{C t}^{*}} p_{M t-1}^{*}
\end{aligned}
$$

On net, we have the 5 additional equations above and 5 new variables $p_{M t}^{*}, \pi_{M t}^{*}, \pi_{M t}^{o *}, z_{1 t}, z_{2 t}$. 


\section{SVAR}

Figure C.1 shows the SVAR-predicted effects of a 100 basis point rise in the fed funds rate. We use the dataset compiled by Iacoviello and Navarro (2018). ${ }^{47}$ The SVAR includes the following variables: EM log GDP, advanced economy (AE) log GDP, U.S. core PCE inflation, U.S. $\log$ GDP, the trade-weighted value of the (real) dollar, the federal funds rate, and the spread between Moody's seasoned Baa corporate bond yield and the 10-year Treasury yield. The variables are included in the order just listed. The sample is 1970:I-2008:IV.

EM GDP is an aggregate across the following countries: Argentina, Botswana, Brazil, Chile, China, Colombia, Ecuador, El Salvador, Hong Kong, India, Indonesia, Israel, Jordan, Korea, Malaysia, Mexico, Peru, Philippines, Singapore, South Africa, Taiwan, Thailand, Turkey, and Venezuela.

AE GDP is an aggregate of the following countries: Australia, Austria, Belgium, Canada, Czech Republic, Denmark, Finland, France, Germany, Greece, Hungary, Iceland, Ireland, Italy, Japan, Luxembourg, Netherlands, New Zealand, Norway, Poland, Portugal, Spain, Sweden, Switzerland, and the United Kingdom.

\footnotetext{
${ }^{47}$ We are grateful to Matteo Iacoviello for kindly sharing the data and codes.
} 
Figure C.1. SVAR Prediction of effects of 1 percent rise in federal funds rate
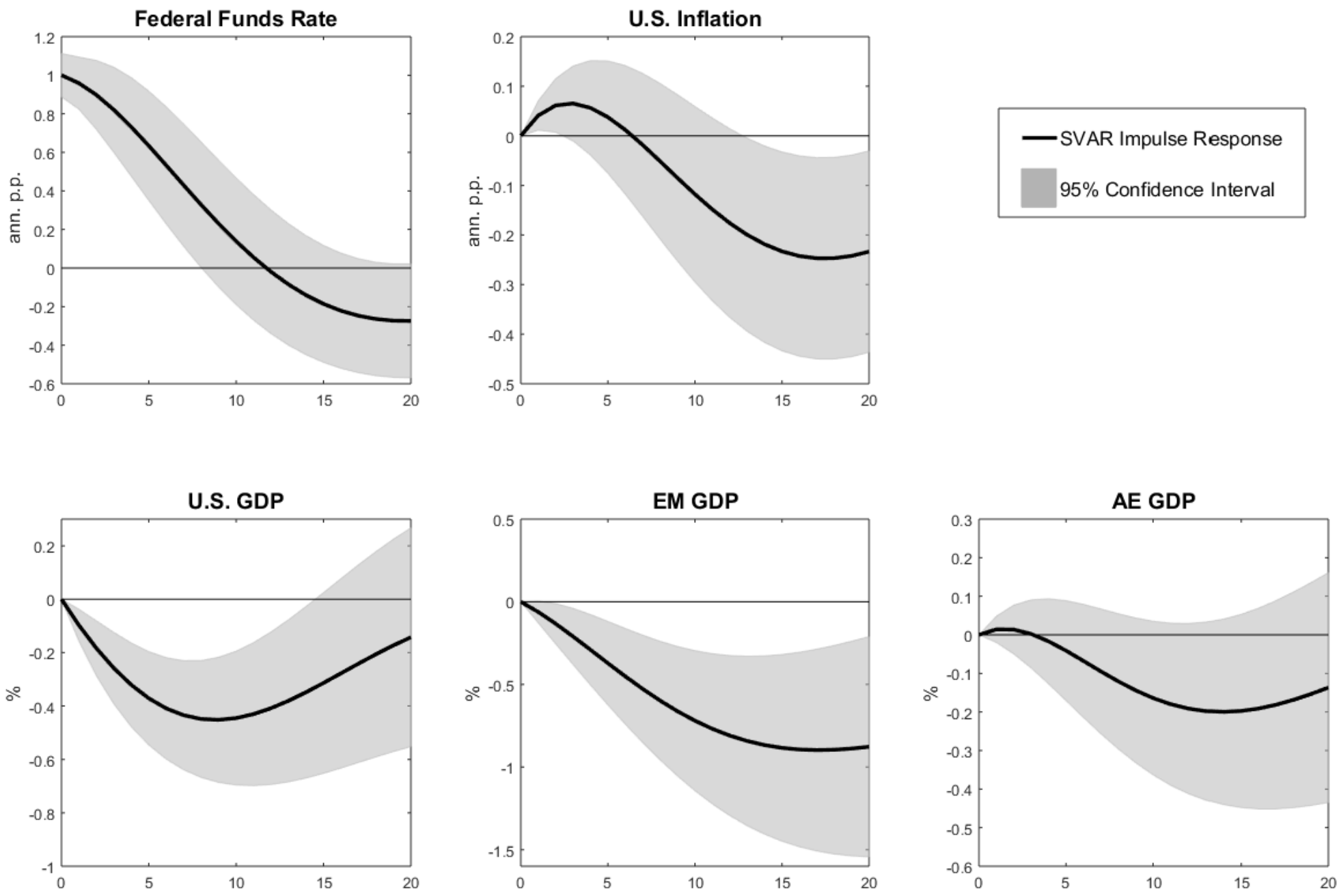

Note: EM GDP refers to an aggregate of emerging markets' GDP and AE GDP refers to an aggregate of advanced economies' GDP (other than the United States). 